\title{
An Exploratory Case Study Examining Transformational Leadership and Organizational Change within the Presidency of a Small, Four-Year University
}

\author{
Daniel Matthew Filer \\ West Virginia University
}

Follow this and additional works at: https://researchrepository.wvu.edu/etd

\author{
Recommended Citation \\ Filer, Daniel Matthew, "An Exploratory Case Study Examining Transformational Leadership and \\ Organizational Change within the Presidency of a Small, Four-Year University" (2013). Graduate Theses, \\ Dissertations, and Problem Reports. 564. \\ https://researchrepository.wvu.edu/etd/564
}

This Dissertation is protected by copyright and/or related rights. It has been brought to you by the The Research Repository @ WVU with permission from the rights-holder(s). You are free to use this Dissertation in any way that is permitted by the copyright and related rights legislation that applies to your use. For other uses you must obtain permission from the rights-holder(s) directly, unless additional rights are indicated by a Creative Commons license in the record and/ or on the work itself. This Dissertation has been accepted for inclusion in WVU Graduate Theses, Dissertations, and Problem Reports collection by an authorized administrator of The Research Repository @ WVU.

For more information, please contact researchrepository@mail.wvu.edu. 
An Exploratory Case Study Examining Transformational Leadership and Organizational Change within the Presidency of a Small, Four-Year University

\title{
Daniel Matthew Filer
}

\author{
Dissertation submitted to the \\ College of Education and Human Services \\ at West Virginia University \\ in partial fulfillment of the requirements \\ for the degree of
}

Doctor of Education

in

Educational Leadership Studies/Higher Education Administration

Sebastián R. Díaz, Ph.D., J.D., Chair

Donna Breault, Ph.D.

Paul Chapman, Ph.D.

Anne Nardi, Ph.D.

Sandra Eckard, Ph.D.

Department of Education

Morgantown, West Virginia

2013

Keywords: Transformational Leadership, Organizational Change, Storytelling Copyright 2013 Daniel Matthew Filer 


\begin{abstract}
An Exploratory Case Study Examining Transformational Leadership and Organizational Change within the Presidency of a Small, Four-Year University
\end{abstract}

\title{
Daniel Matthew Filer
}

As both internal and external threats continue to arise and challenge the traditional mold of higher education, the role of the university president is becoming more and more important. The position is being required to serve in an ever-growing number of capacities in addition to steering the direction of the institution. The purpose of the research study was to examine how presidents at a small, public four-year institution of higher education respond to organizational change. More specifically, my study attempted to discover if transformational leadership is present within the presidency during this era of great change that is affecting colleges and universities. I used case study methodology to define the parameters of the study, as well as qualitative description and the analysis of storytelling to gather my data. The methods of collecting data included formal interviews of three presidents of the institution, as well as three current faculty members who had served under those presidents (one faculty member from each of the university's three colleges). In addition, the use of institution's archives, presidential papers (including speeches and writings), and university publications allowed for layered interpretations and document analysis. I used the data to determine if elements of transformational leadership existed within each presidency, and if the organization experienced significant change. I argue that elements of transformational leadership were found within the presidency, but the use of these elements did not necessarily result in significant organizational change in all situations. I was unable to identify a relationship between transformational leadership and organizational change. 
Table of Contents

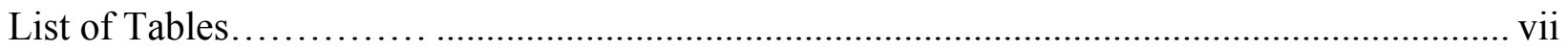

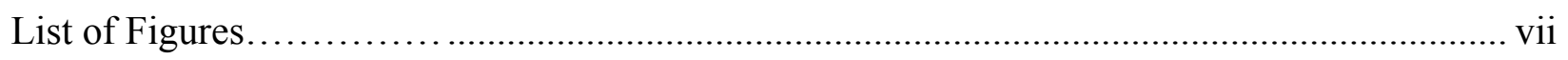

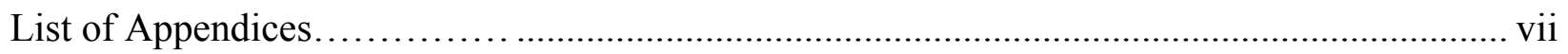

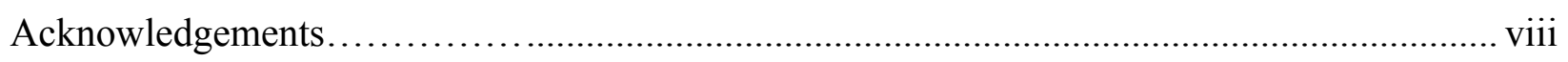

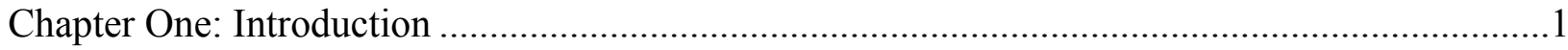

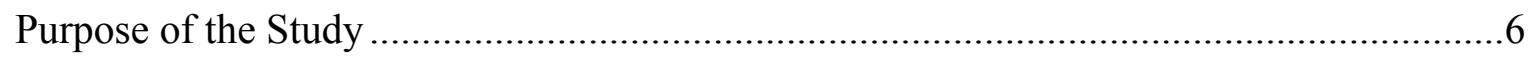

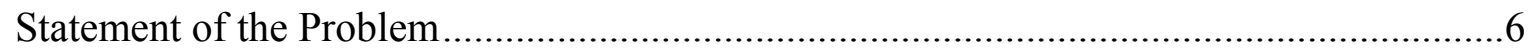

Significance of the Problem.................................................................................

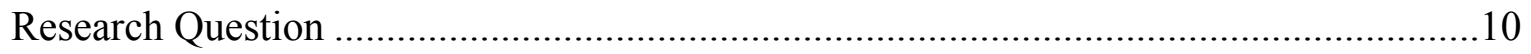

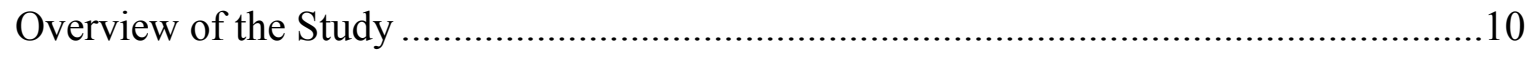

Chapter Two: Review of Related Literature .................................................................... 12

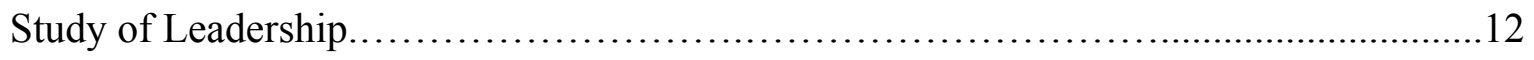

Why Examine Transformational Leadership? .......................................................13

Transformational Leadership: The Beginnings ....................................................14

MLQ and the Four Components of Transformational Leadership ...............................16

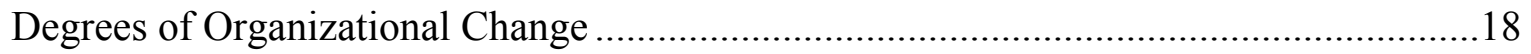

Organizational Culture in Transformational Mode........................................................19

Men vs. Women Regarding Transformational Leadership ........................................20

Learning Transformational Leadership in Higher Education .......................................24

Transformational Leadership and Organizational Change in Higher Education...............26

Culture as a Challenge to Transformational Leadership in Higher Education .................29

Why Transformational Leadership Matters to Higher Education.................................33 
Transformational Leadership, Peter Drucker, and the Knowledge Economy .34

Transformational Leadership: Myth or Reality? .35

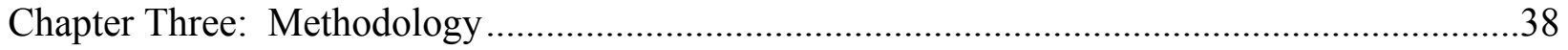

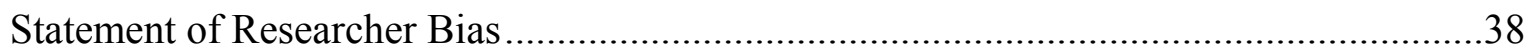

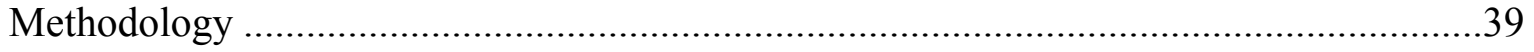

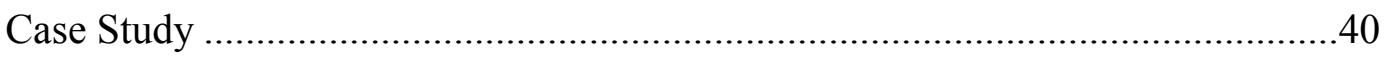

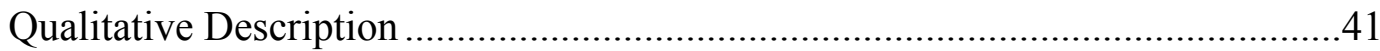

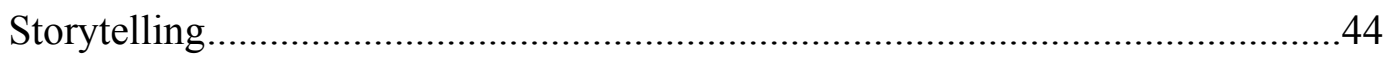

Origins of Storytelling in Education ....................................................44

Storytelling as a Leadership Tool .................................................46

Storytelling and the Value of Institutional Knowledge .........................48

Tying the Three Methods Together .............................................................49

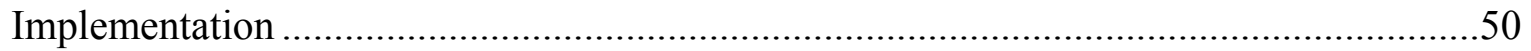

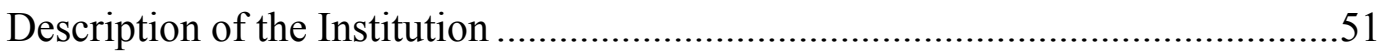

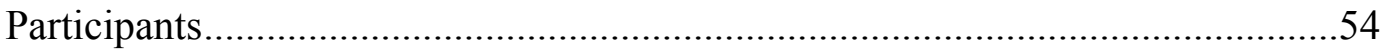

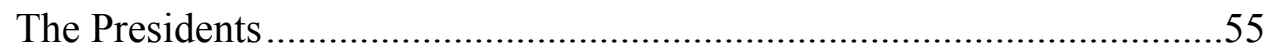

The Faculty Members ...................................................................56

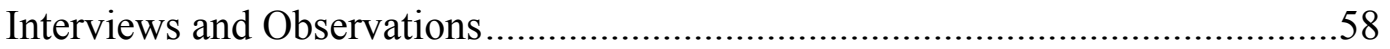

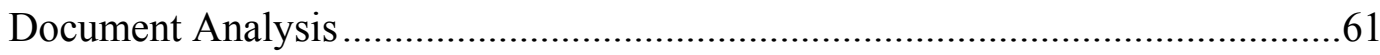

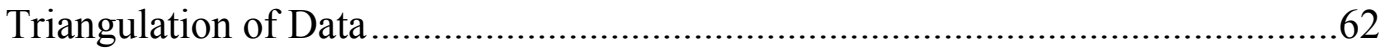

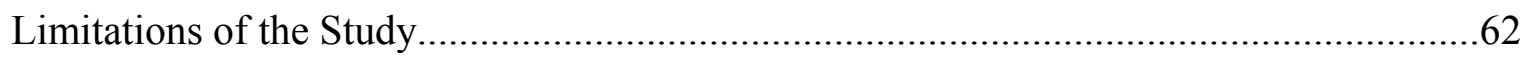

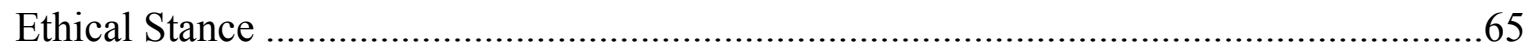

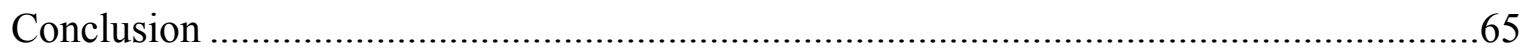




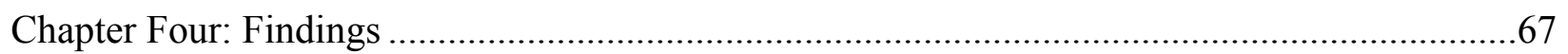

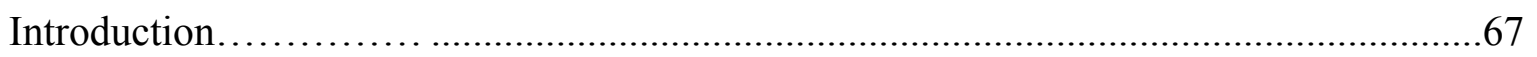

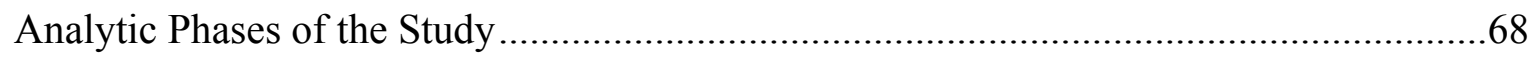

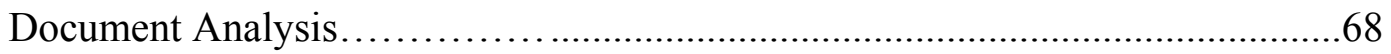

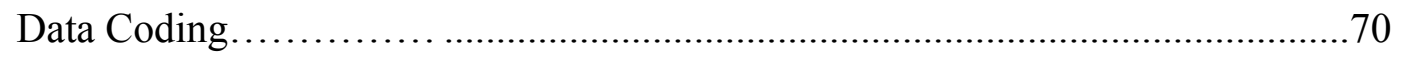

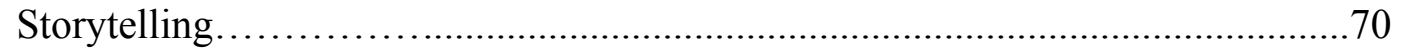

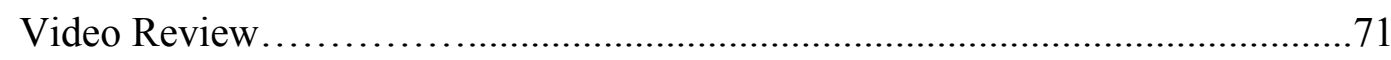

Components of Transformational Leadership ..............................................................71

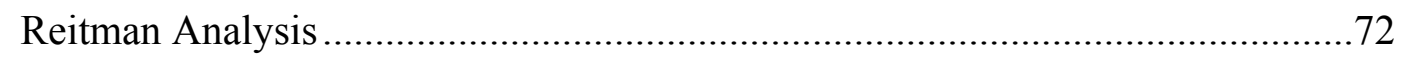

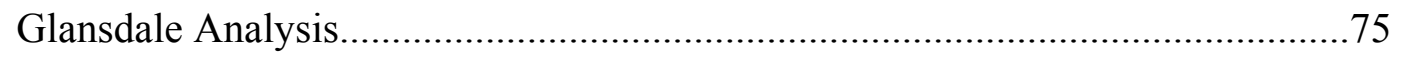

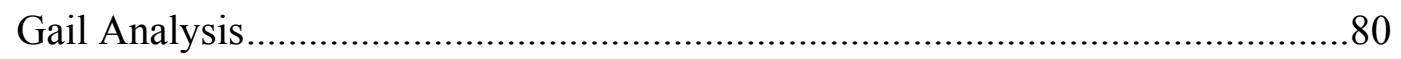

Degrees of Organizational Change and Components of Institutional Change.....................86

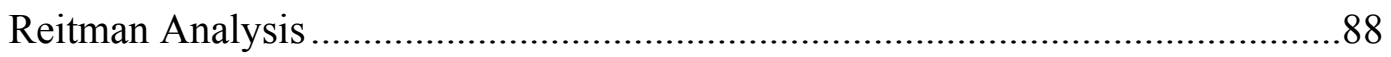

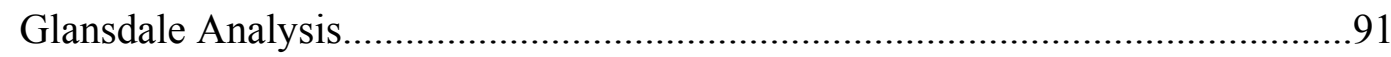

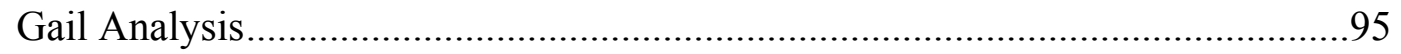

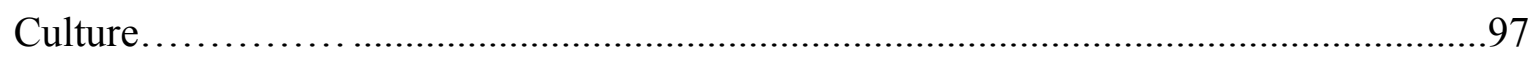

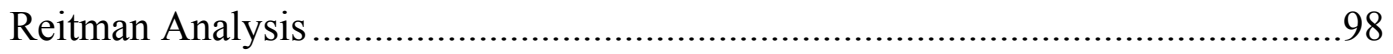

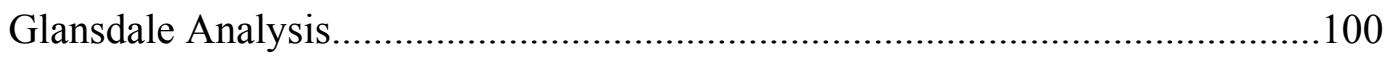

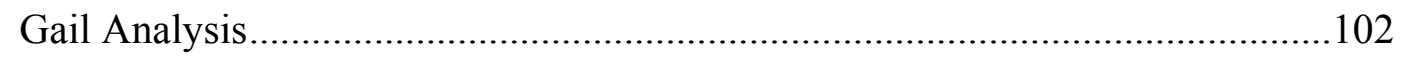

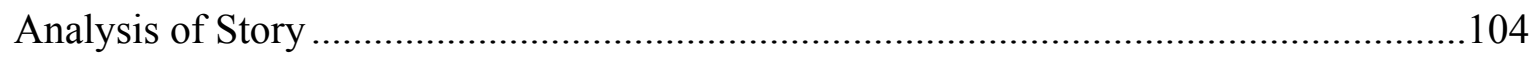

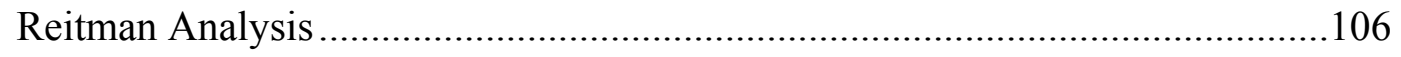

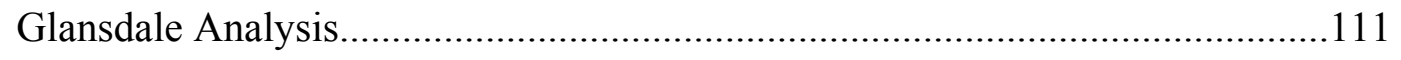

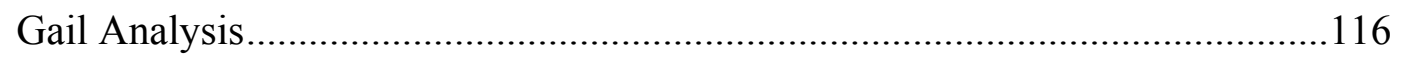


Gender Factor with Leadership .......................................................................119

The Knowledge Management Element ….......................................................... 122

Methodological Issues and Thematic Analysis ........................................................ 125

Video in Qualitative Research and the Humanistic Perspective.........................126

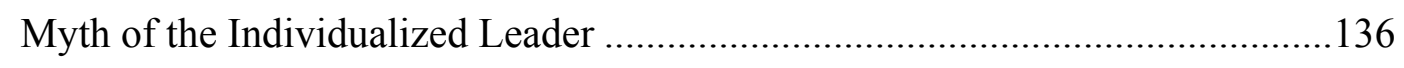

True Role of the Presidency within Higher Education ..................................140

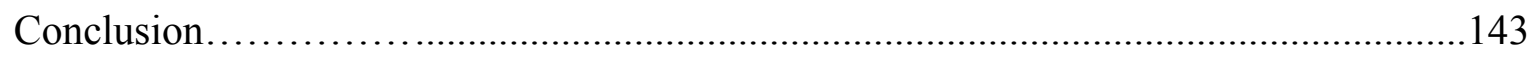

Chapter Five: Summary, Discussion, and Conclusion....................................................... 145

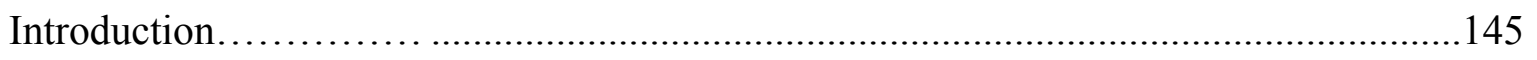

Summary of Major Descriptive Analysis Findings ................................................146

Transformational Leadership and Organizational Change ............................. 146

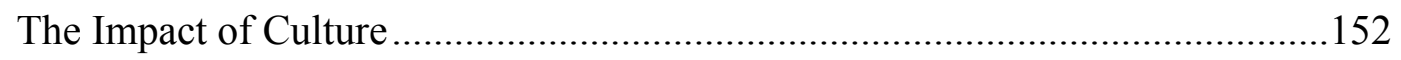

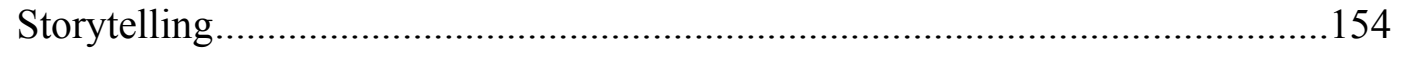

Discussion of Descriptive Findings, Major Themes, and Methodological Issues ............155

Transformational Leadership and Organizational Change ..............................156

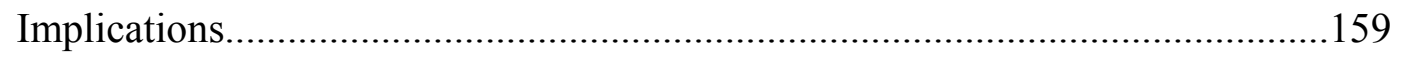

Suggestions for Future Research ....................................................... 172

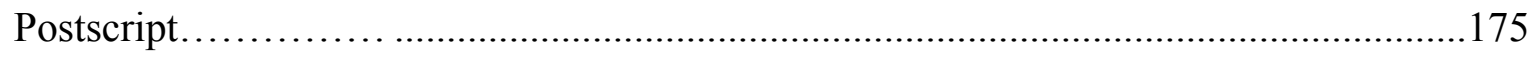

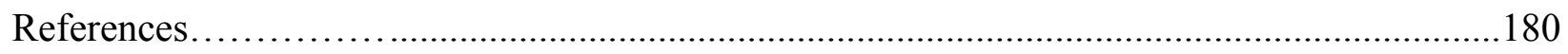

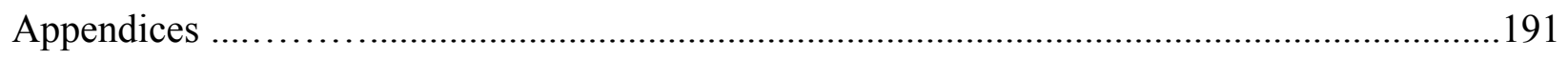




\section{List of Tables}

Table 1: List of Documents Reviewed for the Study (Including Years)

\section{List of Figures}

Figure 1: Presence of Transformational Leadership Components..............................................72

Figure 2: Presence of Organizational and Institutional Change Elements ..............................88

Figure 3: Presence of Culture under Each President ............................................................98

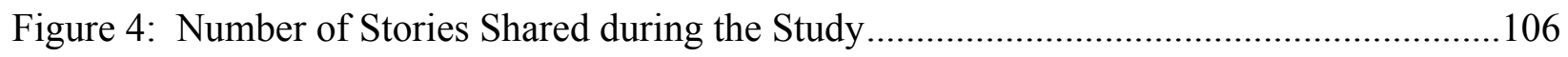

Figure 5: Considering Gender and Transformational Change ..............................................121

Figure 6: Components of Transformational Leadership within Interviews and Documents......148

Figure 7: Transformational Leadership and Organizational Change.....................................150

Figure 8: Transformational and Institutional Change for each President ..............................151

Figure 9: Analysis of Culture for each President ............................................................ 152

\section{List of Appendices}

Appendix A: Institutional Review Board at West Virginia University Approval .....................191

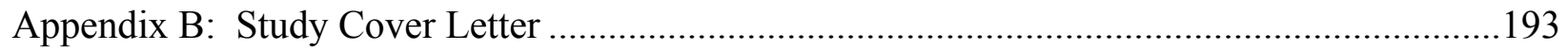

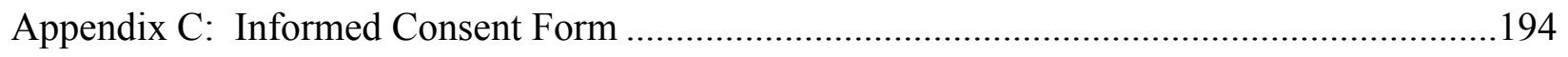

Appendix D: President Reitman Interview Protocol .......................................................199

Appendix E: President Glansdale Interview Protocol ......................................................201

Appendix F: President Gail Interview Protocol .............................................................203

Appendix G: Faculty Member Interview Protocol …....................................................205

Appendix H: Study Codes and Sub-Codes .................................................................206

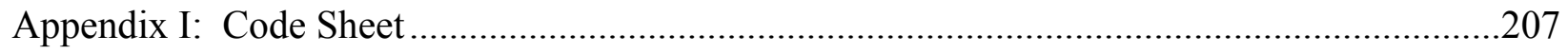




\section{Acknowledgements}

The pursuit of this degree would not have been possible without the support and encouragement of my family, friends, professional colleagues, and my doctoral committee members. I especially want to thank the following individuals for their continued support during this endeavor:

To Ellwood and Barbara Filer, my loving parents, who supported me both emotionally and physically as I pursued this degree. They instilled in me the value of education and the rewards of hard work at a very young age. Their dedication to this goal, along with their unbridled support, made this endeavor not only bearable, but also possible. They never had the chance for an education, so I thank them for giving it to me. First and foremost, I dedicate this achievement to them.

To Leonard and Shirley Winner, my loving grandparents, who supported me throughout this entire experience. I will always cherish the conversations and memories we shared over the many late-night dinners and other meals you provided because I was busy researching and writing for this project.

To Dr. Sebastián Diaz, my committee chairperson, who graciously agreed to serve as my chairperson because you share my love of a good story. Your inspiration and knowledge inspired me to pursue this topic. Thank you for the time and effort you unselfishly provided to help me with this research, and for the unending support in every facet of the dissertation process. Your tutelage made me a better researcher.

To Dr. Donna Breault, who also graciously agreed to serve on my committee and whose time and commitment to my study has been invaluable. You made the writing of this document fun! Your passion and knowledge of qualitative research methods made this a better study.

To Dr. Paul Chapman, who graciously agreed to serve on my committee and provide expertise and advice on leadership in higher education. Your time and commitment to my dissertation have been greatly appreciated.

To Dr. Sandra Eckard, my friend and colleague, who first inspired me to pursue a terminal degree. Your advice and feedback has made me a more intuitive and better writer.

To Dr. Anne Nardi, who graciously agreed to serve on my committee. Your expertise and knowledge of higher education leadership contributed greatly to this dissertation.

To John Noel, my supervisor and inspiration at the National Park Service. Thank you for your unwavering support during this process and allowing me to devote every spare moment of time dedicated to this endeavor. 


\section{Chapter One: Introduction}

Colleges and universities increasingly are being viewed as social institutions within the larger global economy, providing specialized training for the experts of tomorrow while serving as economic engines for their respective economies (Altbach, Gumport, \& Berdahl, 2011). In addition, the environment surrounding higher education continues to change at a rapid pace. Both internal and external forces are driving the accelerated change, forcing traditional colleges and universities to adapt in order to grow and survive. The intensity of these driving forces, which is resulting in marked changes within all of higher education, has called to question the role of the university as we move towards a more globalized system (Readings, 1996).

As these threats continually arise, the leadership of university presidents continues to become more important. The contemporary university president is required to fulfill many diverse roles and responsibilities, including leadership in the intellectual, organizational, moral, and "spiritual" arenas (Duderstadt, 2007, p. xiii). To be successful, today's president, it appears, must have a firm grasp of the academic issues present on his/her campus while also advancing the mission and ensuring that the institution stays competitive with the changing landscape surrounding it, thus leaving the institution in better shape than when inherited (Duderstadt, 2007). In order to cope with this fast-paced environment, today's university president is expected to play "multi-dimensional roles" and be involved in whatever issues on campus demand his/her attention (Duderstadt, 2007, p. 111).

Social, political and economic forces have presented seemingly unavoidable challenges to higher education. College tuition is at an all-time high, leaving many college students with insurmountable debt upon graduation in one of the worse job markets in 
decades (Fischer, 2011). International competition is increasing while student quality is decreasing. A survey of 1,000 college presidents conducted in 2011 by the Pew Research Center and The Chronicle of Higher Education reveals that most presidents have a dismal outlook regarding the future of higher education in America (Fischer, 2011). Nearly half of the presidents participating in the survey surmised that American higher education will barely rank among the top systems in the world in the next ten years, suggesting the challenges facing American colleges and universities will continue to grow if not addressed immediately (Fischer, 2011).

In light of this seemingly important, but still developing, quagmire for modern institutions of higher education, my case study explores the phenomenon, if any exists at all, concerning leadership and organizational change within the presidential position at a small, public four-year institution of higher education. More specifically, my study will discover if transformational leadership is present within higher education during this era of great change that is affecting colleges and universities, and if so, what does that leadership style consist of on a personal and situational level. In addition, my case study will explore whether transformational leadership within higher education really leads to organizational change at the university, or whether the decisions and initiatives enacted by the presidents participating in the study are merely responses to larger events outside the leadership's sphere of influence. In short, do university presidents have the opportunity to be transformational leaders, or are they subject to the ebb and flow of larger influences impacting their campuses? Do their actions and leadership lead to organizational change? My study will consider the phenomenon of transformational leadership and organizational change within the university presidency. 
University presidents may not have the sole power to address the numerous challenges facing them. James Duderstadt (2007), former president of the University of Michigan, argues that shared governance practices, which are more commonplace in today's colleges and universities, put much of the decision-making power in the hands of the faculty members, while the president is left to political relations and fund-raising initiatives. Bess and Dee (2008) argue that "no single leader has all the capabilities necessary to provide the multiple functions of organizational leadership" (p. 875). Bolman and Gallos (2011) reaffirm the notion of Bess and Dee (2008), arguing that no one person can have complete control over what happens at any college or university. In light of these claims, what is the true capacity for a university president effecting organizational change in higher education institutions? Further, are university leaders the catalysts for organizational change or simply responding to larger forces that occur outside their sphere of influence?

The Chronicle of Higher Education recounts numerous stories that describe the daily challenges and forces of change that are facing institutions of higher education, and thus facing university presidents. According to Delbanco (2012), "the American college is going through a period of truly radical, perhaps unprecedented, change" to address both the internal and external challenges facing the industry today (p. B9). These challenges are numerous and ever-growing, including the onslaught of globalization, economic instability, dwindling resources, and the ever-changing uses of information technology within the classroom. In addition, today's institutions of higher learning have had to adjust their curriculum to deal with more and more students who enter higher education unprepared academically while also adjusting to "the breakdown of faculty tenure as an academic norm" (Delbanco, 2012, p. B9). It seems that both the structure and practice of higher education are in turmoil. 
Numerous other significant issues facing traditional higher education have been in the forefront of The Chronicle recently. One of the most significant, and most threatening, may be the increasing popularity of for-profit institutions within the industry. The rise of forprofit institutions has posed serious competition for traditional colleges and universities, especially concerning recruitment, with nearly $10 \%$ of all degree-seeking students enrolled in a for-profit institution in 2010 (Wilson, 2010). Another nagging challenge is the economic downturn in recent years, which has also resulted in a significant reduction in resources for most public and private institutions (Gee, 2011). Finally, the "graying" of America's university presidents, with the average age of a college leader being 60 in 2011 , presents the challenge of "significant turnover" happening across America in the coming years (Stripling \& Medina, 2011, pp. A1-A10).

Recent academic publications have also discussed the current challenges facing higher education and its leadership. For example, the success of for-profit institutions has resulted in traditional higher education institutions actively seeking and lobbying for "regulatory oversight" within the industry of higher education, a first in many instances (Tierney, 2010, p. 174). For the first time in its history, traditional higher education is being threatened by a serious competitor. In addition, the rise of globalization and improved developments in technology has contributed to the role of distance and online education and made higher education institutions more competitive among each other for fewer and fewer resources and customers (Boubsil \& Carabajal, 2011; Vaira, 2004). From a global perspective, American higher education seems to be waning compared to the rest of the world, especially in light of the increase in the number and quality of colleges and universities in Asia (Bruininks, Keeney, \& Thorp, 2010). Thus, higher education institutions 
must continue to change and transform to stay relevant and meet the rising challenges of the future.

As the world of higher education continues to change and the number of challenges facing colleges and universities grows, the need for strong leadership from university presidents will be critical in the years to come. Higher education is being transformed, and the colleges and universities of tomorrow will need leaders who not only are able to facilitate change but who also are able to ensure the organization is progressing in a self-sustaining and positive direction that will benefit all its constituencies. According to David Hardesty (2007), former President of West Virginia University, leading a modern public institution is complicated, with many constituencies to consider. These include not just students and parents, but also local businesses, state representatives, and the local community (Hardesty, 2007). Lawrence (2006) argues that this expanded role of the public university president is here to stay; Once overseers of just academic knowledge and campus affairs, today's university president is required to lead organizations that have far-reaching impacts, well beyond just the student body, faculty members, and the world of academia.

As noted by Pierce (2012), the expanded role of president has drawn atypical candidates from outside the academic world to seek college and university leadership, contributing to an influx of new leadership styles and efforts to promote organizational change. In 2008, 17\% of new presidents appointed to colleges and universities in America came from outside higher education (Pierce, 2012). Sectors from which these leaders came include business, government, and other non-profit organizations to name a few. The entry of these new styles, especially from the business realm, has created an ongoing debate regarding which styles of leadership should be used most frequently by university presidents 
in order to be successful (Altbach, Gumport, \& Berdahl, 2011). Nevertheless, this influx of leadership styles reveals how complex leadership theory in higher education has become, and thus the need for my case study.

\section{Purpose of the Study}

The mounting challenges facing higher education institutions today coupled with the break-neck pace of change within the industry suggest that strong presidents will be critical for the success of a higher education institution in the coming decades. The purpose of my case study is to examine the phenomenon of transformational leadership and organizational change within the presidential position. Results from my study will help determine if the use of particular leadership styles by a college or university president brings about organizational change when needed. My findings will also help determine if university presidents have the power to make sweeping changes at their institutions or if their power has been significantly reduced by shared governance and the increase in external constituencies. Either way, results from my case study will provide valuable insights concerning academic leadership for other similar colleges and universities. Finally, the study will inform and help clarify the expectations that college and university presidents are unrealistically beholden to, while revealing the complexity of organizational change within institutions of higher learning.

\section{Statement of the Problem}

Determining if a phenomenon exists concerning leadership style and organizational change within higher education can be valuable knowledge for current and future presidents. This information will prove even more valuable as the environment surrounding higher education continues to change. The exact nature of presidential leadership was revealed by exploring, through their own words, the phenomenon of transformational leadership and 
organizational change (Bess \& Dee, 2008). In addition, both leaders and those who select leaders for their institutions will now have a better understanding of the complex nature of leadership and change within universities.

I examined the problem using a case study to explore the phenomenon involving leadership style and organizational change. Doing so allowed me, as the researcher, to realistically determine the degree to which transformational leadership exists within a specific university. Stories of leadership shared by the participants were not perfect matches to the specific model for transformational leadership, but they were still transformative for the organization and led to significant change. Examining the data from a qualitative perspective prevented me from having to classify the leadership techniques that I observed. Similarly, some efforts of change as recounted by a leader were nothing more than targeted responses to overarching and influential forces swaying the organization, ensuring that change would happen regardless of the president's efforts.

Does change happen regardless of the college and university president's efforts and leadership? My study attempted to clarify the phenomenon involving leadership and change within the presidential position of higher education. Does organizational change in higher education occur solely because of the president; regardless of the president's efforts; or because of cooperation and collaborative efforts institution-wide? In addition, could the impact of systems, events, and other factors be the real reason for change? This study may help identify and clarify those elements that define what is necessary to have overall capacity for change in higher education. As a qualitative researcher, this case study gave me the latitude to discern what is leading to the organizational change. 
Evidence in the literature also suggests that both leaders and leadership researchers need to be wary of always trying to fit efforts of leadership into prescribed styles. According to Bess and Dee (2008), organizational leaders, especially within higher education, must always be wary of the dangers and the benefits of leadership theory. Presidents within higher education deemed effective are usually able to apply theory to simple, practical problems, but there is always a danger "that truly unusual situations will be overlooked in the press of excessive attempts to fit extant theories to them" (Bess \& Dee, 2008, p. 891). Not only is this warning applicable when considering university leadership, but it is also applicable when researching individual leaders themselves. Researchers need to be wary of codifying all leadership efforts, making sure any leadership style studied in the field fits into quantifiably measured models or structures. My qualitative case study refrained from making the mistakes to which Bess and Dee (2008) refer, but will shed more light on the phenomenon involving transformational leadership and organizational change within the presidential position in higher education.

\section{Significance of the Problem}

The process of leadership, especially within higher education, "is generally considered to be important," yet is often characterized as "a vague and in many ways undefinable process" (Birnbaum, 1992, p. 24). Other researchers have argued that the position of a college or university president has been on the decline since the end of World War II and that today's presidents are weaker figures who are subject to the interests and whims of trustees and strong public constituencies (Bollman \& Gallos, 2011; Dodds, 1962). These conclusions suggest the presidency has become a marginalized position within higher education, unable to be solely instrumental in organizational change efforts. With this in 
mind, my qualitative case study examined the role and influence the president has when considering organizational change while simultaneously revealing how influential and transformational the presidential position is in today's world of higher education.

My study is valuable because of its timing in relation to current trends in higher education (Stripling \& Medina, 2011). The baby-boomer generation is quickly retiring from professional life, leaving many colleges and universities with new leadership and substantial organizational change. These college and university presidents retire, taking their institutional knowledge and leadership styles with them without any efforts to qualitatively record and transfer knowledge to their successors (Nonaka \& Takeuchi, 1995). More importantly than simply saving this information, my qualitative case study will help to better understand the phenomenon of leadership and organizational change so that the future of university leadership can be better informed when considering the association between the two.

Finally, from an institutional standpoint, this study gathered valuable knowledge that the college currently lacks. Two former presidents of the institution agreed to participate in the study, but the researcher learned very early in the study that very few of their personal papers and documents related to their tenure at the institution still existed in archives. Gathering their stories and accounts of leadership and significant change at the institution on audio- and video-recording assisted in the preservation of the institution's administrative knowledge for the last quarter century. Data collected from this study could serve as a recent institutional history for the school as well as a focused analysis of recent leadership initiatives at the university. 


\section{Research Question}

In order to explore the phenomenon of transformational leadership and organizational change in the presidential position within higher education, the following research question was explored:

How do university presidents respond to organizational change?

Transformational leadership is most commonly thought to be associated with significant organizational change, so my study will primarily focus on this type of leadership within the presidency position (Bass \& Riggio, 2006). Other reasons for focusing on transformational leadership within this case study are discussed in the next chapter.

I frequently use the term "relationship" throughout this study when considering the phenomenon of transformational leadership and organizational change. Relationships are commonly explored in strictly quantitative studies. My use of this term throughout the study, however, is not alluding toward a quantitative relationship between leadership and change, but merely suggests a connection between the two areas. I was hesitant to use the term "connection" when exploring the phenomenon of transformational leadership and organizational leadership for fear the reader might imply that a connection inherently exists between these two wholly separate areas of study. Nevertheless, my study explored the relationship between transformational leadership and organizational change as a phenomenon, trying to discover whether a definitive connection exists between these two separate areas of organizational and leadership theory.

\section{Overview of the Study}

My study begins in this chapter with an overview of the problem and its significance within higher education. My second chapter follows this synopsis with an extensive review 
of the literature related to both concepts of transformational leadership affecting organizational change in general and, more specifically, presidential leadership impacting institutional change within the realm of higher education. The methodology I used to conduct my study is explained in detail in the third chapter, including specific descriptions of the population of interviewees, methods of data collection and analysis, and any anticipated limitations or ethical considerations I encountered. My research findings are presented in chapter four. The final chapter includes a summary and discussion of the major findings of the research study, implications for presidential leadership and future research, and a postscript. 


\section{Chapter Two: Review of Related Literature}

\section{Study of Leadership}

Researchers have pursued the study of leadership in comparison to organizational behavior for decades, especially in the twentieth century. As organizations become more complex, and with the rise of large corporations and social institutions which have the power to impact millions of constituents, strong and effective leadership is more essential than ever before in our history (Burns, 1978). As a result, leadership studies and style analyses have become commonplace in academia and bestseller lists alike in recent decades. Authors such as Covey (2004) and Collins (2001) have popularized the need for effective leadership within organizations to achieve success, while also reinforcing the need to classify leadership actions into prescribed styles and techniques. Research in specific areas has resulted in the publication of cumbersome handbooks of leadership that offer leaders hundreds of pages to glean for the appropriate style or theory to apply to any situation (Bass, 2008; Nohria \& Khurana, 2010).

The theoretical framework of my study is constructed of three theoretical views, or lenses. These lenses include transformational leadership, organizational change, and organizational culture. Each theoretical view has its own theorists and viewpoints which, when taken together, will provide the construct for my study. My literature review outlines the major points from each viewpoint of the overall theoretical construct concerning the context of transformational leadership and organizational change. The information from each theoretical view outlined and discussed in this review of literature was critical for the data analysis portion of my study. 


\section{Why Examine Transformational Leadership?}

For the purposes of this study, transformational leadership is the style examined when considering organizational change. I chose to examine transformational leadership when considering the phenomenon of leadership and organizational change for three reasons. First, a qualitative case study analysis that considered all the relevant leadership styles and theories when examining organizational change simply would have been too large and exhausting. Second, transformational leadership has a demonstrated history within the realm of higher education leadership. Altbach et al. (2011) refer to an ongoing debate over the value of transformational leadership within the university presidency, while Kezar, Carducci, and Contreras-McGavin (2006) argue that leadership in higher education needs to be restructured to a more transformative approach. Finally, the very name of transformational leadership suggests significant change and, more often than not, suggests to others not familiar with the term that organizational change would be synonymous with the leadership style. A leader can be transformative, yet instill very little, if any, organizational change. My study explored the true nature of transformational leadership theory in relation to organizational change.

Most important of my three reasons for examining transformational leadership when considering phenomenon of leadership and organizational change in higher education is the theory's prevalence in the literature. Bess and Dee (2008) argue that higher education, much like the business world, is moving away from transactional leadership and more toward transformational leaders. A transactional relationship refers to an arrangement where leaders try to motivate their followers by appealing to their needs and wants, whereas a transformational framework encourages leaders to inspire their followers, asking them to "transcend their own self-interests" for the sake of the organization (Bess \& Dee, 2008, p. 
841). Transformational leaders sacrifice self-interests and personal goals for that of the organization while also encouraging followers within the organization to do the same. Transformational leaders excel at focusing the collective efforts of the organization and are superb motivators (Kezar et al., 2006).

Transformational leadership was examined in this qualitative case study because researchers, especially Altbach et al. (2011) have argued that presidents who take a transformational leadership angle are thought to transform their organizations. Since my study examined the phenomenon of leadership and organizational change, the literature indicates that transformational leadership should be the focus because it is the most likely to change the organization.

\section{Transformational Leadership: The Beginnings}

Transformational leadership was first discussed by James MacGregor Burns (1978) as “transforming leadership" in his seminal work Leadership (p. 36). Although first discussed by Burns (1978) in political and historical contexts, he suggests very early on in his work of the value of transformative leadership when considering any organizational construct. Burns (1978) is also one of the first leadership scholars to distinguish between transactional and transformational leadership, arguing leaders typically exhibited one style of leadership or the other. He describes transactional leadership as more of a give-and-take relationship between leader and follower, with daily tasks within an organization being completed by followers in exchange for reward and payment. Transformational leadership, on the other hand, is a process where leaders and followers work together to achieve higher goals for the organization (Burns, 1978). Burns attributes the transformative approach to leadership 
entirely on the leader's personality and traits, including the appeal and connection to the followers within the organization.

The concept of transformational leadership presented by Burns (1978), referred to originally as transforming leadership, was not only novel, but it was also very progressive for the time. His work suggests that transformative leaders work for the betterment of the organization or team with which they are affiliated, and not just for the betterment of their selves or personal goals. Doing so empowered others around the leader to share in the vision of the organization and inspire everyone to achieve the most difficult of goals. Burns (1978) clearly describes transforming leadership, as a technique that can transform not only followers within an organization but the very face of the organization itself. He clearly recognizes the values of this transformational approach to leadership, but falls short of solely recommending it in relation to the transactional approach (Burns, 1978).

The work of Burns (1978) concerning transforming leadership was continued by Bass (1985), considering more closely the characteristics of this type of leadership. Bass (1985) was the first to label the concept of transforming leadership as transformational leadership in his literature. In addition to coining the name, Bass was instrumental in developing ways to measure transformational leadership and the first to consider impacts on the organization. His research was also the first to look at the impact on followers and consider the overall impacts on an organization (Bass, 1998). In addition, Bass advocated that certain behaviors and traits made leaders transformational. Leadership is about charisma and inspiring followers to take part in the mission of the organization, while transformational leadership is about taking that appeal to a higher level and instilling the culture and purpose of the organization in the personal psyche of followers (Bass \& Riggio, 2006). 


\section{MLQ and the Four Components of Transformational Leadership}

Bass (1985) and other researchers (Avolio, Bass, \& Jung, 1997; Bycio, Hackett, \& Allen, 1995; Howell \& Avolio, 1993) worked together to develop the four components of transformational leadership and the Multi-factor Leadership Questionnaire (MLQ). This questionnaire was developed to determine which transformational and transactional qualities a leader demonstrates (Bass \& Riggio, 2006). Coinciding with the development of the MLQ tool, researchers developed four components that are essential to transformational leadership theory. The four components are thought to capture the integral pieces that make a leader transformational. For example, according to Bass and Riggio (2006), transformational leaders must be charismatic, inspirational, "intellectually stimulating," and considerate of the individual followers (p. 5). Finally, other tools have been developed to measure transformational leadership, such as the Transformational Leadership Behavior Inventory (TLI), which, like the MLQ, determines if the leader aligns with four key dimensions to transformational leadership (Goodstein \& Lanyon, 1999).

The first, and arguably the most important component to the transformational leadership model is the Idealized Influence (II) component. This component explains that transformational leaders "behave in ways that allow them to serve as role models" to others in the organization (Bass \& Riggio, 2006, p. 6). Their actions gain the trust, respect, and admiration of followers within the organization to the point where they can be emulated. Transformational leaders are thought to be ethical and espouse high moral standards in both their personal and professional lives (Bass \& Riggio, 2006). Finally, the Idealized Influence (II) component calls for leaders who are transformational to also be risk-takers and consistent with their decisions and message to the organization. 
The second component of transformational leadership is dubbed Inspirational Motivation (IM). For a leader to be transformational, he/she must be able to motivate followers within an organization. According to Bass and Riggio (2006), transformational leaders excel at mobilizing "team spirit" and can easily display "enthusiasm and optimism" (p. 6). Transformational leaders are effective at convincing followers to share in their overall vision for the organization while also empowering them to have an active role in reaching any goals set forth. As a result, leaders who are transformational must be excellent communicators that are willing to share the future vision of the organization (Bass \& Riggio, 2006).

Intellectual Stimulation (IS) is the third component of transformational leadership (Bass \& Riggio, 2006). Leaders who are transformational must constantly challenge the status quo and encourage followers within the organization to be creative and promote change. Leaders that are truly transformational never criticize mistakes of followers, especially if they are different from that of the leader. Transformational leaders continually encourage followers to try again until they achieve success (Bass \& Riggio, 2006). Transformational leaders encourage followers to identify organizational problems and their solutions, then they work together to address these problems, implement solutions, and make lasting changes to the organization. For any leader to be transformational, he/she must embrace Intellectual Stimulation (IS) and empower those within the organization.

The fourth component of transformational leadership is Individualized Consideration (IC), or the leaders' ability to "pay special attention to each individual follower's needs" for professional development (Bass \& Riggio, 2006, p. 7). Transformational leaders are not only able to motivate followers as a whole with an organization to their cause, but are also able to 
serve as a "coach or mentor" to followers on an individual basis (Bass \& Riggio, 2006, p. 7).

Doing so continues the growth and potential of the individual followers within the organization, making them more valuable and more useful. To promote Individualized Consideration (IC), a transformational leader must encourage two-way communication among followers. Followers must feel a personalized relationship with the leader, so allowing the opportunity to have candid, individual discussions with the leader is critical (Bass \& Riggio, 2006). Leaders developing this component must also demonstrate excellent listening skills and be willing to delegate frequently to followers, as delegation is a sign of empowerment and an opportunity for followers to continue their development.

\section{Degrees of Organizational Change}

Porras and Robertson (1992) developed four levels or distinctions to help researchers, managers, and leaders better understand the degrees of organizational change. The distinctions are planned change, unplanned change, first-order change, and second-order change. Planned change is defined as intentional efforts to improve the organization and its operation in some capacity, whereas unplanned change refers to situations where an organization is reacting to change as a result of external forces. First-order change involves efforts to continually change and improve over time, making subtle changes incrementally rather than deep, sweeping changes all at once (Porras \& Robertson, 1992). As a result, Burke (2002) refers to first-order change as "evolutionary" (p. 130). Second-order change is characterized as the most powerful type of change, with lasting, deep impacts that significantly transform the organization. The definition of second-order change put forth by Porras and Robertson (1992) refers to "revolutionary" change according to Burke (2002, p. 
130). Porras and Silvers (1991) also refer to second-order change as an "organization transformation" because of the significant change involved in the process.

Bartunek and Moch (1994) define the concept of third-order change within an organization. Unlike second-order change, which can be the most lasting and revolutionary (Burke, 2002), third-order change allows organizational members to "transcend" the organizational framework (Bartunek \& Moch, 1994, p. 24). Doing so allows members to become more self-aware of their role within the organization as well as their role in regards to the leader. For example, members of an organization that experience third-order change tend to become more aware of their own limitations, begin to develop their own understanding of their role, and to ultimately become more effective at self-evaluation and change without prodding from the leader or supervisor (Bartunek \& Moch, 1994). In short, third-order change promotes a self-transformation that Bartunek and Moch (1994) characterize as a "mystical" experience "that is very difficult to achieve in practice" (p. 25). For the purposes of my study, both second-order and third-order change were characterized as transformational.

\section{Organizational Culture in Transformational Mode}

According to Bass (1992), organizational culture is what unifies followers and leaders within an organization into one collective group. Deal and Kennedy (1982) define organizational culture as behavior that is learned and reciprocated with each generation of followers that pass through the organization. An organization's culture is what defines the norms of behavior for those within the organization, such as certain behaviors, assumptions, rituals, and traditions. In addition, heroes and stories are identified and passed on through an 
organization's culture. These aspects of culture are what "provide expressive bonding of the members" within the organization (Bass \& Riggio, 2006, p. 99).

The purpose of my study was to explore the phenomenon of leadership and organizational change within higher education. In order for a university president to be transformative, the organizational culture must also be changed. According to Bass and Riggio (2006) a transformative culture exhibits certain traits. First, the followers share a sense of "purpose and a feeling of family" (Bass \& Riggio, 2006, p. 103). Commitments made within the organization are viewed as long-term, and decisions are viewed as mutual among the group. Leaders are seen by followers as role models and coaches that serve more as mentors rather than authoritative figures (Bass \& Riggio, 2006).

According to Groves (2005), transformational leaders will excel within organizational cultures that are more adaptable and conducive to change. In fact, his study argued that transformational leaders will be more effective when operating in an organizational culture that embraces change. Bass and Riggio (2006) argue that any culture "could benefit" from a transformational leadership approach. However, Bass (1985) warns that any leader who hopes to transform the culture of an organization must first have an understanding of the current culture before forcefully implementing new goals and a new vision for the group. Implementing haphazardly, without regard to the current culture or followers operating within, would not be a transformational approach, nor beneficial to the organization.

\section{Men vs. Women Regarding Transformational Leadership}

Recent events at the University of Virginia serve as an example of female leadership in higher education. Teresa Sullivan, the first female president of the University of Virginia, was reinstated in June of 2012 after resigning just over two weeks earlier because of a 
"philosophical difference of opinion" between her and the board (Perez-Pena, 2012, p. 13).

Since becoming president of the University of Virginia in 2010, Sullivan has made great strides to make incremental changes at one of the most prestigious public institutions in the country, dealing with dwindling budgets and growing competition from online universities (Perez-Pena, 2012). She became known for consensus-building leadership at the institution, where significant changes were only implemented if the majority of university leaders were in support. Her dismissal from the presidency was universally unpopular, even from her appointed successor, which lead to a unanimous 15-0 vote for reinstatement as a very large campus crowd cheered her return (Perez-Pena, 2012). Teresa Sullivan's problems at the University of Virginia exemplify the numerous complexities that leaders face in higher education which have been exacerbated by the growing competition from online curriculum. Does Sullivan's situation highlight a unique dynamic in female leadership within higher education?

Sullivan's reinstatement at the University of Virginia symbolizes the growing number of women in leadership roles within higher education, but also the challenges women still face at the top of the higher education pyramid. Almost $27 \%$ of college and university presidents in 2011 were women, nearly a 15\% increase from 2006 (Cook, 2012). This rate is a significant increase from when the last American Council on Education (ACE) Survey was conducted in 2006 , which found that only $23 \%$ of college and university presidents were women (Cook, 2012). Although the position is the same, women tend to take a different path to college and university leadership than men. Women are more likely to have doctorate degrees and to have taught more in the classroom than their male counterparts in the presidential position (Cook, 2012). Men, on the other hand, are more likely to be appointed 
president from another senior executive position or to come from outside the world of higher education to assume the position (Cook, 2012). In other words, women tend to assume the presidency in accordance with the traditional path, whereas men reach the top through more non-traditional paths. The different pathways to the presidency for men and women also speak to family life; unfortunately for women, men are more likely to have children while serving as president than women (Cook, 2012). These data also suggest that men are more apt to juggle both a successful personal and professional life at the top of the higher education pyramid, while women appear not as able to juggle both successfully. This statistic contributes to Cook's (2012) claim that despite the sharp increase in female leadership within higher education, men are still more likely to assume the top role within higher education.

Regardless of the challenges currently facing women who aspire to the presidential leadership role in higher education, current trends in the industry suggest that women may be more pervasive in the presidency in the future. As previously mentioned, nearly $60 \%$ of sitting college and university presidents are age 61 and older, meaning that a wave of retirements will be coming in the immediate future (Cook, 2012). As a result, more than ever before, women will have the opportunity to assume the role of college and university president because of the sheer number of vacancies that will occur (Cook, 2012). Although Cook (2012) argues that women are still under-represented in the presidency compared to their male counter-parts, she admits that women appear to have a bright future within higher education with the most opportunity to fill presidencies in the coming years.

From a leadership perspective, female presidents offer a different perspective to the organization than men. According to Bass and Riggio (2006), research has suggested that 
women have a "greater tendency" to be more transformational to the organization when serving as leader (p. 115). In addition, this research has indicated that women tend to satisfy their followers more so than men, while also being seen as more effective leaders overall (Bass \& Riggio. 2006). Bass and Riggio (2006) argue that numerous studies have been conducted since the 1980s, which suggest that women are more likely to exhibit transformational qualities. In addition, they suggest that women inherently possess many natural qualities found within the framework of transformational leadership. For example, women tend to be more nurturing and work harder to ensure that those around them fully understand the over-arching goals, which are both qualities that Burns (1978) similarly describes as raising the awareness and meeting the basic needs of organizational followers. Corroborating this claim, Myers and McCauley (1985) argue that female leaders are more likely to view themselves as having personalities that focus on the caring and needs of others when compared to their male counterparts. Burns and Riggio (2006) claim that female leaders tend to be more interested in their followers on a social and personal level, not just on a professional level. In most cases, female leaders will strive to build unique inter-personal relationships on an individual basis. Finally, studies have suggested that women better fit the transformational leadership framework because they demonstrate higher levels of moral value; women tend to exhibit greater levels of "responsibility and care" and are less selfserving than male leaders (Bass \& Riggio, 2006, p. 123).

In addition to being more suited as transformational leaders, women may inevitably become more pervasive within the presidential role of higher education because of the changing nature of the leadership role. Historically, many have mistakenly believed that aggressiveness and being competitive, both of which are perceived to be acceptable male 
qualities, were traits of effective leadership (Boyce \& Herd, 2003). Stereotypes, however, have discouraged women from leading with these qualities, essentially closing some leadership positions for women (Boyce \& Herd, 2003). But, Bass and Riggio (2006) argue that the perception of tough, aggressive leadership as an effective technique has changed. More collaborative, transformational techniques are becoming the norm, while organizations are becoming less hierarchical and calling for more team-work efforts. As a result, the inherent qualities exhibited by women are becoming more attractive in leadership roles, especially because of the alignment with transformational leadership. Bass and Riggio (2006) admit, "there is still a glass ceiling" preventing women from equally pursuing top leadership positions, but they are poised to move up as organizations begin to take a more transformational approach to organizational management (p. 124).

\section{Learning Transformational Leadership in Higher Education}

Researchers such as Bass (1997) have made transformational leadership incredibly popular in the business world and within higher education. Early research on transformational leadership was conducted primarily within the military, but later studies have demonstrated that it can be useful in other sectors as well, including education (Bass, 1999). This has resulted in "a veritable explosion of leadership education and development programs in U.S. higher education” (Bass \& Riggio, 2006, p. 134). Most undergraduate and graduate business schools offer degrees or certifications in leadership where transformational leadership is one of the central features (Ayman, Adams, Fisher, \& Hartman, 2003). Nevertheless, Bass and Riggio (2006) argue that transformational leadership cannot simply be executed after taking coursework and earning a degree. Instead, transformational 
leadership "should be regarded as an art and a science" that is only enhanced with education (Bass \& Riggio, 2006, p. 135).

Bass and Riggio (2006) claim that transformational leadership "can be taught and learned" (p. 147). In addition to traditional coursework through formal college degrees, transformational leadership training also involves human interaction and exposure to real-life leadership scenarios. In addition, leaders who wish to develop their transformational leadership skills must have regular feedback from peers on their performance as well as continued interaction with their mentor or coach (Bass \& Riggio, 2006). Doing so will build confidence in the potential leader, as well as help him/her identify and develop transformational leadership skills. Finally, this type of constant interaction and support will help the potential leader develop his/her "core leadership competencies," which are essential for any transformational leader (Bass \& Riggio, 2006, p. 150). These leadership competencies include:

- Developing critical evaluation and problem detection skills through action learning and constant feedback;

- Developing envisioning skills, which include creative thinking, brainstorming, and other activities that develop strategies to grapple with change;

- Developing the communication skills necessary for conveying a vision;

- Developing and understanding impression management, or the ability to take advantage of one's behavior, appearance, and body language;

- Cultivating empowerment by communicating high performance expectations, allowing participation in decision-making, and setting meaningful goals, and developing enticing rewards (Bass \& Riggio, 2006). 
In addition to learning and developing these leadership competencies, a truly successful leader must also be interested in developing their own "leadership capacity" which requires constant dedication and usually a life-long commitment to self-improvement (Bass \& Riggio, 2006, p. 151).

\section{Transformational Leadership and Organizational Change in Higher Education}

The purpose of my study was to examine the phenomenon of leadership and organizational change at one institution. I focused my work on transformational leadership because of its overwhelming presence in the literature (Cameron \& Ulrich, 1986), and to help explore its validity in the world of higher education. In addition, several studies have been conducted supporting the theory that higher education institutions experience organizational change through transformational leadership efforts (Eckel \& Kezar, 2003). According to Altbach et al. (2011), researchers continue to debate and consider the value of transformational leadership for university presidents. According to Kezar et al. (2006), research suggests that certain issues within higher education are more applicable to a transformational leadership approach. Tierney (1991) argues that only a transformational leadership approach can take higher education to the level needed in order to address the serious challenges facing the industry.

Higher education is continually being forced to change. But, according to Eckel and Kezar (2003), both change and continuity have become staples of the academy. In other words, "much of what colleges and universities should do remains consistent with their historic purposes and roles," but they are also being asked to do much more with less (Eckel \& Kezar, 2003, p. 1). As they have always done, colleges and universities are expected by society to provide students with specialized skills, serve as local economic engines, and 
provide the next generation of professional citizens (Eckel \& Kezar, 2003). However, at the same time they are being asked to continually provide these societal benefits, colleges and universities are being confronted with numerous challenges that are forcing them to change. These challenges include dwindling budgets and the constant effort to improve student learning to compensate for under-achieving secondary education programs, while also competing for new revenue from the increasing number of for-profit institutions entering the industry (Eckel \& Kezar, 2003). In order to continue serving the public as they have in the past while overcoming the pressing challenges ahead in an industry where "rules are continually being rewritten," colleges and universities must go through a transformation (Eckel \& Kezar, 2003, p. 2).

In order to transform and become viable organizations that can face the challenges ahead, Eckel and Kezar (2003) are calling for transformational leadership to become commonplace in higher education. Colleges and universities, as organizations, need to go through "significant, institution-wide change" to address the evolving challenges (Eckel \& Kezar, 2003, p. 16). The change needs to be "deep and pervasive" so that the culture of higher education is drastically shifted (Eckel \& Kezar, 2003, p. 16). To make these lasting changes, colleges and universities, as organizations, must change their systems and beliefs, even including their way of operating. In short, Eckel and Kezar (2003) are recommending what they call "institutional transformation" for colleges and universities to continue to thrive in society and provide the education and skills to the next generation of professionals (p. 16).

The type of organizational change considered in my study was more than simply adding a new major or upgrading the technology on a university campus. The organizational 
change being considered is an institutional transformation, or what Eckel, Hill, and Green (1998) define as having four components:

- A transformation that alters the culture of the institution by changing the underlying assumptions and institutional behaviors;

- A transformation that is deep, pervasive, and permeates throughout the entire institution;

- A transformation that is intentionally executed through clearly identified and communicated goals;

- A transformation that occurs over time.

The type of institutional transformation described by Eckel et al. (1998) is not referring to a change in mission for an institution nor is it referring to the constituency an institution serves. Instead, transformational change refers to changing the way the organization functions and how the organization executes its goals. The "historic values and social roles" of the institution, however, will remain unchanged during this transformation (Eckel \& Kezar, 1998, p. 17).

Duderstadt (2007) emphasizes several factors that are critical in successful organizational transformation within a college or university. These factors mirror the elements of transformational leadership discussed by Bass and Riggio (2006). First, he argues that no matter how extensive the organizational transformation, the president should begin by evaluating the elements of the institution that he/she would like to remain intact. Second, those leaders serving directly under the president must buy into the transformation agenda for the change to be successful. During the entire process, opportunities for "active debate" regarding the transformation, including both the goals and the process itself, must be 
in place (Duderstadt, 2007, p. 280). In addition, the president should work to identify and appeal to those individuals within the institution that can carry the message of transformation, empowering them to become advocates of the cause. Duderstadt (2007) also emphasizes the importance of timing, arguing that transformation efforts should be implemented at just the right time, that decisions should be made swiftly ensuring the institution moves toward the predetermined goals, and that no transformation efforts will be complete overnight. In addition, transformational leadership is not something that can be fully delegated to another senior leader at the institution. For the full change to take effect, the president must be involved in every step of the implementation (Duderstadt, 2007). Finally, the president must be prepared to devote enough resources to the transformation to ensure that efforts to change will be successful (Duderstadt, 2007).

\section{Culture as a Challenge to Transformational Leadership in Higher Education}

Presidential leaders face many challenges to transformational efforts within higher education. The clearest and most foreseeable obstacle to transformational change is the institution's culture (Duderstadt, 2007). The values and beliefs of a university, as well as its institutional saga, may very well determine how much the organization can be changed and what timeframe is reasonable for the change. For example, while serving as president of the University of Michigan, Duderstadt (2007) admits to recognizing early on the limitations to any change he implemented, as "the status quo" of some faculty and staff members become stronger as his change efforts become more clear (p. 281). In addition, the short tenure of most presidents at an institution will hinder the changes for sustainable, transformational change unless others within the institution have been empowered and share the message (Duderstadt, 2007). The literature is rich concerning the importance and consideration of 
culture, but scant when considering workable models and methodologies to measure culture. Another importance of my study is to help provide insight regarding how we can measure culture through qualitative techniques, especially when concerning transformational leadership and organizational change.

Other researchers emphasize the challenge culture can present when considering organizational change. Burke (2002) argues that organizational transformation requires a "fundamental change of the culture" (p. 286). Furthermore, the degree of any transformational change within an institution is dictated by how vested the organizational members are in the culture (Foster \& Kaplan, 2001). Burke (2002) also reiterates the importance of time when instituting transformational change, claiming that some efforts could take years depending on the state and influence of the culture. Finally, the ability to influence others within the culture to both understand and spread the leader's message is critical, as this can reduce the amount of time required for the transformation, make the change more lasting, and make the transformation more pervasive (Burke, 2002).

Bass and Riggio (2006) warn that culture may be the most formidable challenge to overcome when implementing transformational change. The norms, beliefs, and shared values within an organization only grow and solidify over time, making them more difficult to change in the future. Similarly, leadership within an organization helps to define the culture (Bass \& Riggio, 2006). As a result, implementing change, no matter how transformational, will undoubtedly impact the culture of an institution.

Eckel and Kezar (2003) argue that real transformation cannot occur "without altering at least some aspects of institutional culture" (p. 130). Institutional culture within colleges and universities can be very pervasive, governing events, behaviors, and institutional policies 
concerning every aspect of the university. For example, according to Bess and Dee (2008), events such as orientation and graduation can reflect the uniqueness of an institution, even drawing certain students to the school because of the tradition. Traits of a culture may also be a draw for faculty and staff as well. For these very reasons, instituting transformative change, which will change the institutional culture in most instances, will usually be met with resistance from followers within the organization (Bess \& Dee, 2008).

Any transformative change efforts made by the president at an institution must consider the present culture. According to Birnbaum (2002), any viable presidential leadership efforts at a college or university must consider the norms and behaviors of the present culture. Before change can be implemented, any leadership efforts must be aligned with the current culture, meaning that organizational culture change must take place within the current cultural framework (Bess \& Dee, 2008; Birnbaum, 1992). In other words, the presidential leader is more likely to implement the appropriate measures to invoke organizational change once the culture is fully understood. While culture can define the leader, leadership efforts can look different when implemented among different cultures (Neumann, 1991). Nevertheless, if a president wants to engage in transformative change at his/her institution, he or she must become an expert on the culture by "carefully studying and understanding it" (Kezar et al., 2006, p. 124).

The literature identifies two schools of thought concerning the impact of culture on change within higher education. Tierney's (1991) framework examines institutional culture as an independent entity, arguing that no two institutions can have similar cultures. More importantly, Eckel and Kezar (2003) claim the value in this framework is its ability "to explore the ways in which culture affects change processes within individual institutions" (p. 
132). The framework examines six categories of culture, including the environment of the institution, mission, socialization, information, strategy, and leadership (Tierney, 1991). The framework examines each category within an institution's culture in depth, aiming to discover which areas of the culture are most susceptible to change. In addition, Tierney's (1991) framework is an excellent way for a presidential leader to better understand the culture of the institution before implementing any change efforts.

Another framework grounded in the literature is Bergquist's (1992) cultures of the academy. Bergquist (1992) identified four types of culture, or archetypes, that a higher education institution could fall under. These include the collegial culture, the managerial culture, the developmental culture, and the negotiating culture (Bergquist, 1992). Each culture, in many ways, refers to the norms and behaviors of the different facets of the academy. For example, the collegial culture values the interests of the faculty, which in most cases involves interests such as shared governance and "scholarly engagement" (Eckel \& Kezar, 2003, p. 132). Managerial culture represents the interests of the institution as an organization, focusing on values such as supervisory skills and mission. The managerial culture is positioned on the opposite end of the developmental culture, which is most concerned with the growth of members within the organization. Negotiating culture, the fourth and final according to Bergquist (1992), involves the understanding of organizational policies and rules as well as distribution of power among the various groups (Eckel \& Kezar, 2003). Institutions can have cultures that fall within one or more of these categories, and understanding that they are present can help presidential leadership understand the present culture and know when transformational change can be implemented. 
Eckel and Kezar (2003) argue that elements from both cultural frameworks of Tierney (1991) and Bergquist (1992), when considered together, provide "a clearer picture of the institutional culture and its effect on transformation processes" (p. 133). Bergquist's (1992) four archetypes allow for easy analysis, placing facets of an institutional culture into discernible categories for consideration. After simplifying the areas, Tierney’s (1991) framework allows presidential leaders to peel away the complex layers of institutions, examining closely the unique intricacies. Considering both frameworks, according to Bolman and Deal (2008), provides multiples lenses from which college and university presidents can understand the culture of their institutions, and ultimately determine if and where transformation is needed. Also, when considered together, Eckel and Kezar (2003) were able to develop five change strategies that, when applied appropriately, can effect transformational change within an institution.

The change strategies identified by Eckel and Kezar (2003) include senior administrative support, collaborative leadership, flexible vision, staff development, and visible actions. The underlying similarity between these five change strategies is that "they are all approaches to making people think differently" (Eckel \& Kezar, 2003, p. 78). When examining six institutions concerning the use of these five change strategies to implement overall transformation, Eckel and Kezar (2003) discovered that together they were effective, but without development in even one area, "transformation efforts suffered" (p. 78).

\section{Why Transformational Leadership Matters to Higher Education}

The value of transformational leadership within the context of higher education is easily seen when considering significant transformational change opportunities. Managing the budget of a college or university is just one such opportunity, especially in difficult 
economic times. According to Neumann (1992), university presidents can use the budgeting process to their advantage, portraying financial difficulties to the faculty and staff as leverage. As a result, Neumann (1992) claims that faculty and staff more often expect college presidents to use transformational leadership to deal with any financial pressure, shielding the campus from the issue and allowing the organization to operate without disruption. For example, one instance shared by Neumann (1992) appealed to the Intellectually Stimulating (IS) component of transformational leadership; the president developed a plan for addressing the budget, clearly presented each step of the plan, and asked for faculty input on the final decision to move forward. As budgets continue to dwindle and financial woes only grow for public and private colleges alike, skills in transformational leadership will become more critical for university presidents to deal with significant issues such as the budget.

\section{Transformational Leadership, Peter Drucker, and the Knowledge Economy}

Drucker (1993) was the first academic to suggest that society is continually realigning itself as civilization grows and develops. This re-alignment includes key institutions, societal values, political frameworks, and, most importantly, what constitutes knowledge. Drucker (1993) argues that society goes through this transformation every fifty years or so, creating an entirely new world which the previous generation could scarcely recognize. According to Drucker (1993), we are currently transforming into a post-capitalist society where information is centralized, computers and technology are rapidly changing our economy, and the nature of leadership and management is constantly changing. This postcapitalist society values the knowledge of the individual, promotes a lifetime of perpetual learning, and presents knowledge as the next resource to drive the global economy. 
Stewart (1999) takes the ideas of Drucker (1993) one step further, arguing the true value and wealth within any organization in today's economy is intellectual capital. How organizations manage their intellectual capital, and how they encourage individuals within the organization to share knowledge with others, will be the defining edge for those successful companies of the future (Stewart, 1999). Leaders of these successful organizations must be effective managers of knowledge, always staying sharp on the latest information impacting the organization. In addition, leaders in the post-capitalist society must continue to learn and understand the industry in which they function. In other words, Stewart (1999) is arguing that leaders who are truly transformational must truly become lifelong learners and recognize the value of intellectual knowledge within their organization.

The arguments presented by Drucker (1993) and Stewart (1999) are extremely relevant to today's higher education industry. Colleges and universities are the original distributors of knowledge, and intellectual capital is big business in many of today's premiere research institutions (Stewart, 1999). Any college or university president who aspires to be transformational must recognize and understand the intellectual capital his or her institution holds. In addition, he or she must continually learn and stay competitive in the information age, never falling victim to an "unwillingness to act" (Cohen, 2010, p. 90). Any leader who wishes to be transformational within higher education must recognize the value of knowledge and remember that he or she is leading in the post-capitalist society.

\section{Transformational Leadership: Myth or Reality?}

Countless leadership articles and books have been written describing the merits of transformational leadership and what individuals in leadership roles can do to become more transformative. Researchers from Bass and Riggio (2006) to Kouzes and Posner (2007) not 
only argue the advantages to transformational leadership, but they also provide instances that exemplify a transformational leader as opposed to a normal leader. Others, such as Bolman and Deal (2008) and Collins (2001) have advocated leadership techniques that are very similar to those of transformational leadership. Transformational leadership has been written about abundantly in the literature, in addition to the countless leadership studies that have been conducted, but is transformational leadership practical? Can college and university presidents truly be transformational leaders?

The goal of my study was not only to examine the phenomenon of transformational leadership and organizational change within the position of president in higher education, but to also explore if the academic presidency even provides the opportunity for transformational leadership and the ability to promote change. Many researchers have argued that the president of a college or university, in most cases, does not have the power to make transformational change (Bess \& Dee, 2008; Bolman, 2011). Cohen and March (1974), for example, argued very early on that college and university presidents face too many ambiguities of power to be any real influence on the direction of the institution. Collins' (2001) research already argues, to some degree, that transformational leadership is not critical for an organization to change and ultimately to succeed. In fact, Collins (2001) argues that leaders who exhibit many of the transformational qualities written about in the literature will not always lead a transformational organization.

Some of the most successful organizations in recent memory were led by reserved, non-charismatic individuals who quietly identified what their companies were good at creating and selling, and then focused on perfecting that product. Collins (2001) dubbed this act the "Hedgehog Concept" and argues that perfection of this concept will transform a good 
organization into a great organization (p.13). The perfection of this concept alone challenges that mantra of transformational leadership. The idea of transformational leadership put forth in the literature suggests great transformational efforts, new ways of doing old tasks, or launching a company to a new level. Collins (2001), on the other hand, suggests that organizations can simply transform themselves by focusing on what they're good at doing and perfecting it. Furthermore, Collins (2001) argues that leaders have very little, if any, impact on taking an organization from good to great.

College and university presidents are in the same position as those leaders examined by Collins (2001), and today's presidents most certainly fit the mold described by Cohen and March (1974) three decades ago. These researchers suggest that transformational leadership may not be as powerful a model as previously written about in the literature. With this being said, my case study attempted to determine if academic presidential leadership can truly be transformational as described in the literature, or to determine if presidents are forced to lead in a more reactionary manner based upon the forces driving the university as an organization. In addition, my study attempted to determine if presidents alone have the power to invoke organizational change. 


\section{Chapter Three: Methodology}

\section{Statement of Researcher Bias}

As a former student and graduate assistant of the institution being examined in my study, I initiated this research with preconceived notions and a natural, human bias. However, I feel that my diverse background and experiences outside the institution both academically and professionally have given me a wider view, allowing me to view a subject or issue from multiple perspectives or lenses. In this respect, I believe my personal bias can be an advantageous, allowing me to draw upon my leadership and organizational change experiences outside of higher education. In addition, I have both a graduate background in education and business, which has provided me with an extensive understanding of the theories and ideas being explored in this study. As a resident of the community in which the institution is located for nearly thirty years, as well as a student of the institution for nearly a decade, I feel that my knowledge, understanding, and perspective may be an asset to the study.

In addition to studying leadership at the graduate level, I have held several leadership positions during my professional career in private, non-profit, and government sectors. I personally feel that leadership is rarely learned overnight, and without sacrifice and dedication. Furthermore, I am skeptical of the effectiveness of transformational leadership in the real world. I tend to believe that in most cases one leader cannot promote significant change without help from both inside and outside the organization. I also believe that culture can be the most challenging obstacle to any kind of organizational change.

Regardless of my personal bias and long-standing affiliation with the institution in the past, I am detached from the data collected in this study. I have no current relationship with 
the participants in this research, nor will I be interacting with them after the study has concluded. I used a critical friend during the data analysis and conclusion portions of the study, which ensured that my personal bias did not influence the direction of the study in any capacity. I, as the researcher, was prepared to discover anything throughout the study, even issues or themes that may have arisen that were not anticipated. I had no motive to skew the data in any way, nor did my connection with the institution shape any outcomes of the study. I stated my perspective up front because it serves as the driving force behind this study, yet does not taint the research in any way. This study is a culmination of my experiences in both the world of higher education and organizational leadership.

\section{Methodology}

Schwandt (2007) defines methodology as "a particular social scientific discourse (a way of acting, thinking, and speaking) that occupies a middle ground between discussions of method (procedures, techniques) and discussions of issues in the philosophy of social science" (p. 193). I chose a qualitative approach to measuring the phenomenon of transformational leadership and organizational change because of the personal perspective that can be generated. According to Patton (2002) and Schram (2006), qualitative inquiry offered me, as the researcher, the opportunity of "being there and getting close to people and circumstances ... in the social sense of shared experience, empathy, and confidentiality" (Schram, 2006, p. 8). For this study I chose to use primarily case study and qualitative description as the methodologies to gather and analyze my data. Storytelling will also be used as a method of research inquiry; I recognized and used the stories to help extrapolate my themes during the analysis. Together, these methodologies provided the conceptual framework for my study. I discuss the rationale behind choosing each method in the 
following sections of this chapter.

Case Study. I chose descriptive case study as one of my methods because it allowed for the study of unique phenomena such as the transformational leadership and organizational change within the presidential position in higher education. Creswell (2013) defines case study as a qualitative research approach where "the investigator explores a real-life, contemporary [case or cases] through detailed, in-depth data collection" (p. 97). The work of Stake (2005) and Yin (2009) have defined the features of case study methodology in the social sciences. My goal for this case study was two-fold: to explore and better understand the phenomenon involving transformational leadership and organizational change in the presidential position of higher education and, if the opportunity arises, to explore if college and university presidents even have the opportunity to promote change at their respective institutions.

Case study offered a perfect fit to the study that I proposed to conduct. First, the goal of my study was to examine the phenomenon of transformational leadership and organizational change concerning two past and one current university presidents at a small institution. These presidents served the institution from the mid-1980s to present, encompassing a quarter century of leadership during a very turbulent time in higher education that included sky-rocketing tuition, the introduction of online learning, and the rise of for-profit institutions to name a few. By using the case study method, I bracketed my research around this time period exclusively. The timeframe in which these presidents served provides the "parameters, such as specific time and place" to strengthen my argument for the use of case study methodology. In addition, these presidents have arguably served over the most significant amount of change the university has ever seen, including the 
attraction of the institution's most generous donors, its conversion from a state college to a state university, and the completion of the school's town and gown initiative.

According to Creswell (2013), the researcher may also choose to utilize case study methodology when he/she hopes to generate an "in-depth understanding" of the unique topic or phenomena (p. 98). In some cases, focusing on smaller groups and collecting various forms of data, such as interviews and performing a document analysis, can be more fruitful than involving larger groups of participants. For the purposes of my study, examining a smaller number of participants more intimately revealed the unique phenomenon of transformational leadership and organizational change, if any existed at all in some capacities. My case study also better presented the human experience of leading a small, public institution (Stake, 2005).

Critics of case study methodology have argued that examining a small number of participants within a small time period or small parameters limits the researcher's ability to draw reliable research findings and make final assertions about the phenomena. Other critics, such as Simons (1996), have argued the extensive amount of time the researcher must spend with the participants, along with the continued submersion in the case itself, inevitably biases the findings. Nevertheless, I felt that case study methodology was the best method to get at the phenomenon involving transformational leadership and organizational change. The in-depth, personal nature of case study analysis was the best method for determining if the participants in my study were actually transformational leaders, or even if their leadership had contributed to institutional change.

Qualitative Description. The goal of this study is to explore the relationship, if any exists at all, between transformational leadership and organizational change. As I suggested 
in my review of literature, extensive research has been done on both topics, primarily in the private sector and business arena, yet very little has been done to explore the relationship between the two within the higher education presidency. As a result, my case study was meant to be a preliminary entre into the phenomenon. Therefore, I chose to complete a qualitative descriptive study to lightly examine the occurrence, to determine if a relationship between leadership and change does exist within the presidency, and examine if any other factors influence that relationship. If anything, I hoped to identify cracks in the theory of transformational leadership, examining if it does in fact make a difference, and provide opportunities for future, more detailed analyses in this area.

Sandelowski (2000) argues that the growing number of complicated methods within qualitative research have made simpler methods less desirable to the qualitative research community at large. However, qualitative descriptive studies are the perfect vehicle for examining a complex relationship or phenomenon at a very high level, paving the way for additional qualitative, quantitative, or mixed method approaches that can provide deeper examinations (Sandelowski, 2000). Instead of presenting the phenomenon in a "conceptual, philosophical, or other highly abstract framework or system," my study sought to present the facts of the case "in everyday language" (Sandelowski, 2000, p. 336). By using qualitative description, I set the expectations of the study by pre-selecting to examine the elements of transformational leadership, organizational change, and storytelling; examining all three of these areas best explored my research question (Sandelowski, 2000).

I found the method of qualitative description advantageous to my research because I was able to consider a very detailed summary of the relationship between transformational leadership and organizational change in "everyday terms" where the "language is [the] 
vehicle, not itself an interpretative structure that must be read" (Sandelowski, 2000, p. 336).

The literature indicated that determining the relationship between leadership and change within the presidency was a new concept, so rather than try to force my data into a particular approach, qualitative description allowed the data to speak for itself without interpretation or filter. Although qualitative description limited my ability to focus on the meanings behind the themes extrapolated from the data, my findings paved the way for additional, deeper research to be done.

Descriptive research has been described as the lowest form of quantitative research in the past (Sandelowski, 2000). However, when the descriptive element is combined with the qualitative element, the researcher has the opportunity to present an unfiltered, simplistic portrayal of the data using rich qualitative themes to support any numerical information that is discovered (Sandelowski, 2000). This method allowed me to provide a summary of descriptive information organized in a fashion that best represents the data I discovered and in a way that is best suited for the audience of my study (Sandelowski, 2000). Otherwise, the same rules of qualitative research apply, including guidance on sample size and interview protocol (Patton, 2002). Similarly, data collection techniques within this realm may also include observations and document analysis, both of which were utilized in my study (Sandelowski, 2000).

Because my case study represented a foray into a fairly new topic concerning the presidency, descriptive research provides a vehicle for just touching the "surface" of the phenomenon, or serving as a starting point, as opposed to a more penetrating representation of the data (Sandelowski, 2000). The value in qualitative description, when used as a research method, "lies not only in the knowledge its use can produce, but also as a vehicle for 
presenting and treating research methods as living entities that resist simple classification" (Sandelowski, 2009, p. 83). The crux of my argument within this study was that real-world presidential leadership may not easily fit into a prescribed box or mold, so therefore the methodology I used to pursue the data allowed me the freedom to explore trends and themes without being forced to put the information into a predetermined framework. A qualitative descriptive study allowed me this freedom to truly explore the phenomenon of transformational leadership and organizational change without applying theoretical interpretations.

Storytelling. My case study examined the nature of leadership in higher education from a qualitative perspective. Styles of leadership used in higher education have been studied extensively in the past in a quantitative capacity, but very little has been examined from a qualitative perspective concerning the phenomenon of transformational leadership and organizational change. My study examined the use of storytelling as a qualitative measure for the primary means of data collection.

Origins of Storytelling in Education. Storytelling has been an integral piece to education and learning in all world cultures since the invention of language. Stories, parables, and allegories of all great cultures and civilizations have "contained the elements of belief systems, historical records . . communication of law, religion, ethics, and values" (Lauritzen \& Jaeger, 1997, p. 36). From both an educational and organizational perspective, “story provides a structure for remembering" (Lauritzen \& Jaeger, 1997, p. 36). According to Eckard (2009), the use of storytelling, historically, was "the primary source for distributing education" before chalkboards, books, and other forms of technology, which are commonplace today (p. 26). Bettelheim (1989) argues that storytelling is first introduced in 
an education capacity by teaching young children the meaning of life at a very early age through personal experiences and fairy tales. Lauritzen and Jaeger (1997) claim the "knowledge of story begins in the preschool years" and is eventually refined into adulthood (p. 34). Others have argued that storytelling continues to be a valuable tool for learning well beyond adolescence (Collins \& Cooper, 1997; Jalongo, Isenberg, \& Gerbracht, 1995; Lyons \& LaBoskey, 2002; McDrury \& Alterio, 2002; McEwan \& Egan, 1995; Witherell \& Noddings, 1991). Storytelling has always had a place in the higher education classroom, both as a method of curriculum delivery by professors as well as a form of professional reflection outside the classroom.

Eckard's (2009) study analyzed the impact of storytelling on the learning process. More specifically, the study sought to determine if "storytelling was a technique that contributed to the learning environments" that included the actual classes, instructor conferences, and writing center tutoring sessions (Eckard, 2009, p. 5). An analysis of stories told in these three venues was conducted to determine educational impact, as well as the likelihood of a story being told by the instructor or student. Results indicated that stories do exist in these environments, that instructors are the primary tellers of these stories, and that stories offer the potential to improve the learning process (Eckard, 2009).

Outside of the classroom, storytelling is a commonplace practice that has become an integral facet of the human experience. According to Schank (1990), storytelling is incredibly valuable to the collective intelligence of humans. In order to understand "prior events successfully," humans must explain them to others for personal and collective insight (p. 1). As a result, "explaining the world" to others is the primary method humans use to construct intelligence (Schank, 1990, p. 1). Through story, humans seek to share their 
personal experiences and better understand the world around them, especially within the culture they exist. Roemer (1995) claims that storytelling does more than contribute to human knowledge, arguing that story is the most fundamental way that humans' connect to each other. Stories "establish a web of explicit relationships" where "all of the figures and incidents are interconnected" (Roemer, 1995, p. 11). The need for connection with others is the most basic human need, and storytelling continues to be a facilitation of that connection, which is all the more reason to use this method as a qualitative measure in my study.

In addition, storytelling “connects us vitally with others," develops creativity, "strengthens courage and confidence," and makes the human experience more memorable (Maguire, pp. 13-14, 1998). Stories are the easiest way for humans to connect to one another and relate experiences, fears, hopes, etc. According to Maguire (1998), individuals will tell stories not just from memory, but also personal meaning regarding their experiences (Maguire, 1998, p. 80). The stories told by members of an organization or higher education institution, in many ways, represent the culture and are responsible for passing along the institutional history. The personal stories continue in the organization through "restoryation," or the re-telling of those experiences in ways that reflect personal experience (Maguire, 1998, p. 78). Stories, then, are rich with information about the changes that have impacted the institution or organization, especially if the individual telling the story has a lengthy career and serves in a leadership capacity.

Storytelling as a Leadership Tool. The use of story is not simply relevant to my study as a research tool; storytelling has been also used as an effective tool for institutional leaders. As a result, I expected to learn that the presidents I interviewed had used or were using story as a transformational leadership tool, especially when dealing with the culture of the 
institution. Storytelling has the power to carry "multiple messages" that can "reflect important values, inspire, and describe appropriate behavior" to others (Hackman \& Johnson, 2009, p. 23). Stories can carry multiple messages to listeners, while also sharing "important values" and inspiring those around them. More importantly, telling compelling stories influences "others to pick up the same story line, thus extending the narrative" (Hackman \& Johnson, 2009, p. 23). For example, the leaders interviewed for my study continued the narrative of the institution through which they serve within the stories they consistently retold not only to me but also to others both inside and outside the institution.

Other researchers have written about the demonstrated value of storytelling from an organizational management or leadership perspective. Armstrong (1992) argues that storytelling is an effective management tool within any organization because of the narrative's power to pass along cultural norms, provide simplistic training, empower employees, and provide for recognition within the organization. Guber (2011) argues that telling stories is the most effective way for a leader to sell new ideas to both internal and external stakeholders. If used effectively by leaders, storytelling can gain buy-in for projects or initiatives, as well as inspire with a "call to action" (Guber, 2011, p. 37). Telling stories can also "empower [the] audience to tell [the] story forward," ensuring the culture of the organization is continued through the "multiplier effect" (Guber, 2011, p. 237).

Denning (2011) claims that "the best way to communicate with people" that need to be lead "is often through a story" (p. 1). He advocates that storytelling is an effective way for leaders to navigate the numerous challenges of leading in the professional world. As a result, he argues that an organization's best leaders are also its best storytellers, able to catch and hold the attention of an audience by "evoking the sights and sounds and smells of the 
context in which the story took place" (Denning, 2011, p. 7). Denning (2011) also admits that storytelling is a rare skill "in which relatively few human beings excel" (p. 7). Once mastered though, storytelling enables the teller to communicate "new perspectives" while also "communicating change and stimulating innovation" (Denning, 2011, p. 11). Denning's (2011) analysis suggests that leaders and administrators of any organization will provide the most insightful stories, as well as be the organization's best storyteller.

Storytelling and the Value of Institutional Knowledge. With the rise of the knowledge economy, and the growing role of higher education in perpetuating that economy, storytelling has become increasingly important to leaders when disseminating institutional knowledge. Denning (2001) argues that storytelling is an especially critical tool for today's transformational leader, especially with the rise of knowledge-era organizations outside of higher education. Today's organizations, especially institutions of higher education, grow and thrive on knowledge and intellectual capital. According to Stewart (1999), "Knowledge has become the preeminent economic resource - more important than raw material" or even money in most cases (p. 6). By helping people easily understand complexity and the benefits of change, Denning (2001) argues the "springboard story" can be used as a catalyst for change in today's knowledge-era organizations. These types of stories use examples, introduce a concept that is new or foreign to the organization, and are brief in length (Denning, 2001).

Stories can be valuable pieces of information to an organization's institutional knowledge and culture. Leaders who aspire to be transformational must understand an institution's culture before promoting significant change (Bass \& Riggio, 2006). Simultaneously, preserving and maintaining the knowledge within a culture can be especially 
critical to any leader. Every year, more and more people retire from his/her profession and are replaced with new employees. This cycle creates a loss of thirty years or more of institutional knowledge, which can negatively impact an institution's progress. "Stories of personal experience," according to Miller (2009), not only reveal past events in someone's life, but also include "life stories" that involve personal "selection, repetition, pruning, and interpretation" of certain memories over a lifetime (pp. 69-72). This process is inherently revealing of the organization with which the teller is associated, suggesting aspects of the organization's culture, policies, and history to name a few. As a result, storytelling has become more valuable to modern organizations, many of which collect these narratives through a process called Digital Storytelling (Czarnecki, 2009).

The purpose of using story in my case study was two-fold: I expected the presidents I interviewed to use story as the primary method of conveying ways in which they were transformational while serving as the head of a higher education institution. As the researcher, I was only able to fully understand the leadership traits of each president when they provided me examples of their leadership through stories. Secondly, I expected to learn that storytelling is an effective leadership tool that these presidents have used or are using as a method of change or as a way of reaffirming that culture of the institution. In any case, I felt that I must demonstrate a comprehensive understanding of the value of story as an educational and leadership tool. The stories I gathered as part of this case study would be valuable to the institution, as they represented nearly four decades of institutional knowledge, history, trends, and leadership elements used within the institution.

Tying the Three Methods Together. I chose to use case study, qualitative description, and storytelling as the three methods of data collection for this study. Although 
each method is unique, I believed that together they would offer an excellent opportunity to examine the phenomenon of transformational change and organizational change at the institution. Applying case study methodology allowed me to focus on a particular segment in time at the institution, teasing out themes and data that could remain buried in a larger, more comprehensive study. Qualitative description allowed me the freedom to brush the surface of the phenomenon and present the data in such a way that will be easily understood by other researchers who aspire to delve more deeply into the relationship between transformational leadership and organizational change within the presidency. The understanding and ability to identify storytelling during the interviews helped me identify the themes and more easily tease out the phenomenon of transformational leadership and organizational change. In addition, the use of storytelling provided a natural way for the participants to deliver the data during the interviews, making them easier to understand and analyze. Combined, I felt these three methods constructed a stronger qualitative study than if each were used separately.

\section{Implementation}

In order to study the phenomenon of transformational leadership and organizational change at the presidential level, I chose a small public institution situated in the Middle Atlantic States. The institution I chose for the case study was ideal for several reasons. First, I was able to interview and examine every president of the institution who served in the last quarter century, beginning in 1986 through the present. Secondly, the small nature of the institution, as well as its geographic location in a very small town, allowed me to focus more exclusively on the phenomenon of transformational leadership and organizational change. The methods of collecting data for my study included video-taped interviews of three presidents, both past and current, of the institution. Three faculty members who have served 
under or been associated with the institution during the tenure of all three presidents that are participating were also interviewed, but these meetings were audio-recorded. In addition to these interviews, my study included a robust document analysis of materials related to each president's tenure, archival research, and visual research of the president's behavior during the interview. Results from the interviews allowed me to conduct a content analysis and retrieve the required information for the case study (Crotty, 1998). Document analysis of archive information, including presidential papers, newspaper articles, and institutional literature allowed for a rich interpretation and analysis of data (Crotty, 1998).

Methods are defined as the specific techniques that I used to acquire data in the case study (Bogdan \& Biklen, 2007). The selection of the appropriate method was extremely important in order for me to fully understand the phenomenon of transformational leadership and organizational change at the institution being examined. I felt that interviews and document analysis would provide me with a large amount of rich data that could reveal the phenomenon concerning transformational leadership and organizational change at the presidential level of higher education. In addition to these established methods, the small institution selected for the study provided the perfect backdrop for a case study of leadership, as well as the three presidents and three faculty members that participated. The presidential interviews provided me with data that identified the presence of transformational leadership, while the interviews with the faculty members helped gauge the significance of the organizational change, if any existed. The document analysis provided supporting information for the themes identified in the interviews.

Description of the Institution. The public institution examined in my study, which was founded near the turn of the twentieth century, is geographically located in the Middle 
Atlantic States region. Like most small colleges and universities in America today, this institution was started by a grassroots effort in the local community to have an educational outlet (Goodchild \& Wechsler, 1997). The school was constructed to offer an education to the children of working-class families situated throughout the region. The town in which the institution was constructed was, like most towns in the early part of their history, a thriving industrial and transportation hub. The institution evolved from a State Normal School into a college and then a university that serves nearly six thousand students today.

Like most small institutions of higher education, the town in which the institution being examined is located has been a driving force since the school's inception. The local townspeople were instrumental in having the state locate a school in the town, with many local miners foregoing a portion of their wages to help pay for the new construction. After the coal-mining industry began to wane in the region, the institution became one of the sole economic engines for the town, sustaining jobs and businesses to support the student influx each year. The school is located within city limits, yet leaders from each group have been able to co-exist for over a century with little interaction until recently. The city today is home to just over eight-thousand full-time residents not counting the student population of the school.

Both the town and the university seem to have very different cultures, regardless of the close proximity and benefit each provides to the other. As a native to the town and also a graduate of the institution, I have witnessed this relationship from both within the organization as a student and from the outside as a member of the community. Although the city recognizes the economic value of the school, at times the institution is viewed by the community as a blight, bringing typical college town problems such as extreme drinking, 
disorderly behavior, and petty crime. From the perspective of the town, the institution brings two major drawbacks to the community: the party school image and relaxed admittance and grading. Recently leadership at the institution has tried to battle these images with programs and other efforts that have received coverage in the local and state-wide media.

As a life-long resident of the town, I have experienced first-hand the culture of the area surrounding the institution. The majority of the town's residents are native to small communities in the region, elderly, and most have only a high school diploma and never attended the institution being studied. Historically, the community is very homogenous with very little diversity present. The town is also located in one of the poorest counties in Maryland, with most residents working in blue-collar or low-level service positions. The region of Middle Atlantic States surrounding the institution is considered by many to be conservative politically and socially. Culturally, the region is also part of the Appalachian Regional Commission's designation of Appalachia.

The culture of the institution examined in this study also influences the perceptions of the participants. The university struggles to battle the perception of a pervasive culture of mediocrity. More specifically, within the last few decades, the institution has earned the reputation as the party school for the state which has resulted in numerous campaigns trying to curb this stigma. In addition, the institution is geographically isolated from the majority of the state, often leaving organizational members feeling as if they are "forgotten," especially concerning budgetary support. The majority of the students attending the institution are from the surrounding area, while others are primarily from the urbanized east including the Baltimore and Washington D.C. areas. Most graduates of the institution, including those originally from the local area, immediately relocate outside the region to find gainful 
employment (J. Taylor, interview, August 23, 2012).

The surrounding community, the unique history of the institution and the challenges it faces, and the faculty and staff provide many different interpretations of the organization. Like any public university in a small town, the institution in my study is a product of the students, faculty, staff, and local community. The geographic area may be the most significant factor when considering the portrait of the institution, as it seems to ultimately define the school in many ways. In addition to being located in a remote corner of the state, the institution is located and serves a region clearly defined as Appalachia. For example, funding for the school and the surrounding community and culture are considerations that must be weighed by any leader of the institution. Conversely, the mountainous region where the institution is located offers one of the last natural escapes within the state as a whole, with numerous state and national parks within a sixty-minute drive of the institution.

Nevertheless, the different backgrounds of the participants in this study, along with the unique aspects of the institution itself, will paint a rich portrait for qualitative analysis.

Participants. Participants were chosen for the study through what Bogden and Biklen (2007) refer to as purposeful sampling, where specific participants were targeted and included in the study because I believed they would help expand the developing theory because their history within the institution could represent the changes taking place over the selected period of time. I targeted the three presidents of the institution because they served during the last quarter century, arguably the most significant time of change in the institution's history. Together, their testimony provided a portrait of how the institution has changed under their respective leadership. I recruited the presidents by reaching out to each individually; two are now retired and living in different parts of the country, and the current 
president resides locally. I attained their contact information through contacts I have on campus through the president's office and through a faculty member contact. I approached the current president of the institution directly and asked him to participate. The participants are referred to in this study as pseudonyms to protect their true identities and attempt to maintain confidentiality. The following descriptions of the presidents are kept purposely vague so as not to reveal their identities.

The Presidents. Dr. Reitman served as the president of the institution from 1986 to 1991. He arguably oversaw the most significant physical changes at the institution, including the naming of the institution's library and the conversion from college status to university status in the state's public system. Dr. Reitman was also one of the first presidents to begin tapping the local community and successful graduates of the institution for donations and funding to expand the campus' physical structures and academic programs. He had served at other institutions as president before coming to the school in my study, and was also instrumental in taking another school to university status. Including Dr. Reitman in my study was critical because of his work in making the school a university and transforming much of the campus into its current state.

Dr. Glansdale came to the presidency of the institution having never served as a higher education president before. She served as president of the institution from 1991 to 2006. She ascended to the presidency through the traditional path of teaching, beginning at a high school just outside Baltimore, Maryland. In addition to Dr. Reitman's work, Dr. Glansdale is also responsible for much of the physical appearance of the institution's campus today. In addition to being an accomplished president, she served in leadership positions in higher education at the state, regional, and national levels, as well as having an accomplished 
academic publishing career. Dr. Glansdale was especially valuable to my study because of her work in securing funding from the state, her efforts in connecting the local community with the campus, and because she is the only female president in my study. As the literature suggested, I expected to find a distinct difference between her leadership and that of her counterparts.

Dr. Gail is the sitting president of the institution, taking over for Dr. Glansdale in 2006. He came to the institution from another presidency, and like Dr. Glansdale, ascended the higher education ladder through the traditional path of teaching. His initiatives have included creating a green and sustainable campus, initiating large capital campaigns for campus improvements, and furthering town-and-gown initiatives begun by Dr. Reitman and Dr. Glansdale. In addition, Dr. Gail has taken the institution to the next level, facilitating the launch of the institution's first doctoral degree. Dr. Gail's participation in this study was critical both because of his accomplishments since assuming the presidential role at the institution, but also because of his perspective as the sitting president.

The Faculty Members. In addition to the three presidents, I selected three faculty members who served under all three presidents during their tenure at the institution. The human resources department of the institution was able to generate a list of faculty members who served under the three presidents selected for the study. From this list, I selected three faculty members who I thought would be able to provide objective, yet insightful, analysis of each president's performance when considering transformational leadership and organizational change. These three faculty members also represented each of the three colleges at the institution; I did this in an effort to ensure that every possible perspective could be provided from the institution's standpoint. Their teaching background and area of 
expertise was considered, as well as their involvement in the campus and community. Since I grew up in the immediate area of the institution, was both an undergraduate and graduate student, and was employed at the school for nearly a decade, I was able to use my intuition and past experiences to determine which faculty members were best suited to discuss the phenomenon involving transformational leadership and organizational change during their tenure at the institution.

Dr. Parker began working at the institution in the early 1970s and represented the College of Education's perspective in my study. In addition to teaching nearly fifty different undergraduate and graduate courses during his tenure at the school, Dr. Parker has served in many administrative capacities including on the Faculty Senate and as chair of graduate programs. He currently focuses on program development, both developing and launching new programs while also ensuring that launched programs continue to meet standards. His particular areas of interests are early childhood education and growth and development. He, like other senior faculty in the department, has worked diligently with departmental faculty members in the college for the unveiling of the institution's first doctoral program in the fall of 2012. In addition to providing insight as an educator, Dr. Parker lived and raised a family in the community. As a result, he also brought a personal and intimate perspective to the interview.

Dr. Smith, who represented the College of Liberal Arts and Sciences, began his tenure at the institution in the late 1980s. A native of the community surrounding the institution, Dr. Smith taught in the public school system before becoming a professor. In addition to teaching various English courses, Dr. Smith has served in numerous leadership and administrative roles on campus including Faculty Senate, Associate Chair of the English 
Department, the President's Cabinet, and on curriculum and executive committees. Being a native of the town, Dr. Smith was able to provide very unique insights into the growth and organizational change of the university as both an outsider and as a member of the institution. In addition, he worked very closely with Dr. Glansdale on the President's Cabinet and was able to provide especially valuable insight into over 15 years of leadership at the institution.

Dr. Sanders also joined the institution in the late 1980s and represented the College of Business in my study. Although not from the immediate community, Dr. Sanders grew up and resided less than twenty miles from the institution's campus his entire life except for when attending undergraduate and graduate school. His career at the school has consisted of teaching economics courses, serving as the Chair of the Economics Department, and serving on the Faculty Senate. I expected that Dr. Sanders, like Dr. Parker and Dr. Smith, would be able to speak about the institution as a member of the surrounding community and as a faculty member, but not to the same degree. The majority of students who graduate from the institution are either education or business majors, and the business department has received extensive presidential attention in recent years because of its popularity. As a result, Dr. Sanders was able to reflect on this presidential involvement and speak to presidential initiatives and changes on campus.

Interviews and Observations. My case study examined the phenomenon involving transformational leadership and organizational change. I used the interviewing and observational model of Rubin and Rubin (2012) known as responsive interviewing, which allowed me discretion during each interview to present prompts that would deviate in accordance with the participant's conversation. The questions asked during the presidential interviews aimed to identify if transformational leadership had been exhibited, if significant 
organizational change took place during the president's tenure, and if that change was a result of transformational leadership being present. The faculty members were interviewed after the presidents, not only to affirm the stories and accounts shared by the presidents, but also to represent the views held from the campus regarding significant organizational change and the presence of transformational leadership. As a result, the presidents and faculty members were presented with different, yet similar sets of interview protocols to guide the interviews. These interview protocols can be found in the appendices of this study. I also reserved the right to contact both the presidents and faculty members for several brief, informal follow-up interviews that would be videotaped (for the presidents) or audiotaped (for the faculty) as I conducted the document analysis portion of my study so they could answer any questions that may have arisen.

Data from the interviews of the president and faculty members were analyzed using Dedoose, which is a web application for qualitative research that is the successor to EthnoNotes. The interviews with faculty members were audio-recorded and transcribed for analysis and review. I also made extensive mental observations during the interviews and took very few written notes so as to not distract the participants during the interview. The interviews with the presidents, conversely, were video-recorded and transcribed for analysis. I noted any observations or thoughts I had during the interviews, but also had the audiorecorded raw data to review during my data analysis as well. Video-recording my interviews allowed me to conduct a more comprehensive analysis, as I was able to review body language and visual cues, looking deeper for themes and connections I may have missed during the interview itself (Pink, 2007). My study also included member checking, allowing each participant to review their interview transcript and striking anything from the record that 
may be disingenuous to their message or not representative of them. After my data analysis concluded and this study is completed, the video and audio tapes will be destroyed.

Video-taped interviews with the presidents were also important because of the nature and intent of my research. Conducting qualitative research using an audio recording involves an "analysis of the semantic representations of the interviewee's comments in written fashion” only (S. Diaz, personal communication, August 20, 2012). Audio-recorded interviews must be transcribed for any kind of manifestation of data or analysis, and therefore may lose the intent of the participant. Identifying and researching the intent of these presidents will be essential in identifying how their leadership was able, or unable, to provoke organizational change at the institution.

The participants in my study were not being asked to communicate their intentions and respond to my questions through the written word; therefore my method of data collection must gather the non-semantic devices used by the presidents and faculty members to communicate meaning. Video-taping the interviews allowed me to gather both semantic narrative along with nonverbal language, such as gestures, expressions, and timing and pitch of conversation. These interviews were rich in nonverbal data, so using strictly audio for all interviews would have limited my study significantly. In addition, digital video allowed me to continually review both the visual themes and observations in raw form which helped me, as the researcher, identify more subtle and easily missed pieces of the discussion (Pink, 2007). Not only did it help me identify if transformational leadership was present at the institution, but to also learn more about the phenomenon involving both transformational leadership and organizational change within the presidential position in higher education. 
Finally, the interaction between me, as the researcher, and the interviewee generated meaning that could only be captured on video-tape for qualitative analysis.

Both the presidential and faculty member interviews were conducted in private where there was little room for distraction. The current president of the institution, as well as the three participating faculty members, was interviewed in their offices, while the two retired presidents were interviewed in their homes. The presidents were interviewed first, followed by the faculty members; this order allowed me to identify the major events and issues that faced the institution during the timeframe being examined, and then corroborate information by asking faculty members questions on these items. I used a basic digital video camera and each participant wore a lapel microphone to ensure that audio was also captured clearly for analysis. Both the audio and video recordings were transcribed and then reviewed with each individual to ensure accuracy of the data. I first identified themes present in the presidential interview transcripts, and then used the video-recording to tease out visual cues and body language that aligned with themes from the transcript. I repeatedly reviewed both the audio and visual data, as well as the transcripts, to identify any themes that addressed the phenomenon involving transformational leadership and organizational change.

Document Analysis. In addition to interviewing and observation gathering, I conducted an extensive review of documents, which can be "a particularly rich source of information about organizations and programs" (Patton, 2002, p. 293). These documents included any presidential papers from each respective president, as well as archival material from the institution's library and articles from the local newspaper. I searched these documents before I conducted my interviews to identify any themes as they related to organizational change and transformational leadership. I hypothesized that these documents, 
like the faculty member interviews, would corroborate any themes I identified and ultimately the conclusions I made during this study. I was granted full access to the institution's presidential files as well as any archival material before the interviews were conducted.

Triangulation of Data. My study was triangulated through the use of interviewing, observations, and document analysis. I triangulated my data as the final step of the case study, allowing me to narrow the focus of the three data sources, identify minute themes, and present consistent written results from the variety of sources. In addition, using the three methods made my study less vulnerable to errors and "provide cross-data consistency checks" (Patton, 2002, p. 556). I expected the majority of my themes to be identified during the interviews with the presidents, which I could then explore further as I continued my document analysis and interviews with the faculty members. I included guiding questions for the faculty interviews in the appendices. This interview protocol was created primarily with themes identified during the presidential interviews, but also from information gathered during the document analysis. The Dedoose qualitative research tool was used to assist with my triangulation of data, helping me identify common themes from all three methods.

\section{Limitations of the Study}

Although I consider this study very progressive in the examination of the phenomena involving transformational leadership and organizational change, several significant limitations existed both in myself as the researcher and in the research design. First and foremost, I have a significant relationship with the institution that is participating in the study. In addition to working at the school in student employment programs for over eight years, I have attained three degrees from the institution and grew up in the immediate area. I have never had a personal relationship with any of the presidents being interviewed, but I 
have had professional relationships and have taken some courses with all of the faculty members participating in the study. I have a personal bias towards the school; I have had a life-long affiliation and love for the institution in question. In addition, I have aspirations to be employed at this particular institution in the near future.

The research design that I proposed also had limitations. I proposed to examine the phenomenon involving transformational leadership and organizational change at the presidential level through stories and examples told primarily through face-to-face interviews, observations during those interviews, and an exhaustive document analysis. Nevertheless, there are only three surviving current and former presidents, limiting both the number and potential for participants. After conducting preliminary interviews with all three presidents, I anticipated that all three would be excellent interviewees and would be very forthcoming concerning transformational leadership and organizational change, but there was no guarantee. I faced the same potential limitation with the faculty members that are participating, even after I had conducted preliminary interviews with them. Another assumption was that I would be able to find sufficient documents that support the themes and topics that were extracted from the interviews. I had met with archival and library staff at the institution prior to beginning the study and have been assured that some documents existed, but that I may be faced with a limited selection of documents, especially for the two retired presidents.

Another limitation of my research design involved the use of qualitative description as my methodology for this study. Although this method was best suited to explore "events in everyday terms" and allowed me the freedom to present the case study findings as the data dictated, this method prevented me from delving deeper into the themes and trends identified 
than just on the surface (Sandelowski, 2000, p. 334). As a result, the findings of the study are not presented in the typical qualitative format that involves the analysis of rich, thematic data. Instead, my findings raise several very significant and intriguing questions with which I explore in detail, but the method I chose this study disallows me to make any concrete conclusions based upon these themes. Nevertheless, my findings reflect a shift in the accepted knowledge of transformational leadership and organizational change, suggesting the small cracks on the surface of this commonly-accepted relationship may only be the beginning to understanding leadership and change within higher education. As a result, this study is best used as a precursor for other researchers who hope to delve deeper into this phenomenon.

To mitigate the limitations in my methodology, as well as my personal biases concerning both the institution and several participants, I used a critical friend to review my analysis and interpretation of data. I identified someone affiliated with the institution, but separated from the presidents and issues being examined in my study. This individual is familiar with the setting and able to review my work with a critical eye and ensured that my personal affinity for the university or participants does not further bias the study in any way. This person also checked my sources, especially in the document analysis portion of the study, ensuring that I did not choose inaccurate or embellished information in the study that may romanticize participants' work. This individual was selected during the implementation stage of this study and I have had several recommendations from agents of the institution that are familiar with my study for replacements or alternates. 


\section{Ethical Stance}

The strength behind any qualitative study resides in a strict research design and methodology, which will maintain ethical standards with which I tried to adhere. Prior to any fieldwork, I secured approval from the Institutional Review Board at West Virginia University for my study. The letter of approval, as well as my approved study cover letter and informed consent form have been included in the appendices of this study. Before I conducted the six interviews, I had all participants sign the informed consent form allowing me permission to use any data gathered in my study. Any notes taken during the interviews and during my analysis were kept private and will be destroyed at the conclusion of this study. The identities of both the institution and the participants will be kept as private as possible to the extent allowed by law to ensure for human protection (Bogden \& Biklen, 2007). Presidents participating in the study understood that it is impossible to keep their identities completely anonymous. Given the geographic location of the institution being examined, as well as the clearly stated timeline my study examined, someone could potentially discover the true identities of the presidents. The faculty members, however, were assured anonymity in my study. All presidential participants agreed to be video-taped for the interviews with the understanding that it remained private even after the conclusion of this study. All faculty members participating in my study agreed to have their interviews audio-recorded for transcription purposes with the understanding that it remained private and would be destroyed at the conclusion of the study.

\section{Conclusion}

Even though the literature is rich with research and analysis on the value of transformational leadership within any organization, Bass and Riggio (2006) admit that "we 
still have a long way to go" in understanding the theory (p. 236). In addition, they both argue, along with other scholars in the field, that future research on transformational leadership and organizational change needs to "take a broader and more varied perspective" (Bass \& Riggio, 2006, p. 235). My study took this broader approach by exclusively taking a qualitative look at the presence of transformational leadership and its impact on organizational change at a small public, four-year institution in the Middle Atlantic States. My hope is that conclusions and themes revealed during this study can provide a better understanding concerning the phenomenon of transformational leadership and organizational change within the presidential position in higher education. The results from my study may have high transferability among other similar institutions within higher education. In addition, my case study serves as an intricate look at leadership and its direct impacts at this small institution, providing a brief institutional history of the major organizational changes in the last quarter century. 


\section{Chapter Four: Findings}

\section{Introduction}

According to Burns (2003), leadership is "an expanding field of study that someday may join the traditional disciplines ... in scholarly recognition" (p. 2). In an effort to further that research, my case study attempted to examine the phenomenon of transformational leadership and organizational change within the presidential position. I explored the phenomenon from both a descriptive and analytical perspective through qualitative description. My descriptive findings are presented at the beginning of this chapter. The analysis describes the phenomenon of transformational leadership and organizational change by considering the presence of transformational leadership, organizational change, and cultural elements within the interviews. Also, by measuring the presence of these elements, I can more easily suggest, with some certainty, if transformational leaders do invoke change, or more accurately determine which types of culture might be more conducive to organizational change, for instance.

The second part of this chapter serves as my analytical examination of the data. While my descriptive analysis strictly measures the presence of story and other elements considered in my study, the thematic analysis presents my deeper understanding of the themes while also considering my attempt to develop a deeper understanding of the nature of leadership and change within the presidency. After reviewing the literature, I purposely designed my study in a unique fashion; I aspired to examine these presidents from a humanistic approach, considering their leadership and impact on the institution from a personal, intimate perspective. I feel my discussion of these themes in this chapter, after considering the descriptive data, presents an accurate humanistic representation of the presidency that also 
reveals the nature of leadership within the presidency. The triangulation of both the descriptive and analytical data helps me to better understand the phenomenon.

Results from my study provide valuable insight into the presidency. My findings may help determine if the use of particular leadership styles by a college or university president brings about organizational change, or help determine if university presidents have the power to make sweeping changes at their institutions. In addition, my results also consider if presidential power has been significantly reduced by shared governance and the increase in external constituencies at the institution. Burns (2003) has argued that "vigorous interaction between transforming leaders and their followers is itself a powerful causal force for change" (p. 25). My study attempted to clarify if transformational leadership was enough to invoke change, providing valuable insights concerning academic leadership for colleges and universities.

\section{Analytic Phases of the Study}

In order to explore the phenomenon of transformational leadership and organizational change using qualitative description, I blended the use of interview transcription, document analysis, data coding, identification of storytelling, and video review. Considering these numerous and diverse elements within Dedoose helped me to lightly discover and explore the connection, if any existed at all, between transformational leadership and organizational change. Each element of my methodology served to make my qualitative descriptive study stronger.

Document Analysis. After conducting the interviews with the participants, the audio and video files were transcribed and uploaded into the Dedoose system. In addition to uploading the interviews, I also uploaded any relevant language from my document analysis 
to be considered along with the interview data. My study included an extensive document analysis that not only revealed additional ideas and themes for consideration, but also allowed me to effectively triangulate the data (Patton, 2002). This document analysis focused primarily on any presidential papers housed in both the university's library and the president's office. Some of the most revealing documents also came from the presidents themselves, having kept them in their own personal files years after they had left the university and retired. In addition, I also searched other sources that were present both at the library and online (see Table 1). These documents were important both in designing the interview protocol questions and when determining the presence of transformational leadership or gauging organizational change.

Table 1

List of documents reviewed for the study (including years)

\begin{tabular}{|lc|}
\hline Document & Years Reviewed \\
\hline Local Newspaper Articles & 1985 - Present \\
\hline Faculty Senate Materials & $1986-$ Present \\
\hline Board of Regent Materials & $1991-$ Present (online) \\
\hline Student Newspaper & 1985 - Present \\
\hline Student Alumni Magazine & 1986 - Present \\
\hline Faculty/Staff newsletters & 1986 - Present \\
\hline Convocation Remarks & 1986 - Present \\
\hline Presidential Speeches & 1990 - Present \\
\hline
\end{tabular}


Data Coding. Based on my literature review, I identified six codes and seventeen sub-codes with which I coded my data. These codes included the components of transformational leadership (Bass \& Riggio, 2006), degrees of organizational change (Porras \& Robertson, 1992), elements of institutional transformation (Eckel, Hill, \& Green, 1998), type of culture (Bess \& Dee, 2008; Bergquist, 1992), story (Denning, 2011; Guber, 2011; Hackman \& Johnson, 2009), and comments that were notable to the researcher. As I reviewed the transcribed interviews and documents, I labeled excerpts based upon the criteria of each code as discussed in the literature review. The codes were not weighted in any fashion. In addition, I prepared a code sheet outlining the criteria of each code for easy reference as I analyzed the data. These descriptions were also entered into Dedoose and quickly populated when I scrolled over each individual code for quick reference. The codes, sub-codes, and code sheet for this study have been included appendices.

Storytelling. Before coding the data within Dedoose for leadership, organizational change, or culture, I sought to identify any stories that were told by the participants. Throughout the coding process I frequently discovered that more elements of transformational leadership, organizational change, and culture were present when they were shared within the context of a story. In this sense storytelling became more than just a communication tool within leadership, but a means with which I was able to more easily identify the elements most associated with transformational leadership and organizational change. I only considered the identification and quantity of stories told by each president in the study and did not attempt to identify the type of story shared, nor did I attempt to analyze which elements of story were most commonly used by the participants. Considering storytelling at a deeper level would have went beyond my intent of this qualitative 
descriptive study. However, analyzing the types of stories told and the narrative elements most present within the study would provide a deeper, more complex perspective of the phenomenon. This would serve as an excellent follow-up study.

Video Review. The use of video as my data-gathering technique for the presidents allowed me to continually re-immerse myself in the interview and re-experience the data in its natural form. I reviewed each film very closely as I transcribed the interviews, then watched each video four more times during the analysis and coding process. I began transcribing immediately after each interview and then immediately uploaded everything to Dedoose and began coding. I was exposed and re-exposed to an individual president daily for nearly two weeks during the data analysis process. After I completed the transcription, coding, and analysis of all three presidents, I went back and reviewed each video one more time in sequential order as an attempt to identify any ideas or themes I may have missed. I was able to more easily identify stories as well as qualitative themes because I was able to reexperience the interview just as it took place. Nearly all of my human senses were reengaged, triggering thoughts and ideas during the data analysis that I had during the actual interview.

\section{Components of Transformational Leadership}

One aspect of my case study attempted to determine if elements of transformational leadership were present within the university president position. I determined this by identifying stories and behaviors during the interview that exemplified the four major components of transformational leadership (Bass \& Riggio, 2006). This type of analysis is usually done through purely quantitative assessments such as the Multi-Factor Leadership Questionnaire (MLQ). My study was unique in that I attempted to identify the presence of 
transformational leadership strictly by aligning qualitative data, including transcribed narrative and behavior during the interview, with the components. The results from this analysis, including the individualized components, can be seen in Figure 1.

Figure 1

Presence of transformational leadership components

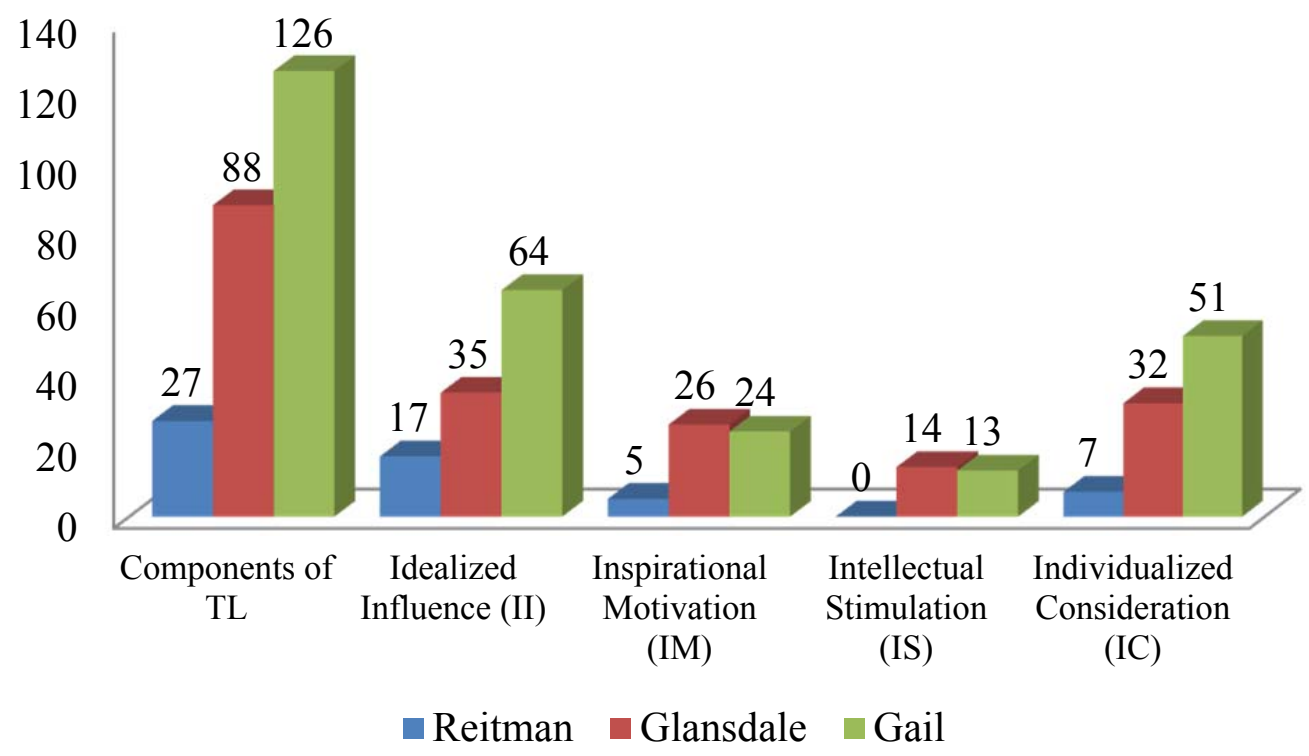

Reitman Analysis. Dr. Reitman oversaw one of the most significant organizational changes not only in this study, but in the organization's entire history: transitioning from a college to a university. He acknowledged this during his interview, as well as did others who participated in the study. Reitman himself even acknowledged the impact:

Well, I think just everything we did I took great pride in, because we were really moving forward, and I think the fact that people around the state knew that, said it, and we knew it because they said it, made us all feel good. And I can't think of any one-I guess if I had to, again, to put my finger on one thing, it would probably be the university status, because even the governor said, "You can't do that. It won't work." 
Nevertheless, very little substantial evidence outside of the interviews exists attesting to his leadership. Very few documents remain in the library archives that speak to his tenure, yet his personal interview as well as the interviews with faculty and the other presidents offer a glimpse of his leadership.

Reitman's interview and document analysis revealed over twenty instances where his behavior and actions represented some component of transformational leadership. Of the four, Reitman most commonly fit the mold of Idealized Infleunce (II), or a leader who best served as a "role model" for followers and served as the quintessential representation of the organization (Bass \& Riggio, 2006, p. 6). Faculty members who were interviewed during the study noted:

But he did a good job speaking to us and for us, and everybody was impressed by him. He seemed to be what the university needed, and he was hired with that in mind, and he did it, you know? It went from a college to a university. That's pretty major! In the life of this university, there aren't many milestones that measure up to that one.

- Smith

When he came here, he was sort of a-he was sort of a showman, and he was a great advertiser.

- Sanders

I'd say I think he was a very—this guy was a very flamboyant-dynamic leader.

- Sanders

Reitman became known as the face of the university, reaching out to new recruits and parents to sell the newly-minted university, bringing large-scale events to the area such as the Maryland State Games to increase visibility, and supporting the institution's athletic 
programs to increase recognition. In addition, he became very visible in the community, throughout the state, and even on campus with faculty, staff, and students. For example, he frequently engaged in:

“Dorm-storming," and I called them "no-agenda meetings." And we would gothere would be three vice-presidents, myself, and my assistant-and we would sit down with 40, 50, 60, 80, 90, 100 students, and say, "We don't have any speeches. We don't have any agenda. You start it off, and if nobody says anything, we'll wait for about a half an hour and we'll all go home. But we'll talk about anything you want to talk about." Well, it was a great opportunity for kids to complain about anything. You know, they complained about the food or whatever, but that was a great opportunity. But we would leave there-we would feel good, except one of my vice-presidents would always say to me, “[Reitman], do we have to continue doing these?”

- Reitman

Reitman's leadership also demonstrated Inspirational Motivation (IM) and Individualized Consideration (IC). Although on a much smaller scale than Idealized Influence (II), Reitman showed signs that he had the ability to mobilize "team spirit" and display "enthusiasm and optimism" while also paying attention to the individualized needs of his followers (Bass \& Riggio, 2006, p. 6). This became apparent during careful review of his personal interview, the interviews with faculty, and during the document analysis. The following excerpts from both the interviews and the document analysis reveal some insights: 
[Reitman] hopes to "develop and create cheerleaders for [the institution]" ...not just people who dig into their pocketbooks...but people who verbally are supportive of the school"

- Newspaper

"I ask that we begin to make decisions based on what is good for the college," [Reitman] challenged. "Think more and more collectively, because only then can we reach that potential."

- Newspaper

I knew that in higher education, in order to be successful you had to be open, you had to be honest, and you had to make other people feel that they were a part of the whole thing, that they had to buy into it. A lot of institutions don't do that; a lot of my colleagues around the country didn't do that.

- Reitman

Reitman spoke with a motivating tone during the interview, and the corresponding faculty members I interviewed corroborated his motivating abilities. He could also recall the names of nearly every mid-level manager who worked for him, and expressed a keen interest in the well-being of individuals within the organization. Nevertheless, my analysis did not reveal a significant amount of Inspirational Motivation (IM) or Individualized Consideration (IC) present in Dr. Reitman's leadership, nor did I note any instances of Intellectual Stimulation (IS).

Glansdale Analysis. Dr. Glansdale occupied the presidency position for over fifteen years, allowing her the opportunity to leave the most significant impact on the institution. In addition, she was the only female president in my study. Her interview and document 
analysis revealed nearly ninety instances of transformational leadership during her presidency. The most telling excerpt from her interview puts her entire presidency in context from her perspective:

Well, it seemed to me that when Dr. [Reitman] accomplished a very significant change in the name of the university, it went from [Mid-Atlantic] State College to [Mid-Atlantic] State University. And so when I got there, I thought to myself, "How can we really define this as a university, more than just a cosmetic kind of change?” So it occurred to me we should take what is the basic mission of an institution located in a place like this, a rural, small town, and expand its reach, so that its educational programs served [the broader area].

Dr. Glansdale views her presidency as carrying on the work of her predecessor, completing the organizational shift from small college to regional university that was begun by Dr. Reitman. She admitted during her interview that she spent her presidency leading toward that complete transition.

Dr. Glansdale's leadership was highest in the arenas of Individualized Influence (II) and Individualized Consideration (IC). She exemplified both during her interview, and the documents I reviewed from her presidency supported her strength in these areas. The faculty members I interviewed also felt that Dr. Glansdale was extremely strong in these two areas of her leadership:

Well, a president has to represent us downstate, where the decisions are made, and he has to bring that back to us, and inspire us, and in good times and bad. And mostly, in 
terms of money, it's been bad for a long time. And I think Dr. [Glansdale] did a good job of that.

- $\quad$ Smith

[Glansdale] had a scholarship and an eloquence that was-it happens-that was who she was.

- Parker

I'd say she was sort of a quiet, "I'm really in control behind the scenes, but I don't mind if somebody else is out front doing the speaking."

\section{- Parker}

In addition to serving as an exemplary role model for the institution, Dr. Glansdale showed great efforts in trying to relate to individuals at the institution on a very personal level: When you get into administration, you don't agree with them, and it drives you crazy if they don't understand what you want to do, but you can understand their perspective, and you don't-you don't denigrate them, and you don't judge them negatively because they look at the world from their own perspective.

- Glansdale

Well you know, I'm, again, whether you call it feminine, whether you call it maternal-whether you call it whatever, I call it humane! You know, you want to care about the people whose life you are impacting.

- Glansdale

Let me tell you how I met her. I think it was at a picnic before school started for the year. She was new, and one of the first things she said to me was, "How is Jackie?" Those were her words. "How is Jackie?” She had never met Jackie, you know. 
That's my wife, but she had done some research and she got it right, and she actually cared.

- $\quad$ Smith

Dr. Glansdale's efforts to serve as a role model for the institution while also caring for her followers on an individual basis did not go unnoticed and left a lasting impact on the institution.

Dr. Glansdale also appeared to be successful in convincing others to share in her vision for the institution, as several instances of Inspirational Motivation (IM) were revealed during the faculty member interviews:

I'm very proud of the fact that we have some sterling programs that have elevated recognition, respect, admiration for the whole region, like the Appalachian Festival, the ethnobotany program, all those programs that have lifted up to the broader community what a wonderful place it is-both the university and the community, the area. I'm proud of that; I think there's more recognition of that outside the immediate area. And I'm very proud of the quality of the programs that we have, academically.

- Glansdale

It is difficult at times like these not to see the light at the end of the tunnel as an oncoming train, not to settle into a cycle of despair and disengagement and even cynicism. But, as we have learned when a national tragedy or a communal tragedy or a personal tragedy has struck us, there is comfort in mutual support.

- Speech

She was an extremely generous person, and I was-we had a program reviewer on campus for the English Department, and I was escorting him around and showing him 
the new performing arts building, and Dr. [Glansdale] was there, and whether she intended it or not. But in the presence of the chair of the Theater Department, she told the examiner that he was looking at the English Department, the finest department on campus, and I think she meant it. And we believed, and we knew, that she valued us.

- Smith

Dr. Glansdale was motivating even as I interviewed her, as she told her favorite stories and recounted the numerous accomplishments from her administration. Her speeches, of which I was able to retrieve nearly every convocation address and only a few commencement speeches, were highlighted with inspirational messages directed at faculty, staff, and students.

Unlike Dr. Reitman, Dr. Glansdale's interview and document analysis revealed significant elements of Intellectual Stimulation (IS), which is a component of transformational leadership that encourages followers to identify organizational problems and solutions (Bass \& Riggio, 2006). As her high Individualized Consideration (IC) descriptive analysis already suggests, Dr. Glansdale was very interested in tapping the creative intelligence of those around her at the institution:

"I don't see myself at the top of a pyramid but rather at the center of a circle," [Glansdale] said. She said the style is based on the old Japanese quality circles of leadership but has matured beyond that and, in the 1990s, is permeating Fortune 500 companies. "It is a style that includes the people who are affected, the employees, the students," [Glansdale] said. "I'm very discussion-oriented; discussion and consensusbuilding is just who I am." 
So, it began to build, and more and more ideas. But that was something, again, where I felt my role was to encourage it, to support the application, and then to bring recognition to it. So, it happened more by happenstance.

\section{- Glansdale}

But you also have to encourage and empower your deans, and your other colleagues on the campus, sometimes faculty, who know somebody who really wants to help [the institution].

- Glansdale

Dr. Glansdale frequently referred to herself as a consensus-builder and very much saw her leadership as a group effort. Throughout her interview she quoted most of her accomplishments as efforts that started out among the group. She was well-respected by the faculty as a scholar and leader, which also partly explains her high performance in the Intellectual Stimulation (IS) component of her leadership.

Gail Analysis. The current president of the institution, Dr. Gail, had by far the most instances of transformational leadership in his interviews and document analysis. A reason for this may have been the abundance of written documents and resources that were available during the document analysis, of which his administration had significantly more than the other presidents. Nevertheless, Dr. Gail's leadership fits every component of transformational leadership, with over one-hundred and twenty instances identified during my analysis, nearly one-third more than his predecessors at the institution. I think much of this may reside in Dr. Gail's view of what a university president should be to an institution: So my view on vision — my view on important milestones and where we need to go as a university, in part, have to do with my heartfelt belief in collaboration, my heartfelt 
belief that every organization exists in a context, and that, to some degree-there used to be a time when presidents came to universities, and it really became about that president. So it wasn't as much about the university, it was more about the president. And, at times, it often got caught up in that president's ego. And you see that a lot historically, where presidents begin at universities; they stay there for 30 years. And I think it's important to know when you can make the most of your contribution to a university, and when, perhaps, you've outlived your ability to be useful to a university—and you want to maximize the benefit that you can actually provide.

\section{- Gail}

In many ways, Dr. Gail's position on the role of university president suggested a transformation within higher education, where the organization as a whole is the driving force and the president merely contributes to those efforts.

Like Dr. Reitman and Dr. Glansdale, Dr. Gail was the highest in Idealized Influence (II) during my analysis. A further discussion will follow in the final chapter of this study, but this is not surprising since the role of any modern university president, first and foremost, is to serve as the quintessential face of the institution (Duderstadt, 2007). Dr. Gail is very aware of the power behind serving as a role model for the institution:

And my son-my son goes here. And you know, he can talk to Dr. [Gail], and I mean he knows who he is. I don't think many students would have felt like that with [other presidents].

- Sanders

Now, here's the word that I would use for him, where he shines-its accessibility. And I mean to students, to faculty members, to whatever. You don't go through anybody to 
get to him. You get directly to him. Probably I could pick up the phone here and get him on the line. He's very, truly accessible, and pleasant and nice, and he works hard.

- $\quad$ Smith

Now, he's a bigwig; he's been across the nation. He's talked to other institutions, and he knows what they've tried. So, he was sharp enough to know that the infrastructure had to be developed at [our university] in order to sort of let us bubble up with the same ideas that everybody else had. I think that he did it right, in a sense that he let us have-he let the institution, not me, personally—have some ownership in solving the problem.

\section{- Parker}

Gail has clearly poised himself as a role model and representative for the institution that faculty members can associate with and support. He indicated throughout his interview that most of his initiatives were already campus priorities before he arrived and he simply serves as an institutional advocate on behalf of the faculty and staff.

Individualized Consideration (IC) was Dr. Gail's second-most influential area according to my analysis. The most striking take-away for me, from both the interviews and the document analysis, was Dr. Gail's ability to be literally everywhere on campus while also serving to represent the institution downstate. He keeps a grueling schedule, balancing both student and administrative engagements. Regardless, Gail is clearly leaving an impact on individuals within the organization: 
My impression is-and I have two sons that are students here right now. My impression is that they think he's trying to stay in touch with them and he's making an attempt to make things as nice here for them as he can.

- Sanders

I'll tell you this: you know, I see him jogging around the campus, and he always says, “Hi, [Dr. Sanders].” And I mean we barely talked to each other. It kind of impresses me that he knows my name, because I usually think "Ah, he doesn't know who I am." But he does.

- $\quad$ Sanders

He comes to senate every month at the beginning, and he opens the floor for questions. That's pretty brave. And you know, and because there are Indian warriors in the crowd! [Laughs] And he's just sitting there in the middle, smiling, and he's answering the questions. He's very frank and he's very open. He presents his report of what's happening downstate and he takes question on that. He talks about initiatives on campus. He takes questions on that. They're frank answers to questions. But he answers the questions that we give him, and I'm impressed by that. He goes around to departments and talks to them. I'm impressed by that. He visits across the campus. I'm impressed by that. As I say, I can get him on the phone if he's anywhere around. And if he's at home, I can call him there.

- $\quad$ Smith

And with [Gail], there's the openness that I spoke of, and seeing the student as a whole person and not as a name on a class list. And that's important, too. 
Dr. Gail's accessibility to every constituent on campus was a constant theme during my research. This access is a reflection of how much he values the individuals within his organization. I was personally impressed with my access to him, even as a lowly outside researcher of the institution, especially as I learned of the demands on his time.

Inspirational Motivation (IM) was also high during my analysis for Dr. Gail, just under Dr. Glandsdale. The majority of these instances fell in the document analysis, primarily from the speeches delivered by Dr. Gail. This makes the three presidents hard to compare, as no speeches from Reitman were analyzed and I only had access to primarily convocation addresses for Glansdale, whereas I had access to every formal speech Gail has delivered at the institution (including some in both audio and written format). Gail, like Glansdale, appears to have an excellent ability to connect and motivate his followers: Those of you who were at Fall Convocation last year may remember that I issued a call to action. [The institution] had reached a fork in the road, and we realized it was time to take the "Road Less Travelled"-the high road—the path that would lead us to becoming a high-quality academic institution with national distinction.

- Speech

One such meeting, in late 2008, demonstrated the community's interest in the college and [Gail's] style of leadership. Gail had invited bar owners and beverage distributors to campus to discuss how they could help reduce student alcohol abuse. "I was told nobody would show up," he recalls. But "it was standing room only." Among the attendees: bar owners, bar managers, bartenders, beer distributors, the mayor, police chief and members of the [local] liquor board. 
The goal is not to bring back Prohibition; the goal is to keep students safe and encourage them to stay in control. Our efforts are broad-based, much more than simply cracking down. Help has come from our students, who created and continue to staff a safe-ride program and who create nationally recognized peer-education programs; from local law enforcement, which now shares information and partners with us in other ways; from faculty and staff members who take the safety of our students to heart; and even from some local bar owners, who have changed their practices.

- Speech

Inspirational Motivation (IM), as I will discuss in the final chapter of this study, is difficult to gauge from just interviews with a small group and written documents. But Dr. Gail, like his predecessors, was very passionate about his vision of the institution. Not surprisingly, he seemed to be a very motivating individual from his interview, speeches, and other written documents.

Intellectual Stimulation (IS) was equally as strong for both Dr. Glansdale and Dr. Gail. The analysis of Dr. Gail quickly revealed how important Intellectual Stimulation (IS) is to his overall leadership efforts:

However, I am still in the process of forming a definitive vision because I feel that for it to be successful, it must be crafted collaboratively with the campus community and build upon the core values of an institution, with a view toward the future. As a result, I have spent a lot of time listening — to students, to faculty, to staff, to alumni and to community members. I have a growing idea of the [institution's] unique character and 
quality as an institution. I am also getting a better sense of the unique challenges [the institution] faces, and the actions the campus needs to take to move forward.

- Gail

As a University community we will engage in many conversations about priorities and where to best invest our resources. In doing so, let's approach this dialogue with respect for one another, realizing that debate will be both inevitable and healthy. It is my sincere desire that what I speak to is seen as a shared vision - a view and direction for the future that we can all embrace and support and collectively work to achieve. In the coming months and years, we will craft together a sense of shared purpose and direction on this campus and find appropriate ways to measure our progress.

- Speech

Folks-we have arrived at a crossroads and the moment has come for us to rise to the occasion and truly become a distinctive university with national recognition. We've worked too hard not to do this.

- Speech

Dr. Gail clearly values not just the opinions of his followers at the institution, but also their skills and abilities as educators. Nearly every speech he had given ended with a challenge to the campus community to solve some larger problem the institution was facing. Dr.

Glansdale also used this tactic very frequently in her speeches and commentary.

\section{Degrees of Organizational Change and Components of Institutional Change}

The goal of my study was not only to determine if elements of transformational leadership were present in the university presidency, but to also determine how university 
presidents responded to organizational change, or if they even have the ability to respond. I identified two measures in my literature review to conduct this analysis: the degrees of organizational change model that was originally developed by Porras and Robertson (1992) that has been revised and critiqued by others (Bartunek \& Moch, 1994; Burke, 2002) as well as the four components of institutional change that were identified by Eckel, Hill, and Green (1998). For the purposes of this study, I identified both second-order and third-order change, if present, as transformational change, thus confirming that transformational elements of leadership could lead to significant organizational change. The results from this analysis, including the breakdown of each degree of change and component, can be seen in Figure 2. I found no presence of third-order change during my analysis, or evidence that followers at the institution were able to "transcend" the framework and become more selfaware of their role within the organization (Bartunek \& Moch, 1994, p. 24). 
Figure 2

Presence of organizational and institutional change elements

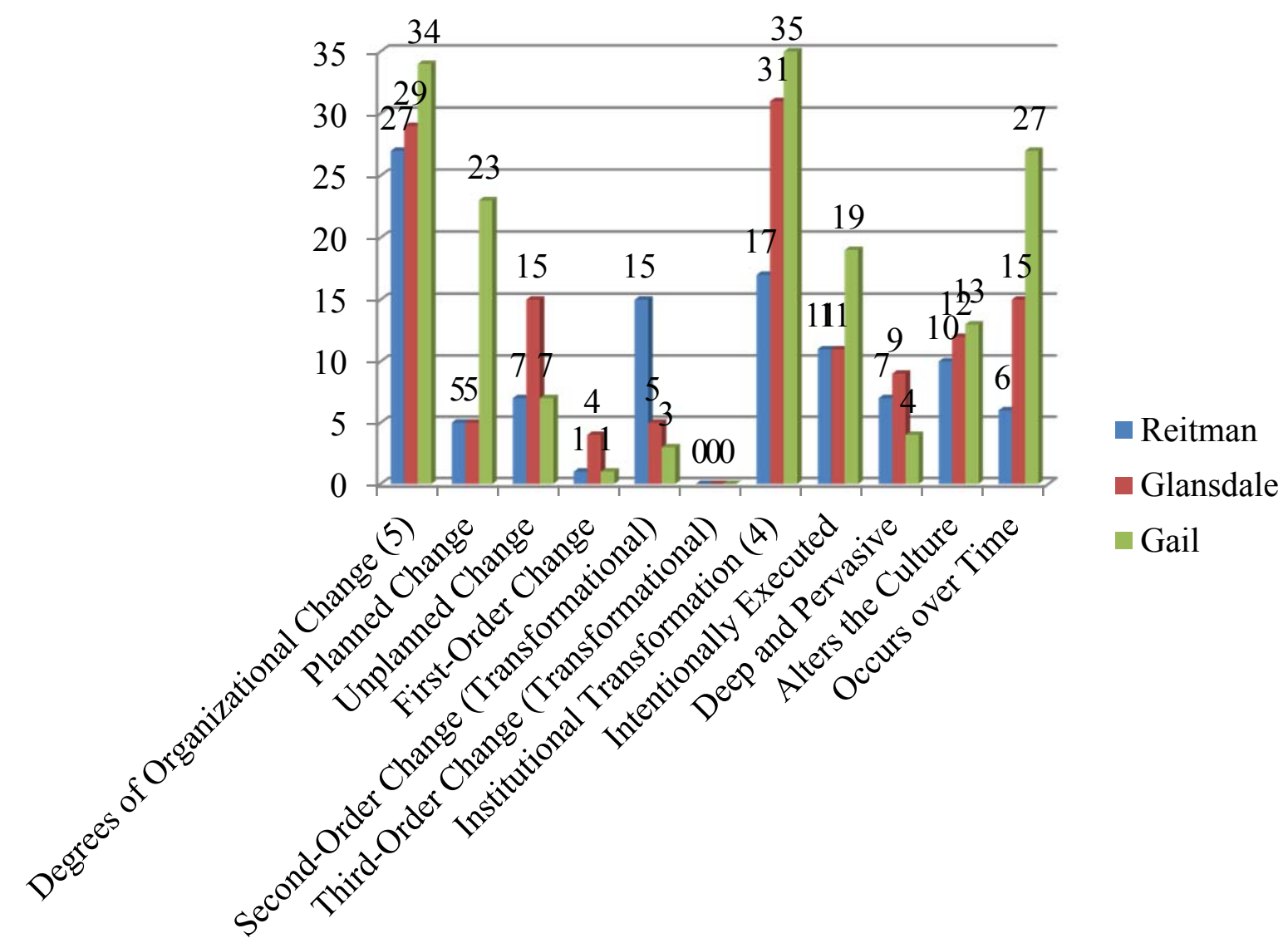

Reitman Analysis. As I mentioned during the transformational analysis, Dr. Reitman oversaw one of the most significant organizational changes not only in this study, but in the organization's entire history: transitioning from a college to a university. He acknowledged this during his interview, as well as did other presidents who participated in the study.

But when I think about all the things we did, probably the most significant, longlasting thing was the university status.

- Reitman

Well, it seemed to me that when Dr. [Reitman] accomplished a very significant change in the name of the university, it went from [a] state college to [a] state university. And 
so when I got there, I thought to myself, "How can we really define this as a university, more than just a cosmetic kind of change?”

- Glansdale

It's an interesting thing, because Dr. [Reitman] was a visionary.

- Gail

In addition to gaining university status for the institution, Dr. Reitman presided over the expansion of the campus to other communities and the creation of a foundation to solely support the institution. These significant changes are why Reitman was the highest among his peers in the study for elements of second-order change, which was deep, lasting, and ultimately significantly transformed the institution. This type of change is being considered as transformational for the purposes of this study.

Dr. Reitman performed significantly in the areas of planned and unplanned change when considering the degrees of organizational change. The scoring in the areas is primarily a result of the views from the faculty members who participated in the study. For example, the three presidents collectively viewed the transition from state college to state university as the major turning point in the institution's history, and in many ways, a turning point for the community. The institution was now able to diversify its programs and offer a wider range of programs while also serving as the regional educational center. However, one faculty member put the organizational change into a different context:

Well, what was happening at the time has to be put into a bigger picture of what occurs within the nation and the nation's teacher colleges. The teacher colleges have had a progression, and the teacher college, which [this institution] was rotates into a state college with a broader purpose and broader goals, and then from the state 
college, it becomes a university. So the movement into a university which [Reitman] is addressing was not unanticipated. It was something that had occurred within many institutions like [this institution]. So, yeah-so it's not something which you would say, "This is because of the tremendous personality of [Reitman]." It's something that you would be saying, "This is something that's the next domino."

- Parker

From this faculty member's perspective, the shift to a regional university was more of a planned change, as the larger national movement simply swept through the state.

The analysis of Dr. Reitman also revealed significant institutional transformation as well. The major theme that continued to resonate among the interview and brief document analysis of Dr. Reitman is best described in his own words:

And so it was my feeling that we had to reach out, that we had to become known, and if we did that, then ultimately we would be known as the institution of higher education for [the region].

- Reitman

Every shift at the institution was intentionally executed by Reitman's staff and very little of his administration seems to have been in response to outside forces, except for the shift to university when considering the national trend. The attempts to build a relationship with the local community, the use of facilities to generate revenue over the summer, and the creation of the institution's first alumni groups were all directly executed by Reitman's administration. In addition, most changes were pervasive and directly aimed at altering the culture of the institution: 
And I talk to people now, on occasion-for example, I spend a lot of time on the golf course, and every once in a while, I'll see a Maryland shirt or something. And I'll say to somebody, I worked in western Maryland, and somebody will say, “That's where [the institution] is." I'll say, "Yeah, I worked there,” whatever. But [the institution] now is known, and I think unfortunately, years ago it was not nearly as well-known as it is today. And I take pride because I played some part in that, but a lot of others played a big part of it, too.

- Reitman

The most significant thing, as I said before, if I had to list one, it would be the university status. However, I think it would be fairer to say along with that-almost tied with it, side by side, is this whole thing of changing the culture of the institution, and even changing, to some extent, the culture of an area.

- Reitman

Unlike the debate over what really influenced the change of the institution to a university, institutional transformation clearly took place under Dr. Reitman's tenure at the institution.

Glansdale Analysis. Dr. Glansdale presided over the institution for over fifteen years, much longer than Dr. Reitman. The analysis of Dr. Glansdale revealed thirty instances of organizational change and institutional transformation respectively. The most notable element within the degrees of organizational change was unplanned change, with over half of the instances falling into this category. The primary reason for this was Dr. Glansdale's battle with budget cuts right after assuming the presidency.

It started in the fall of '90, the cuts. And I was at the University of Baltimore as the provost. And we got a call on Christmas Eve, I did, from-well, first of all our vice 
president of finance did. And then he called me, and he called the president; we were both at home. And we went in to the university, and we had to give back I've forgotten how much it was—maybe $\$ 250,000$ or something, out of a multi-million dollar budget, within twenty-four hours, or close of the next business day, or whatever it was.

- Glansdale

Budget battles would challenge Dr. Glansdale's administration for the next few years, undoubtedly stunting the growth of the institution permanently.

Now, it struck a blow, it stunted our growth forever. We are, I believe, the lowest, or one of the lowest paid in the system. We never really caught up, but we didn't get pink slips. There weren't lay-offs.

\section{- $\quad$ Smith}

Although these budget cuts were part of a larger trend throughout the state, it forced Dr. Glansdale and her administration to constantly be in readiness for when the next cut might come, and be less available to make planned, revolutionary changes.

The second-half of Glansdale's presidency did allow for some instances of secondorder, or transformational change. These included pioneering a public-private partnership to build new student housing, gaining several accreditations for academic programs on campus, and the building of several new facilities on campus to name a few. These were not immediate changes, lending the support for Glansdale's high performance in the category dealing with significant institutional transformation over time. Glansdale herself viewed her presidency as one that worked to fulfill the name of university and overcome precious stigmas that plagued the school, as did the faculty members in the interview: 
But it was-it was to, again, redefine the image of the institution. That's really, I think, that was my biggest challenge. [Laughs] You know, it had a party school image. It had the image of being God knows where, out there, you know, and that nobody could enter it. You'd think Maryland was Texas, that it was so far away, you know, all this kind of thing. Or that it was a teacher's college, and it didn't have anything else to offer programmatically. Who would ever think there was any significant research going on out there? So it was redefining, redefining. Well, the whole region gets it bad, because it's Appalachia.

\section{- Glansdale}

Well, it's a work in progress, and so I think it's hard to define it. A permanent change is different from, I think, an evolutionary change. I think I am proud of the fact that we did deserve the title of university, by virtue of expanding on many fronts. That is, I think-and I think it's still doing that, and I think it's still evolving as an educational institution of quality, an institution that has a major impact on the social, cultural, educational, and economic environments in which it lives.

\section{- Glansdale}

We had the name university, but we didn't have the feel of a university, and the look of a university, but we had the name. And she-in her sixteen years here it went from a college with a university name, to a university with colleges in it.

- Smith

So even though Glansdale oversaw significant change at the institution, it seemed that most elements of that change took place over time and were not immediate. 
My analysis also revealed that Dr. Glansdale significantly altered the culture of the institution. The most glaring change in culture was the institution's efforts to become the regional education outpost for the state:

Identifying strengths at [the institution], and matching them to potential strengths elsewhere, enhanced us all, you know. I think we're all the better for it, so that-as I said, building those partnerships was a way of getting at that broad sense of making a quality university in all those ways. And you can't identify the region without doing partnerships with the Amish out in Garrett County and all those other things. You define a sense of place, as I said, that kind of spirals outward.

- Glansdale

The College of Business also became AACSB accredited under [Glansdale] and that's kind of a big deal. That's the biggest accreditation that a college of business can get anywhere in the world.

\section{- Sanders}

And so [Glansdale] was here when there was a lot of funding fights and budget crunches. Now, it was preserving the quality of the institution, making it a quality place-but she created an aura of its quality.

\section{- Parker}

Even though the transition to university happened under Dr. Reitman, my analysis left me feeling that that institution's culture was not affected until the work of Dr. Glansdale. This may have been a result of Dr. Reitman's departure almost immediately after university status was attained for the institution, or because Dr. Glansdale was at the helm of the institution for 
over fifteen years. Nevertheless, the culture seems to have been significantly altered during an institutional transformation on the campus and within the surrounding community.

Gail Analysis. The analysis of Dr. Gail revealed the most instances of organizational change and institutional transformation of any other president, with over thirty-five excerpts in both areas. This is slightly above the descriptive analysis of Dr. Glansdale, but she served in the presidency for over fifteen years compared to his six years. As I alluded to before in other areas of this analysis, this may be a result of the overwhelming amount of documents I was able to review for Dr. Gail, as compared to Dr. Glansdale. Dr. Gail's strongest areas were planned change at the institution and transformation that occurred over time, outpacing his peers in the study significantly. He also performed significantly in the area of planned change that ultimately altered the culture of the institution.

Dr. Gail's planned change efforts have been behind nearly every change he has made at the institution since assuming the presidential role in 2006. His most notable changes are his efforts at constant communication with the university community and transparency. In addition, he has tried several programs on campus in an effort to distinguish the institution from other competitors while also creating a sizable endowment for the school's future: And if you go to the president's website, you'll find that there's a budget website, and every year we upload budget information on that website. And prior to my coming here, honestly, people said they had no access to that information, and because of that they were always suspicious. Now, could you find a more ethical person than [Dr. Glansdale]? I don't think so. She was doing nothing devious, had nothing to hide. But the reality is that because there was a lack of availability of that information, people came to perceive that there was something being hidden, and there was not. 
- Gail

I think the university was ready for change. I think that it's important. It was important then that it not just be change for the sake of change, but there needed to be some change. Generally, people had, in part, lost confidence in the university, and some people here were part of that lack of confidence. And so I needed to make some personnel changes.

- Gail

"We've become a generally sound university. Let's find our niche that makes us unique." And I think that's what he's been all about here, and he's been working toward our niche as: we're going to be green-conscious, environmentally friendly, and sort of take a forefront in that kind of movement. Then, I think the other big thing he's done is that he's really tried to focus on the students, specifically to limit drinking.

- $\quad$ Sanders

Probably from our perspective, we haven't seen enough of it yet. In the creation of endowments, and the monies that accrue, they're future-oriented. You create this endowment, and it's for the future. So at the present time, it hasn't filtered down a lot. So I would say that in terms of what I'm doing every day, it's minimal.

- Parker

All of these efforts have been planned and will take time to significantly change the culture. However, his effort to involve the campus community in the discussion and to provide constant information to them has also impacted the culture. Like his predecessors, these changes will take time. 


\section{Culture}

Culture was a factor in my study because, as I explained in my review of literature, in order to have significant organizational change the culture of the organization must also be changed. Eckel and Kezar (2003) argue that real transformation cannot occur "without altering at least some aspects of institutional culture" (p. 130). Bass and Riggio (2006) have also acknowledged that culture can also be the most formidable challenge to overcome when implementing transformational change. For the purposes of this study, I attempted to identify which of Bergquist's (1992) cultures of the academy was more prevalent in each president's administration. Although none of the four cultures have been dubbed transformational in the literature, some cultures by definitions lend themselves more to transformational change, or suggest that certain cultures may be more open to transformational change than others. The results from my analysis of culture can be seen in Figure 3.

The analysis of Dr. Gail was the most revealing concerning culture, with over fifty instances in both the document analysis and interviews. Dr. Glansdale had over forty instances for sixteen years of service, while Dr. Reitman had nearly twenty excerpts that hinted towards the type of culture that was present at the institution during his administration. Just like other areas of my analysis, this scoring may be a result of the documents, or lack thereof in some cases, that I was able to review during my document analysis. The majority of Dr. Reitman's culture excerpts come from the interviews, whereas half of Dr. Gail's excerpts came from speeches and other documents. 
Figure 3

Presence of culture under each president

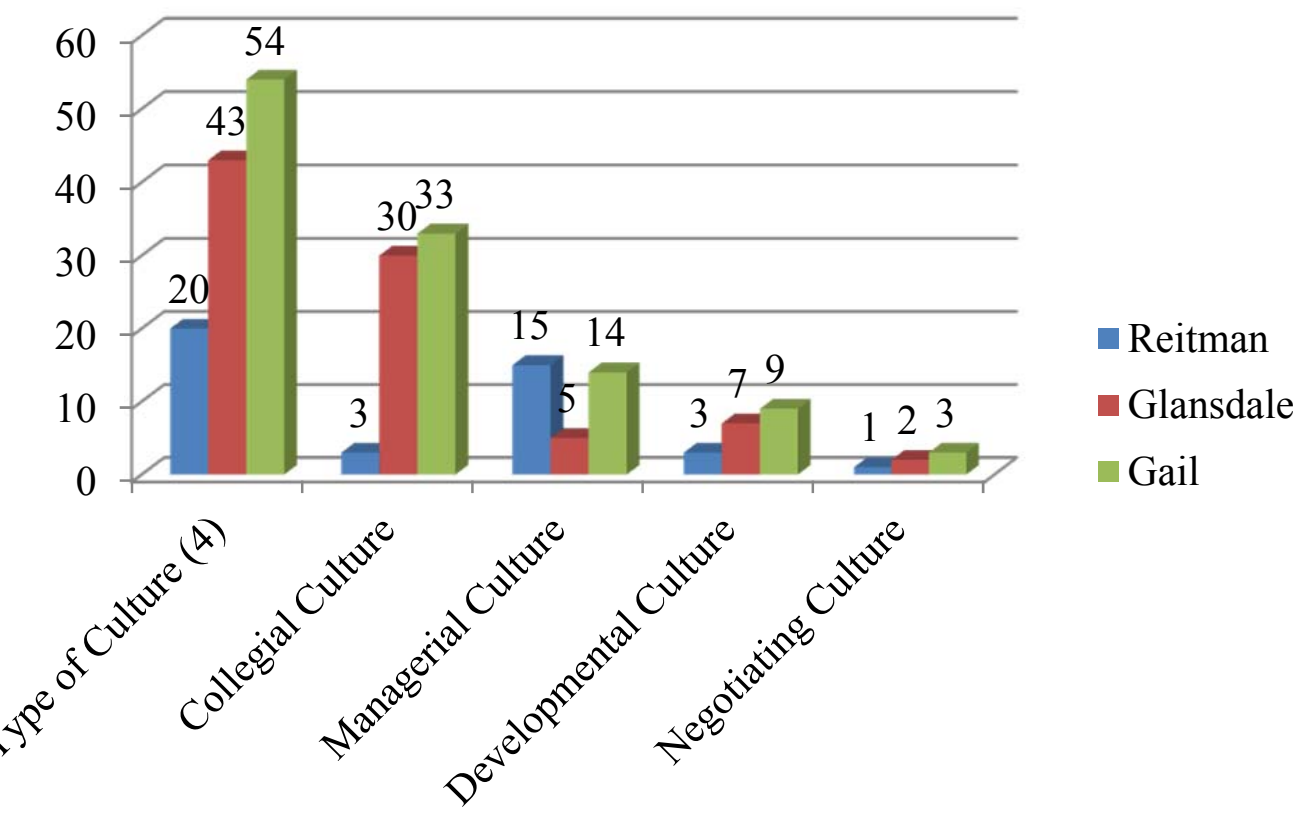

Reitman Analysis. The analysis of Dr. Reitman found the fewest instances of culture in the study, but I firmly believe this was because of the very few documents I was able to obtain for my document analysis from his presidency. The excerpts that were identified reveal a primarily managerial culture in place at the institution under his leadership, where the followers were primarily concerned with the overall interests of the institution.

And so it wasn't me doing it; they bought into the vision, but then they begin to carry some of these things out, and they were very much like I was. They were aggressive. They wanted the place to grow, to be good. They wanted us to be the regional university for western Maryland, whatever. 
He described the college as being "big business" and (when looking at the organizational structure of the college) "we have to do more than in the past. We have to be as effective, aggressive, and progressive as we can," Reitman pointed out.

- Newspaper

He had a way of getting things done. To me he seemed like a man who could get things done, and after he left, there were people who wanted him to leave but later said, "Well, we need him now. He could get this done."

- Smith

As I've already mentioned in my analysis, Dr. Reitman seems to be best known for the big, sweeping changes he made at the institution during his five years, such as university status for the institution and creating a foundation. The interviewees remembered these accomplishments as efforts which benefitted the institution first and foremost. In addition, it seems that some institutional employees may have originally doubted some of the efforts:

I think by now we would be [a] university even without him, but we wouldn't have been [a] university as quickly without him.

\section{- $\quad$ Smith}

The analysis of Dr. Reitman revealed a president who was dedicated to advancing the institution's image.

In addition to a managerial culture, Dr. Reitman's presidency showed signs of also having elements of a collegial and negotiating culture, both of which would certainly align with a more transformational culture. Dr. Reitman himself described his presidency as very open and collegial: 
And that's just the way my presidency was. I felt that we had to be open about things, and so we shared all the ideas about reorganization with people, and said, "What do you think? What are your ideas?" whatever. And I still feel today, if I were to go into a presidency today, it would be with the idea that we're going to be a very open, very honest, nothing undercover, whatever, and everybody's going to try to feel a part of it. We're going to try to make everybody feel a part of it. So that's why we did all that, and I think it proved successful. But we did it with students, you know, and there was nothing pretentious.

\section{- Reitman}

So we changed the culture. We were no longer quiet; we were no longer sleepy. We were no longer —we no longer had that big wall around the campus. We reached out. Western Maryland, I thought, became proud of us, because they had a regional state university.

\section{- Reitman}

In addition to being collegial, Dr. Reitman also offered a negotiating approach in some instances, as he alluded to in his first comment, where decisions were made transparently and involved many groups on campus.

Glansdale Analysis. Unlike the strong descriptive analysis of Dr. Reitman in managerial culture, Dr. Glansdale appeared to be strongest in the collegial realm. In fact, she was overwhelmingly strong in this area, with over forty excerpts in the collegial column as opposed to less than five in the other three cultures of the academy. By definition, collegial culture refers to situations where shared governance and "scholarly engagement" are the priority over anything else within the organization (Eckel \& Kezar, 2003, p. 132). Dr. 
Glansdale described her leadership as consensus-building and believed in listening to others throughout her organization:

I think when I became the faculty senate president; I was adjudicating, negotiating, with administration when the faculty had issues that the administration and we didn't agree with. When I became a dean, I had all these department chairs to deal with. And at every university, there is some dysfunctional department. But you had to bring consensus. And I mentioned earlier, when you're a provost you deal with deans, and each of them has a separate agenda, and you try to bring them together.

- Glansdale

The President's Cabinet, which now includes not only senior administrators but also several representatives from the faculty, as well as a representative from the classified staff and two students... a broad cross-section of the campus community.

- $\quad$ Speech

"I don't see myself at the top of a pyramid but rather at the center of a circle," [Glansdale] said. She said the style is based on the old Japanese quality circles of leadership but has matured beyond that and, in the 1990s, is permeating Fortune 500 companies. "It is a style that includes the people who are affected, the employees, the students," [Glansdale] said. "I'm very discussion-oriented; discussion and consensusbuilding is just who I am."

- Newspaper

Dr. Glansdale openly valued academic work and cherished those faculty and staff who promoted the quality and academic reputation at the institution. At the same time she opened the discussion to everyone on campus, valuing the opinion of the experts in her staff and 
embracing their contributions. The type of collegial culture that was apparently promoted under Dr. Glansdale seems very conducive to transformational change.

Gail Analysis. Like Dr. Glansdale, Dr. Gail performed the strongest in the collegial culture category, more aligning his administration toward a culture that might be conducive to transformational change. Dr. Gail had just over thirty instances of collegial culture in my analysis, outpacing Dr. Glansdale by only a few excerpts. This is surprising, especially since Dr. Glansdale served the institution for over fifteen years and Dr. Gail has been at the helm for just over five years. Dr. Gail provides every indication that he cares about the involvement of his followers at the institution:

I really do believe that a president of the university's never going make something happen because they alone want it. You have to build those alliances to be able to get where you want to go.

- Gail

I think there's a lot, still, for me to learn, and the bottom line: university presidencies have changed. What we have to do has changed. I mean, I'm enrolled right now in an MBA program. I'm actually working on an MBA online-

\section{- Gail}

You need to be respectful. No matter where you want to go, you need to respect people for who they are, and what they bring to the table. You can't beat people up, and you can't force them to make things happen. Doesn't mean that on some level people won't feel beat up, but it's the president of the university-I learned a long time ago, you don't win any favors by screaming at people. You always have to present an image of dignity and respect in this office. 
Dr. Gail has prided himself on his transparency and his efforts to stay connected with his staff and students at the institution, and he appears to have been largely successful. He even admitted during our interview to pursuing an MBA degree online just so he could better understand the online experience as academic programs at the institution began to transition to the online forum. He clearly advocates change, but appears to listen to his organization as he guides that change forward.

In addition to appearing collegial, the analysis of Dr. Gail also revealed a significant amount of managerial culture present within his administration. Dr. Gail noted very early in the interview that his vision for the institution must align with the followers of the institution: I think that when any new leader comes into an organization, you have to assess what the needs of the organization are. You also have to assess how ready the organization is for change. You know, it is-I think that what happens many times is that when any new leader comes in, many new people will ask, "What's your vision for the future of the organization?" Vision's an important issue here, but I think that it's important to recognize that my view on vision — and I've always said this; I even said it at my inauguration—was, this is not my vision. This is not about [me]. This is about [the institution]. With that in mind, I wasn't initially prepared to have a vision. I was prepared to spend time listening to what other people believed the future of the university could and should be about.

\section{- Gail}

I think the university was ready for change. I think that it's important. It was important then that it not just be change for the sake of change, but there needed to be 
some change. Generally, people had, in part, lost confidence in the university, and some people here were part of that lack of confidence. And so I needed to make some personnel changes.

\section{- Gail}

Dr. Gail's message seemed to align perfectly with that of the institution during my analysis, and he very much seemed to represent the interests of the institution. He was always accessible to faculty, staff, and students throughout my analysis. His inauguration message of sustainability was a focus of the campus community at large, not even his personal focus at the time:

We're getting ready for my inauguration in April of 2007, and we're trying to think of what's going to be the theme of that inauguration. And to be honest, the students came to me and said, "We would like to you to sign”-at that time, I think it was, oh, some international sustainability agreement- "and then based upon that, we would like to make the theme of your inauguration sustainability." I said, “That's so consistent with my values, I would be happy to do that."

\section{- Gail}

Although Dr. Gail has an element of managerial culture present in his administration, the elements of collegial culture far outweigh the others and suggest a culture that could be open to embracing transformational change.

\section{Analysis of Story}

Another goal of my study was to measure the value of story within leadership while also attempting to gauge if transformational leaders were storytellers by nature. My review of literature explains the value of story within the human experience as well as the learning 
process (Eckard, 2009; Schank, 1990). Storytelling can also be a leadership tool as well; storytelling has the power to carry "multiple messages that can reflect organizational "values" while inspiring followers toward a common mission (Hackman \& Johnson, 2009, p. 23). Storytelling is a natural human tool for sharing and passing along cultural norms of the organization (Armstrong, 1992). Others, such as Denning (2011), argue that story is the most effective way leaders can communicate with their followers. Finally, storytelling is not only an effective tool for managing knowledge, which is especially important in today's knowledge-era organizations within higher education, but can also be a catalyst for change through tools such as the "springboard story" (Denning, 2001).

The use of story had great value for my study not just as a facet of leadership, but also as a qualitative research tool. Through the use of story, I was able to gather the personal experience of the presidents within their leadership role at the institution. I was able gather their experiences "holistically in all its complexity and richness," presenting a side of presidential, and potentially transformational, leadership that has been often lost in quantitative studies (Webster \& Mertova, 2007, p. 10). The picture of leadership presented in my study is a human-centered approach that can help reveal what may best contribute to organizational change from the position of an institution president. My study captured not only stories told by the presidents, but also memorable stories told by the faculty members who served under them. These stories were very revealing, and the majority of the transformational leadership components, organizational change elements, and elements of culture that were identified in my data analysis were extrapolated from the stories shared by both the presidents and the faculty members. The results from my analysis of story can be seen in Figure 4. 
Figure 4

Number of stories shared during the study

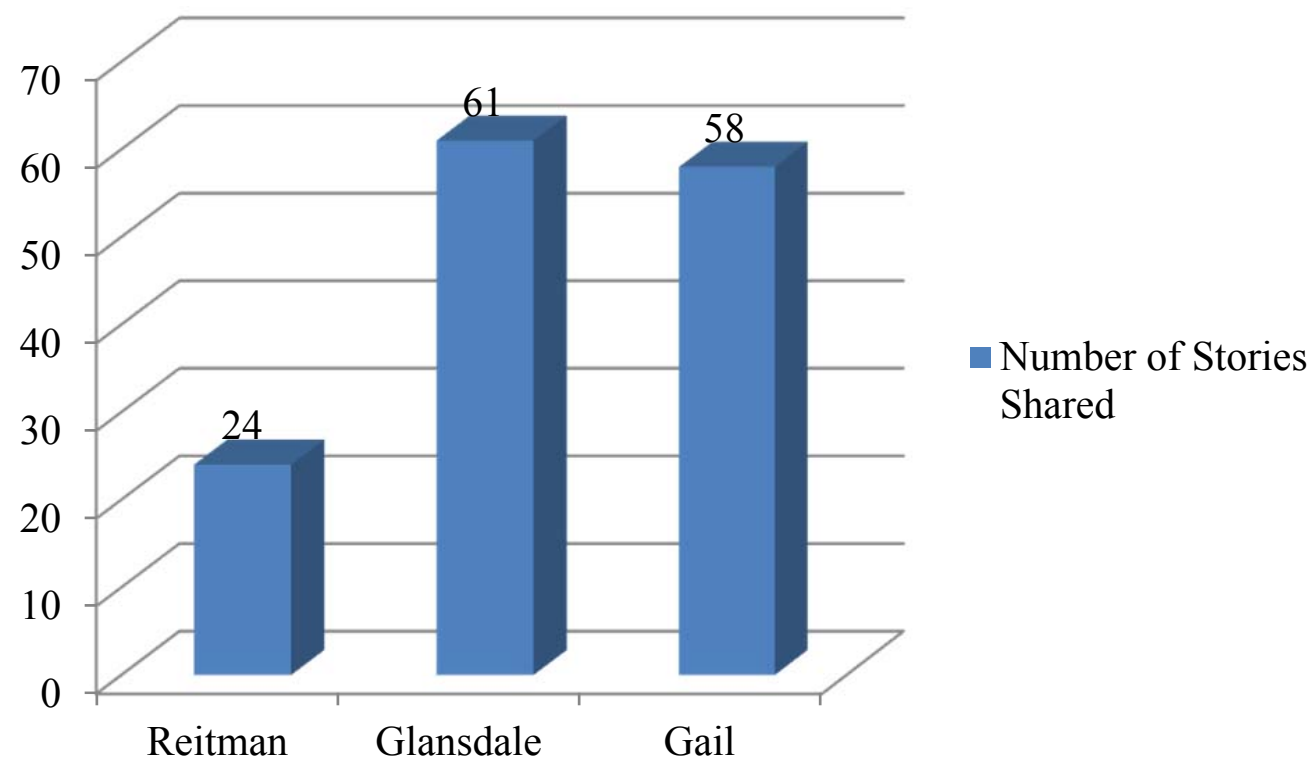

Reitman Analysis. Fifteen of the stories recounted during the analysis of Dr.

Reitman were told by himself about his experiences as president, while just over five were told by the faculty members who participated in the interview. Dr. Reitman told the least amount of stories of the three presidents, but the narratives he recounted were still powerful and revealing of his leadership. Some of the most engaging focused on how he was able to implement significant change at the institution, such as how the institution was able to achieve university status:

Governor Shaffer, who then was the Mayor of Baltimore, was campaigning for Governor of Maryland at the Kelly-Springfield Plant in Cumberland. I was privileged to be one of the 25 or 30 people that was invited to hear him talk, and to ask him questions, and whatever. And about two weeks before that, I had been invited to speak at the Rotary Club in Cumberland. And in that speech, I said, toward the end of 
it, "I think that western Maryland should have its own state university, and I think [the institution] could serve well in that capacity." Well, I had people come up to me afterwards and say, "Oh, that would be wonderful," and, "If it was a university, you could do this, you could do that, whatever.” And it really started a whole, almost like a big eruption, that people were all excited about that. So when Governor Schaefer was there, somebody said, toward the end of his meeting with us, "The president here at [the institution] thinks that [it] could serve as a university. What do you think about that, Governor?” And he just sort of chuckled, and said, “Well, you know, I don't know. I hadn't thought much about that." So after the whole meeting was over, he called me over, and he said, in a very nice way- "Mr. President, that will never work." He said, "The timing is not good. The legislature would never approve that. You just can't do that." And so we talked for a minute, and I said, “Can I ask you a question, Governor-to-be?” And he said, "Sure." And I said, "If we ever got a legislative bill on your desk, would you sign it?" And he chuckled and said, "Sure, I would." Well, I think it was three months later, we had a bill on his desk, and he signed it, and I think that developed a relationship between the two of us. But I can vividly recall the day that the legislative committee approved that-us becoming a university. And then we opened the door for some others to follow after we did. But at the time, we had all the signs on the campus. We had all the screws loose to put up new signs and whatever. We had a big celebration on the campus; we had fireworks, whatever. 
Another story told by Dr. Reitman revealed his charisma and influence as a leader, building connections with policy makers and state officials to benefit the institution's mission:

We decided -I forget when, but it was early in my tenure at [the institution], to have receptions in Annapolis for legislators. [The institution] had never done those kinds of things before. It was very quiet; it never reached out, whatever. So our whole plan was to lobby with legislators, to become known and get their attention. So we started going to Annapolis. We started inviting legislators. And I was standing at the reception in Annapolis; I think it was the first one we had. A state senator was standing next to me. I can't even think of his name right now, and it's probably best that I don't. But he said, “[Reitman], where did you grow up?” I said, "Well, basically, Cincinnati, Ohio, before my mother and dad and I moved to Hollywood, Florida." And he said, "You were from Cincinnati?” I said, "Yes, sir, until I was about 15." He said, “Where'd you go to high school?” I told him, and he said, "Oh, my gosh! I went-, " and he mentioned the high school he went to, and we were bigwe were big athletic rivals. And he said, "When were you there?" And I told him, and he said, "That's about when I played football. Did you play football?” I said, "Yes, sir." He said, "We probably played," and he used some words that I won't even use now. And then he said to me, "What are you trying to do? You've talked to a lot of legislators about this—some kind of center you want to build?" And I said, “A performing arts center." “Why do you want to build that?” So we had a big discussion about it, and before I knew it, within a few weeks-and he and I talked a number of times on the phone-he had introduced a bill, and it sailed right on 
through, and the university and the college, had been trying to do this for years. But it's amazing how those kinds of things happen. And that's how that happened!

\section{- Reitman}

Other stories reveal how Dr. Reitman was able to promote the campus among the local community, taking the first key steps to develop a community of donors that would lead to a foundation solely supporting the institution:

One of the best stories that I can think of is that my wife, [Mrs. Reitman], said to me one day, “Do you know this man, Lou Ort, in Cumberland?” And I said, "I've talked to him; I've called him. I've gone over and talked to him.” And she said, "What do you know about him?" I said, "I know that in years, he had never been invited to the campus.” She said, "Why?” I said, "I don't know." And she said, "Why don't you invite him to a football game with us, to sit with us?" So I did, and Lou Ort came. Lou Ort fell in love with the [institution's] cheerleaders at a division three football game, and just roared about the college, and the campus-and had never been there, in all of his years, and he grew up in that area! And it was Lou Ort, then, who gave us a lot of money. We named the library after him. He received a medallion that we started, and he became a very good benefactor for [the institution]. In fact, it was amazing that he came to my office one day and he said, “[Dr. Reitman], can we drink a cup of coffee?" And I said, "Sure." So I got my secretary, who was just a wonderful person, to fix some coffee for us. And Lou said, "What are you trying to raise money for now?" I said, "We need a lot of equipment in the classroom." He said, “For who?” I said, "For faculty and whatever, to work with students.” And I said, "All that kind of stuff takes money." And he said, "How much you trying to 
raise?” And I told him-and for [the institution], it was a lot of money, but for a major university, it would be nothing. So he took out a checkbook, and he wrote me a check, I think, that day, for like $\$ 19,000$ out of his checking account, and said, "[Dr. Reitman], this is all I can give you right now, but I'll transfer some money by the end of the week, and I'll write more." And I about passed out, because I don't think anybody had ever written me a check for \$19,000, but Lou Ort did. And he became a big benefactor. But again, he became that benefactor because of one thing: we invited him to the campus; he went to a football game. He liked what he saw. We treated him right. He was a great guy, and so our public relations efforts, I think, really did pay off well.

\section{- Reitman}

Dr. Reitman is clearly an experienced storyteller, and I left the interview with the impression that story was an important tool in his everyday communication. I would imagine that story was used frequently in his role as president, whether to set an example for his followers or put perspective around an initiative he was promoting at the time. Interestingly enough, Dr. Reitman presided over some of the most transformational change at the institution, yet told the least amount of stories of the presidents. Unlike the disparity between the presidents and the numbers of documents I was able to examine, each president was given the same opportunity to tell stories during their interview. So, I found it interesting that Dr. Reitman, arguably, witnessed the most significant changes but was the least narrative president of the group. 
Glansdale Analysis. Dr. Glansdale demonstrated the most amount of storytelling in the study, with over sixty stories being told either by the president herself or by faculty members. She told an overwhelming forty stories, revealing that narrative was certainly a key feature in her daily communication and leadership style. She was very comfortable telling stories, and I could tell she was very passionate about the message those stories told concerning her leadership at the institution. Like Dr. Reitman, many of the stories discussed initiatives or significant events during her administration, such as landing the spring training contract for the Washington Redskins:

Oh, it was incredible. They were everywhere! They were everywhere, not only the fans, the players. You know, they would hang out in places like the-what do they call that? The Repub, or something like that. There were sightings of Redskins. Well, it was interesting, because what happened was I went to a Christmas party in Cumberland, and Cas Taylor was there. And he said to me, "What would you think about this?" And I said, "Well, I think it might be worth thinking about and exploring." And there were people who initially said, "No, they'll come in and they'll ruin the town, blah-blah-blah-blah." You know, there was a lot of caution, I should say. Including [Dr. Reitman's predecessor], who ended up coming to the picnics all the time, with his wife. But, so it started that way, and so Cas said, "I'm going to arrange for Mr. Cooke to come out to the campus and look around." So he came, and we had a luncheon for him, and we invited all these people from the community, business leaders and stuff like that, who were clearly interested in having them come. So, he started out-he was a character, anyhow, but he started out by saying, "When Cas Taylor said to them, 'Why don't you think about moving from Carlisle to [the 
institution]?' they said, 'Where the hell is that?'” Cooke said, "But this morning we drove through Flintstone, and now I think anything is possible!" [Laughs] So we go through that and there's a kind of courtship. So then we got down to brass tacks. And I remember being at a conference in Washington DC, and telling him-I was pulled out. And I said, "I can't talk to you, Mr. Cooke. I'm in the middle-." I was on a panel, and I said, "But if you call this evening in the hotel, we can talk." And we were fine-tuning the contract on the phone. So we wanted an escalation clause in for every year, you know, a cost of living increase. He said, "Madame," he said, "I own the Chrysler Building in New York, and I don't have an escalation clause for my tenants." And I said, “Mr. Cooke, I'm a humble servant of the State of Maryland, and I'm not going to lose my job over this contract. There is either an escalation clause, or there is no contract." So there was an escalation clause. So we went through that, and then after the contract was signed, a floral arrangement-I swear to God-as big as this, almost covering my conference table, arrived from Mr. Cooke. And from that point on, we were in good shape.

- Glansdale

The story of the Washington Redskins revealed how tough Dr. Glansdale could be when needed, but also that she cared deeply for the institution and always ensured its interests were protected. Other stories reflected how Dr. Glansdale built inroads into the community and empowered others to carry the mission of the institution forward. The creation of the annual Block Party event between the local town and the institution was an example:

That started with a woman named Lois Hawn, who worked in the Hallmark store on Main Street, and she ran that. And then there was a guy-oh God, I've forgotten his 
name! He was with a bank, and he was I think maybe chair of the-whatever it is, whether it's technically Chamber of Commerce, or something like that. And so we began to talk about what the university could do. But Lois was the first contact with me. And what we could do to try to stimulate some awareness of the fact that there is a town [right outside the institution]; there's not just a campus. Because what happens with parents, for example, is that they come up for Parents' Weekend and they usually stay in what is now the Hampton Inn area, or the one next to it, which was something else at that time, but they don't go into the town, and they don't patronize the town. And students aren't as aware that a mile away from the edge of the campus is this little town. So the merchants then got together, and decided that they would offer some freebies; they would do various things, you know. And then we got the civic groups involved, so the Elks always roast hot dogs and do hamburgers, and people from the campus who belong to the Elks were always flipping hamburgers. And it grew. It grew, and then what I really loved about it: it was completely intergenerational - we bused kids from the residence hall. Others could walk, but we also had busses running over behind Main Street, and would drop off the kids. So we would have our students, but you would look around, and you would see senior citizens, you would see young families with kids in strollers. You would see high school age kids, elementary school kids. It was a town gathering. And then the town, before the block party, which is always the first week of school, began to put those banners up at the edge of town, saying, “Welcome [Institution] Students,” or whatever. So it just suddenly was organic; it just grew on its own. 
Dr. Glansdale's favorite story, which involved the student response to the commencement ceremony one snowy December, was the most striking to me. This story revealed a president who was passionately dedicated not just to the institution, but to the experience of the students:

I say, if you want to know what the spirit of the student population is like at [the institution], let me tell you this story. Well, I got a call. The snow started on Thursday-and it went to forty inches. Forty inches! [Laughs] So we knew we had to cancel Saturday Commencement. So I got a call on Friday from this young woman, and she said, "Can't we have it on Monday?” And I said, "No, we can't have it on Monday, because we have to close the university, and the employees are going to be off. Everything shuts down, so we can't do that." And so she started to cry-I don't know her name-and she said, "Is that what I worked four years for?” And she's crying, and I said, “No." I said, "You worked for four years for a degree. Congratulations for finishing in four years. You're a rarity. And you know, that's what really matters. And you know, the May Commencement, people can come back." And I knew that wasn't going to satisfy her, because obviously people don't alwaysthey're not in the area; they can't come back. Anyhow, so it snowed and snowed and snowed. Anyhow, [laughs] the phone rings that Saturday morning, and I get a call. And it's the same young woman, and she said, "We would like to have a mock graduation ceremony. Will you come?” And I said, "Well, if I could get out of this place, I would come." But I looked out the window; I couldn't even see my car. I couldn't see anything. I said, you know, “Good luck with it,” or whatever, and I hung up. So not too long later, there's a knock on my apartment door. And I was on the 
first floor, and these guys had come, and they were frats-they had their hats on backwards, with the letters here-in a Jeep, and they were going to take me back to the Lane Center. And they had shoveled off the way out to the apartment. So I went with them, and I got there, and they had rolled scrolls into mock diplomas. There was a piano in the Lane Center, in that big room, and somebody knew how to play "Pomp and Circumstance" by ear. They had signed their names, so that I could call their names, and they could come forward and get a mock diploma. And they put in their nicknames, like you know—I'll make this one up—John “Wolf” Jones, or you know, whatever. So, and then they had their caps and gowns, because they had picked those up from the bookstore before the storm. And there were people in the audience, because there were undergraduate students who were stranded as well, and they came. And the word spread through the residence halls that there was going to be a graduation, so they came! So, I got up, and I wore my robe; I took my robe and everything, and did the shtick about-you know. First I called out their names, and they had a valedictorian, and they chose their own, and I think it was by playing "rock, paper, and scissors." In any event, that's what I heard afterwards, but I never validated that. But it could have been the lowest GPA in the class, giving that. So then I called them up, and we gave the diplomas, and they walked across and everything. And then I said at the end, "By the power vested in me by the University of Maryland Board of Regents, and the state of Maryland, I hereby grant you any degree you think you got!" And they threw up their hats, and we had the commencement. But I say, you know, they could have sat in those residence halls, or off campus, wherever they were, just feeling sorry for themselves. And they didn't do 
that! They just picked themselves up and did something creative! And it was my favorite story.

\section{- Glansdale}

The stories told by Dr. Glansdale shared the culture of the institution under her guise as well as her values as an individual. They were very revealing of her collegial nature and consensus-building skill, as well as her passion for educational quality and the promotion of the institution.

Gail Analysis. The analysis of Dr. Gail's storytelling nearly equaled that of Dr. Glansdale's instances of story, with just over fifty-five instances of story. However, only about twenty-five stories were shared directly by Dr. Gail, far short of Dr. Glansdale’s incredible number of forty. His stories also connected with me on a personal level, drawing elements from his background but always driving toward an initiative or major change at the institution under his administration:

First of all, on a personal level, I remember when I was-this was in 1972, when there was a gasoline shortage in this country, and when I was in high school. I had my driver's license, driving a 1963 Volkswagen, and it was odd/even gas rationing, and literally every other day I was either sitting at the gas pump waiting to fill my mother's car, or waiting to fill my own car. I can see by my poster there-that's a 1972 original Earth Day poster, signed by the artist. I have always been deeply committed to the environment and to sustainability. Move ahead in time and here I am at [the institution], and we're getting ready for my inauguration in April of 2007, and we're trying to think of what's going to be the theme of that inauguration. And to be honest, the students came to me and said, "We would like to you to sign"—at that 
time, I think it was, oh, some international sustainability agreement- “and then based upon that, we would like to make the theme of your inauguration sustainability." I said, “That's so consistent with my values, I would be happy to do that."

Many stories shared by Dr. Gail aligned with the format of the one above; a personal experience in his development defined his values, which then influenced his decision-making on campus. His experiences with alcohol prevention are very similar:

When we talk about prevention-and I come by this because, to be honest with you, when I was a faculty member early on in my career in higher education, my wife worked on the same campus administering a what was called FIPSE, Funds for the Improvement of Postsecondary Education, a grant, and the grant was focused on alcohol and other drug prevention. And even back then-and now, this is in the late 1980s, early '90s — on that campus, we had a death due to students overly consuming alcohol. A student who was my advisee died. He was at a party off-campus, got into a fight, kid took out a knife, cut him across a major artery, and he bled out before the ambulance could even get there. So, fast-forward to 2006 when I get here, and the off-campus community, quite honestly, had become almost an inner-city ghetto. It was out of control. Nobody knew how to deal with it. So I formed an alcohol task force. I brought members of the local community onto the task force. I couldn't do it alone. I needed landlords involved. I needed bar owners and servers involved. You talked about bringing the bar owners together, and the people who were serving alcohol? I didn't think anybody would show up. I didn't have room for them to sit in my boardroom, there were so many people showed up. The local-the head of the local 
liquor control board helped me to bring those people to the table, and he told me they wouldn't show up, but he said he'd be willing to help me. One of the things that came out of that meeting was I said to them, "What do you need? How can we help you?" I tried not to blame them. And one of the things that they said to me about what they needed help was, they said, "We can't even afford to make sure that all of our servers are TIPS trained." It's a national program about responsible beverage service. I said, "Okay, no problem. You give us the list of the names of people who need to be TIPS trained; we'll pay for the training. We'll offer the training on campus." And we've started doing that on an ongoing basis.

The attractiveness behind Dr. Gail's storytelling was his ability to clearly convey his values, through narrative, and then to align them with a current initiative or goal of his administration. Doing so made his particular initiative, such as sustainability or alcohol prevention, crystal clear to me as the listener. He used story to fully explain his reasoning, which aligned with constant effort to be transparent and help the campus and surrounding community understand his reasoning behind every decision.

Dr. Gail also demonstrated a very keen understanding of the role of president at the institution, much of which he learned as he climbed the ranks in higher education. He clearly embraces his background in human development, not being afraid to use the lessons of his past to guide his presidency now. One riveting story reveals how he gained those insights: Couple of-this was in about 1988, [Mountain View College], off-campus party. I told you the story a little bit earlier, but I'll fill in some of the gaps now. And a bunch of students in an apartment off-campus get drunk. One young man, who was my 
advisee, says something to another. Kid pulls out a knife, unintentionally waves the knife. He cuts him across a major artery. The kid bleeds out in about ten-about, not even five minutes, he's dead. The next morning, six o'clock in the morning, the president of that college gets a phone call at home from the superintendent of schools. Superintendent says, "I'm so sorry to hear about what happened. Please let me know if there's anything that I can do to help." The president said, "What are you talking about?” “I don't even know what you're talking about.” He didn't even know. And I walked into the vice president for student life's office, and I said, "What? Why doesn't Fred know what happened?” “I didn't want to wake him up. I figured I'd tell him when I got here." I looked at him, and I said, "Have you lost your mind? You had to have known that the newspapers were going to be calling him up, probably before he woke up. It doesn't matter if it's three o'clock in the morning! You don't have the authority to decide independently what that president needs to hear."

$$
\text { - Gail }
$$

The clarity and relevance of Dr. Gail's stories made many of his narratives the most memorable from the study. In addition, the passion and demeanor with which he shared the tales reinforced his belief in learning from his past experiences. He had an uncanny ability to bring his past lessons to life for his listeners.

\section{The Gender Factor within Leadership}

I had originally planned to consider the phenomenon of the role of gender in presidential leadership styles in my study since it involved two male presidents and one female president. As I analyzed both my descriptive and analytical data, I quickly realized that my sample size of three presidents would not allow me to make any definitive 
conclusions on the role of gender within the presidency, nor was my research design especially conducive to considering gender. Nevertheless, I felt the descriptive data breakdown was still valuable to share within my data findings for the study. I still believe gender within the presidency is a fascinating study topic and make recommendations in the next chapter on how it could be considered in the future within research that is similarly designed to my study.

As my literature review discussed, the number of women in leadership positions within higher education is growing. The literature indicated that women tend to have taught more in the classroom than their male counterparts in the presidential position (Cooke, 2012). This is certainly the case for Dr. Glansdale, who had a full career in the world of secondary education before transitioning to teaching and administration in higher education. Although the literature argued that men are more likely to assume the presidency from non-traditional paths and sometimes even from outside higher education, all three presidents considered in my study made the climb in accordance with the traditional path.

The literature also suggested that female presidents offer a different perspective toward the organization than men. More specifically, Bass \& Riggio (2006) suggested that women may have a "greater tendency" to have more transformational characteristics when serving as leader of an organization (p. 115). Women tend to work harder to satisfy followers, are more nurturing toward employees, and work harder to be transparent and ensure those around them fully understand the goals and mission of the organization (Bass \& Riggio, 2006). These qualities, such as Individualized Consideration (IC) and promoting collegial or developmental culture, are paramount in leading toward transformational change (Burns, 1978). Studies have shown that women work harder to develop inter-personal 
relationships, demonstrate higher levels of moral value, and are less self-serving than men in leadership positions (Bass \& Riggio, 2006).

Considering the leadership of Dr. Glansdale compared to that of Dr. Reitman or Dr. Gail was a natural angle for this study. Dr. Glansdale was a mainstay of the institution, serving sixteen years, longer than the national trend and much longer than any other president in this study. How she compared to her peers in the core areas of analysis of this study can be seen in Figure 5 .

Figure 5

Considering gender and transformational change

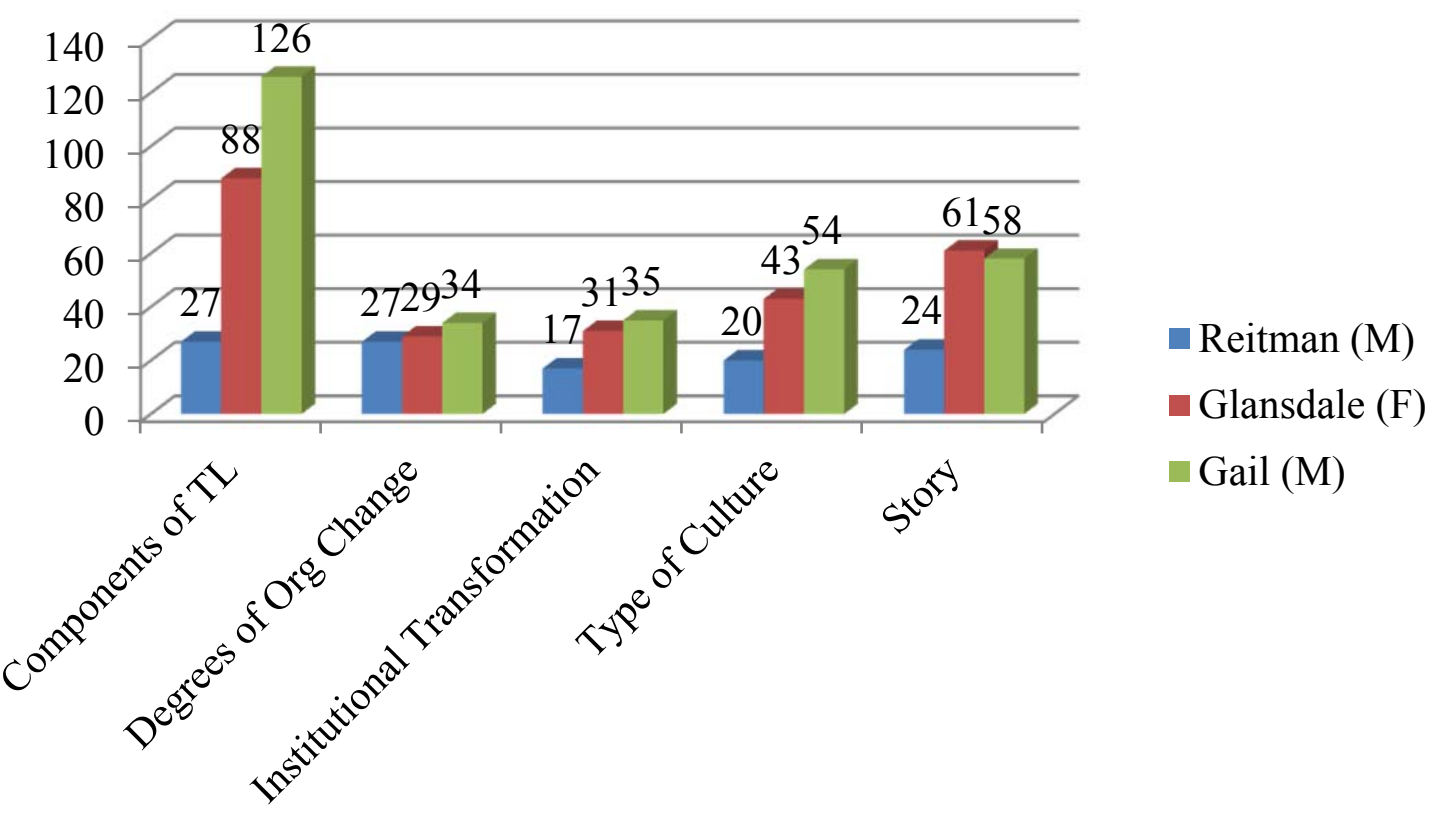

Figure 5 clearly indicates that Dr. Glansdale, like Dr. Gail, showed significant signs of transformational leadership while also experiencing organizational change during her tenure. In addition, she was a much more prolific storyteller than her peers, which may allude to strong marks in Individualized Consideration (IC) and the consensus-building attitude of her leadership. Dr. Glansdale did face the most challenging budgetary cuts of any president at 
the institution for the first several years of her presidency, forcing her to have an overwhelming number of unplanned changes that distracted her from the ability to focus primarily on planned, transformational change. The most prevalent type of culture during her administration was collegial, which aligns with the characteristics and trends of female leadership discussed in the review of literature, but Dr. Gail was also abnormally high in this area as well.

Aside from the brief observations mentioned above, no other conclusive themes or trends concerning gender within the presidency were drawn from my findings for several reasons. First, the presidents in my study served a varying number of years in the presidency, with Dr. Glansdale serving significantly more than her peers. These varying periods of time skewed the data in favor of her analysis, yet Dr. Glansdale was the only woman in my study, putting her at a distinct disadvantage. Furthermore, I was unable to find an equivalent number of documents for each participant, skewing higher performance toward the current president because of the plethora of documents available for the document analysis of Dr. Gail. Nevertheless, Figure 5 clearly demonstrates that Dr. Glansdale could hold her own in the presidency, showed significant numbers of transformational leadership components, and presided over remarkable changes at the institution during her presidency. She is clearly a master storyteller and has incredible inter-personal skills, which she was able to use in her leadership toolbox. Nevertheless, my research design did not allow me to make any conclusive recommendations regarding gender within the presidency in my findings.

\section{The Knowledge Management Element}

I considered implications for knowledge management in this study because of the value of knowledge when considering leadership within the presidency, as well as more 
recent changes in how such knowledge is codified. Countless books, articles, and studies are written every year discussing how university presidents and other leaders can improve their skills and make instrumental change within their organization. In addition, my study focused on an institution of higher learning and cultural learning center for its region, where knowledge is supposedly valued and celebrated. I also considered the power of storytelling in my study, which inherently served as an age-old method to transfer knowledge from one individual to another (Denning, 2011). My review of literature also discussed how society has transitioned to a post-capitalist society where information is centralized into computers and ever-changing technology is forcing the nature of leadership and management to constantly change (Drucker, 1993). Information and knowledge are becoming more important to organizations, and institutions of higher education, at first glance, should be centers where knowledge, or "intellectual capital" (Stewart, 1999), is preserved and shared with the generations of students attending each year.

When considering the role of knowledge management, the institution in my study did a poor job of recording historical components of institutional knowledge. I was shocked by the lack of documents present in the institution's special collections that supposedly housed presidential documents. I was able to retrieve more documents from Dr. Reitman's personal collection concerning his presidency than what the university had on file concerning his tenure. Dr. Glansdale served the institution for sixteen years and the president's office only had one small file containing a few of her speeches, while the library had little more. Dr. Gail himself admitted his frustrations with the institution's inability to preserve its history as he was creating a wall of presidents in the student union and was unable to find photos and dates that key presidents had served at the institution. 
In addition, the findings of my study served as a preliminary examination of transformational leadership and organizational change within the presidency. If anything, the results from my study began to examine how we, as members of the higher education constituency, view the role of transformational leadership and significant organizational change. My hope is that additional studies will follow suit, continuing to evaluate whether or not leadership frameworks make a difference when applied to the presidency. This type of research will undoubtedly result in a positive impact on the knowledge economy within higher education and those who benefit from its training by increasing the knowledge concerning presidential leadership. The questions my findings raised may indicate a shift in the knowledge concerning presidential leadership, and suggest deficiencies in the effectiveness of traditional leadership frameworks when applied to the presidency position. Institutions of higher education should be excellent knowledge managers, housing intellectual capital that is passed on as each generation of researchers and educators makes a contribution to its discipline. These contributions should also benefit the institution, setting an example for knowledge management best practices. My study offered a way to gather and preserve institutional knowledge through story, and my analysis and findings revealed how important institutional knowledge can be for the president, and how detrimental it can be when that knowledge is not being preserved by the institution. I was not able to evaluate the three presidents in this study fairly and equitably because of the sparse number of documents; the further back the president served, the less likely any documents existed from his/her administration. This inherently skewed any data results in favor of the current president, as more documents were available for him than anyone else. The lack of institutional 
knowledge severely hindered my ability to fully understand presidential leadership and organizational change at the institution simply because knowledge was not being preserved.

As research institutions struggle with increased demands coupled with decreasing revenues, so do small public institutions that also need to preserve their intellectual capital and their history. Any leader who aspires to be truly transformational will recognize the value of knowledge and strive to create a culture that preserves it. The institution in my study needs to strive harder to create a culture that values its past and preserves it so that future presidents and researchers will have better access to the knowledge capital. My use of storytelling in this study offers a model for other small institutions to follow in order to preserve knowledge and make institutions of higher learning valuable in the knowledge economy of tomorrow, while both my descriptive and analytical data analysis techniques can serve as a way to measure leadership styles and gauge organizational change.

\section{Methodological Issues and Thematic Analysis}

Whereas the prior discussion focused on quantifiable elements observed during the interviews and document analysis, the second portion of my study findings focused more importantly on results from an analytical approach, considering several themes and rich data that were extrapolated from my findings. These findings represented my qualitative analysis of the study. The following themes were identified throughout the three presidential analyses and offer deep insight into the phenomenon of transformational leadership and organizational change. The themes I identified include the humanization of leadership, the myth of the individualized leader, and the true role of the presidency within higher education. These themes are each discussed in greater detail in the following sections, while larger implications resulting from these themes are discussed in the final chapter of this study. In 
addition, the importance of video in qualitative research also became apparent as a result of this study, questioning commonly practiced methodological procedures for research.

Video in Qualitative Research and the Humanistic Perspective. The use of video as a method to collect data during my presidential interviews was a sticking point throughout my study development. First and foremost, very few qualitative research studies have been conducted using video-recorded data collection methods, while the use of audio-recording is often thought to be the most accepted and least invasive method when considering the protection and well-being of the participants (Pink, 2007). I argued to use video, however, because I felt it would provide a better showcase of the presidents as they truly are in their natural surroundings. In addition, video-recordings allowed me to return to the interviews as I experienced them, to revisit the surroundings in the space, to re-experience the non-verbal cues as I analyzed the written transcripts, and to once again immerse myself in the interview in its entirety. I conducted the interviews as recommended by Patton (2002), so I took very few notes as I engaged the presidents and completely focused on our discussion, leaving little opportunity for distraction by note-taking. The video-recording allowed me to return to the interview repeatedly and make fresh observations of not just the presidents, but also their surroundings and our interactions throughout the experience. The opportunity to return to the raw data allowed me to make several valuable observations in this study.

The use of video allowed me to not only capture the dialogue, stories, and the vocal tones of each president throughout the interview, but also their surroundings. At first consideration, the surroundings during these interviews may not sound important to my analysis, but my ability to review the interviews on video quickly revealed the significance. I gave each president the option to choose where the interview would be conducted. I 
expected Dr. Reitman and Dr. Glansdale to choose their homes because they no longer served as the president and had no offices on the premises of the institution, nor lived in the surrounding area any longer. I had expected Dr. Gail to choose his presidential office because he is the sitting president of the institution and because we met during business hours. Nevertheless, I still found the locations chosen by the presidents to be significant. The surroundings of these rooms in which the interviews were conducted portrayed the presidents in a more personal, intimate light for my analysis. For example, Dr. Reitman had me interview him in his living space as he reclined in a comfortable rocking chair. Hanging on the wall, not far from where we conducted our interview, hung a medallion he was awarded from the institution. The room was filled with family photos of children and grandchildren, as well as relics from his hobbies such as golf. My descriptive analysis of Dr. Reitman was not very revealing because of several impediments, such as the poor document analysis I was forced to conduct on his presidency, but yet I learned so much from his surroundings during the interview. Reitman is a compassionate and dedicated family man, and even in retirement presents himself and his home in a professional manner. He had a lap-top next to his chair, suggesting he used it frequently to stay connected to family, friends, and to stay abreast of current events.

Dr. Reitman also insisted that I view with him and record two video segments that were done when he was president of the institution. One video segment was from the local news, announcing the sweeping changes being made at the institution after Reitman's arrival, while the other was a brief special interest piece on Reitman and the institution. He sat with me as we watched, providing commentary and connecting pieces of the videos to topics we had discussed during the interview. He stopped the videos several times to elaborate on 
points being made in the videos or provide context to help my understanding. It became clear, even during the interview when he referred to these videos, that he wanted me to see these visual representations of himself on video when he was the president. He really enjoyed watching these with me and sharing the memories; he commented several times how happy he was to recall these good memories with me.

Using video as my data-gathering technique provided a completely different perspective for the analysis of Dr. Reitman. My descriptive analysis, although brief, suggests that Dr. Reitman exuded very few transformational leadership qualities. Yet, from the video I was able to identify a charismatic individual who showed considerable signs of Individualized Consideration (IC) and Idealized Influence (II), for example, in the few hours we spent together. Repeated review of the video revealed a more humanistic perspective to Dr. Reitman, which was a perspective that was certainly not identified in the descriptive analysis.

The video helped me get past the professionalism of the presidency and view Dr. Reitman as a human being. As I re-lived the experience through repeated plays of the video, I felt less like I had interviewed a university president and more like I was listening to a wise, accomplished administrator who was reflecting back on his career after retirement. Dr. Reitman looks excellent for his age and is truly aging gracefully. He looks as if he could serve in the presidency once again and serve as the role model for the institution. In many ways, Dr. Reitman still looked, dressed, and acted the part of advocate, spokesperson, and role model for his cause, whether it is president of a university or in some other capacity. I never would have made these connections without video data, allowing me to revisit the experience and reflect over time. 
In qualitative research, the researcher is the instrument that measures the phenomenon, which in the case of my study, allowed me to view the presidents much more holistically (Patton, 2002). Freire (1970) also addressed the challenge in his theory: "the conflict lies in the choice between being wholly themselves or being divided" (p. 48). I sought to portray a holistic, undivided picture of presidential leadership that included both professional and personal perspectives of these individuals so that a greater understanding of leadership might be generated from my study. Video was not an element of descriptive analysis, but its effectiveness in helping me identify larger themes from the data warrants discussion for future qualitative research within higher education leadership arena. I see great value in using video to continue exploring leadership and the human element, capturing both the professional and personal components of leadership.

I experienced the power of holistic exploration first-hand when I made one significant observation about myself while viewing the video with Dr. Reitman. I have always made a point to address the presidents in the study by their formal titles as a sign of respect and professionalism, yet I caught myself referring to Dr. Reitman by his first name on two occasions during the interview. These two occasions were when he had me engrossed in story. Without even realizing, I had shifted from academic researcher to friend and admirer as we discussed commonalities shared by our connection to the institution. I may never have identified my own personal transition with only audio because I was originally drawn to Dr. Reitman's excited non-verbal cues during the stories that elevated my senses to notice my own shift in behavior.

After making this realization, I reflected on the conversations we had over the telephone and the numerous emails we had exchanged before meeting. I drove a great 
distance to conduct the interview, and then I virtually spent the day with Dr. Reitman and his wife afterwards, having lunch and going through old photos and documents from his tenure at the institution. I had taken the impersonal nature out of leadership and now had the opportunity to get to know Dr. Reitman as most university presidents are never known: as a human being first and foremost. I came to understand many of his decisions while serving as president that I had read about in the document analysis and had developed a deeper understanding of him as a person.

The video of Dr. Glansdale was also very revealing. I was captivated during the video and noticed very little of our surroundings. She chose to be interviewed in her home office because she felt the lighting was better suited for the camera. However, I realized later that much about her character and interests as a person were revealed in her surroundings. Just beyond Dr. Glansdale, situated just above her as she sat on the couch during the interview, was a gorgeous water color painting depicting an iconic shot of the clock tower in the central quad at the institution. This clock tower has been a mainstay at the institution for decades, and those who have attended or were affiliated with the institution in any capacity would immediately recognize it. I was captivated when I first noticed it on video, as I completely missed seeing it during the nearly two-hour interview.

My descriptive analysis of Dr. Glansdale revealed a dedicated, compassionate spokesperson for the institution. Of the three presidents that I interviewed, I feel she developed the most genuine affinity for the institution. She admitted to devoting her sixteen years of service to the institution in elevating the name and making it truly a university. That water color, which was the central wall decoration behind her during the entire interview, reflects that love and dedication. Even in retirement she keeps the thought of the institution 
at the forefront of her mind, and she is clearly proud to be affiliated with the school, even as she lives nearly three hours away. I would like to think she chose that location in her office so that water color could clearly be seen in the video, almost as a subliminal message of support of the very institution she helped grow. The stories she shared in the interview, especially her story of that snowy, cancelled graduation, clearly reflected her caring and devoted leadership to the institution. This watercolor, however, and its placement during this interview, visually captures her genuine commitment to the institution.

Like my interview with Dr. Reitman, I left the interview with Dr. Glansdale with a more humanized and intimate persona of a president. Dr. Glansdale was the president when I attended the institution for both undergraduate and graduate school. I held several student employment positions during that time which required me to drop off files and other documents to the president's office. I knew of Dr. Glansdale and could easily recognize her about campus and in the community, but knew nothing about her personally, her background, or her personal interests. Like Dr. Reitman, I spent the day with her, having lunch and reminiscing about the institution and the memories we had there. I gradually grew closer to understanding Dr. Glansdale as a person, not just a president.

Repeated reviews of the video data, however, allowed me to draw so much more from the experience. Before becoming president, Dr. Glansdale was a Shakespearian Scholar. She served as an English teacher and then lecturer when she entered higher education. Her speeches and writings as president of the institution were full of references to Shakespeare and other literary works, but I was unable to realize the magnitude of her passion and love for this literature until I reviewed the video. Just to her left during the interview was a book case that was full of books. Those books included topics on Shakespeare, English literature, and 
poetry. As I noticed these books for the first time in the interview, I quickly recalled a comment from Dr. Glansdale that had been published in the institution's student newspaper just before she retired where she looked forward to once again having time to read Shakespeare and literature when she left the presidency.

That moment, for the first time, and weeks after I had conducted the interview, was when I truly realized her passion for literature and connected with her on a personal level. I had realized why literature had become such a defining element in her leadership and communication with her constituents. Literature defined who she was as a person, and therefore needed to be central to her leadership and communication as president. This realization made me view her leadership as more genuine and reflective of her true personality and interests. Also, for the first time, I saw her once again as a teacher with a passion for a substantive academic area, not a person serving as the impersonal face of an entire institution of higher education. I would have missed these humanizing elements, as the researcher, without having access to video.

The ability to review the video during my analysis also allowed me to focus on Dr. Glansdale and to make observations about her I may have missed during the initial meeting. Like Dr. Reitman, Dr. Glansdale is truly aging gracefully. Unlike the other two presidents, I had a personal reference point with which to gauge Dr. Glansdale's appearance because she was president when I attended the institution nearly a decade ago. She looked much healthier and younger on the video, probably because she no longer had the weight and responsibility of an entire institution on her shoulders. Still, she reminded me of the age-range of most higher education presidents, another humanistic element I had missed in the descriptive analysis. My review of literature indicated that university presidents, particularly in 
America, are "graying," with the average age of a college leader being 60 in 2011 (Stripling \& Medina, 2011, pp. A1-A10). That impersonal, distant view of a president often neglects that many are just on the cusp of retirement and are senior-citizen age.

A comprehensive review of Dr. Gail's interview on video was just as revealing as his predecessors for my analysis. Dr. Gail chose to be interviewed in his office during business hours. As a result, I treated my interview with him much more formally; I dressed much more professionally and found myself interviewing him during his busy working schedule. My anticipation was certainly much higher leading up to and for much of the interview simply because I wanted to respect his time while also getting a substantive, revealing interview. In addition, he had very important meetings both before and after my interview, so I felt a level of expediency and haste that was not present with Dr. Reitman and Dr. Glansdale. Finally, unlike Dr. Reitman and Dr. Gail, the interview was conducted on the campus in the president's office, so I had a chance to view the full weight of the position and its work load first-hand.

As a result of the venue and schedule I was working within, I found that nearly all of the themes I identified from Dr. Gail's surroundings came from the video. The first and most obvious theme I identified from the video of Dr. Gail was the tremendous power and influence exuded from the office. Dr. Gail was interviewed behind his desk, and behind him were large windows that looked out on the lower quad of campus and the iconic clock tower that I described with the analysis of Dr. Glansdale. In the forefront of that view scape is the unmistakable outline of a large building being constructed. As I re-capped the interview on video, with Dr. Gail telling stories from his past and about his leadership with the silhouette of a large, new building being erected in the background, I felt for the first time the awe, 
inspiration, and power behind the presidency position within higher education. In that moment, Dr. Gail's words meant progress, advancement, and the visual personification of growth, especially since I knew this structure would be a center for communications and instructional technology for the campus. I felt the power of leadership and was immediately consumed and understood the rhetoric I had read so much about.

Another observation I quickly made about Dr. Gail's surroundings, like my observation with Dr. Glansdale, concerned the books he had filed on his desk. Dr. Gail had many leadership titles, including both volumes of Bess \& Dee's (2008) Understanding College and University Organization. This title was incredibly influential in my research, so I was delighted to see that Dr. Gail owned copies and kept them close at reach. This observation really humanized Dr. Gail for me and I made a connection with him; I owned the very same books and consulted them regularly for my research. His copies looked somewhat worn, so I assumed he did as well. The presence of recent leadership publications reaffirms the descriptive analysis of Dr. Gail; he exuded significant amounts of the transformational leadership components because he clearly had read about them extensively and understood the concepts.

His surroundings and behavior during the interview also reinforced the themes of accessibility and transparency that were identified in the descriptive analysis. I described in my descriptive analysis how Dr. Gail, more than anything else, met the element of Individualized Influence (II) of transformational leadership. He serves very well as the role model for the institution and prides himself on accessibility and connection to the students at the institution. His surroundings reinforced these themes; situated behind Dr. Gail sat a new, advanced Apple computer, reinforcing his knowledge and role of using cutting-edge 
technology on the campus. In addition, the office was very inviting, with Dr. Gail's guest chairs positioned very near his sitting position behind his desk. I remembered, after viewing the video repeatedly, that I became surprisingly relaxed and comfortable as we conducted our dialogue.

The final theme that I identified through video with Dr. Gail was his posture and behavior during the interview. More so than any other president, Dr. Gail appeared very relaxed and comfortable during the interview. Again, I did not make this observation right away, but much later when I was analyzing the video. He frequently leaned back in his chair during the interview, often verbally reflecting from thinking positions where he searched for his responses, and at one point even pulled his wallet from his back pocket and threw it on his desk to get more comfortable. For that brief time of the interview, I felt as if I had the president's undivided attention. Furthermore, I felt that, based on his behavior and nonverbal cues, that he was truly enjoying the experience and really trying to answer my questions thoughtfully and honestly. I mention in my descriptive analysis that Dr. Gail was a skilled and frequent storyteller during his interview, but most of his stories were so easy to identify and enjoyable to watch because his behavior and the tone of his non-verbal cues drew me in on the video. Because Dr. Gail is the sitting president, and because we conducted the interview in the president's office, I expected to have the hardest time conceptualizing him in a close, intimate, and humanized way. Yet, his behavior and composure during the exchange was so inviting and warming, I felt as if I understood him more and more on a personal level each time I cycled through the video.

The way my study was conducted concerning how university presidents respond to organizational change generated an added benefit in the findings: an examination of the 
human element of leadership within the presidency. Instead of conducting the MLQ or some other quantitative measure to determine the relationship of leadership and organizational change, my study also considered the intent of these presidents through story and other visual cues that could only be identified through video. The descriptive analysis allowed me to strictly identify elements of transformational leadership, organizational change, culture, and the presence of story. But video allowed me to identify and observe much richer, analytical themes that mostly humanized the presidents and brought a personal exposure and angle to leadership.

Having the ability to relive the interviews over and over through video allowed me to re-immerse myself in the data during the analysis. On many occasions, as I transcribed and coded data while the interview was being re-played, I felt as if I were there with the presidents once more. I was often able to recall thoughts and emotions I had during the interview but was unable to record in my notes, allowing me to make more extensive connections after the fact that may not have happened otherwise. I was also able to repeatedly experience these presidents as people; to see their informal take on leadership while reflecting on their impacts to the institution. I feel the use of video for my data collection in this study was invaluable, and I advocate for its expanded use in qualitative research in the future relating to this topic and others.

Myth of the Individualized Leader. I focused this study on examining transformational leadership within higher education for a number of personal reasons, but the most important was that I questioned the value of the explosion of leadership training literature in higher education programs and other formal venues. As I discussed at the beginning of this study, the traditional model of higher education is under attack from for- 
profit institutions, online education programs, and other primarily free forums like the Khan Academy and the Massive Open Online Course (MOOC) movement. The logical response from the public and university constituents alike is to turn to the college and university presidents for answers, or to bring in presidents who can transform traditional higher education so that it can survive during these relentless forces of change.

The institution I studied is also facing these threats, and I expected the attitude and response to be the same. I expected the presidents to be products of their times, yet I expected them to have unique agendas for the institution based upon their backgrounds and personal beliefs which they brought with them to the presidency. What I found was quite opposite; the institution, in many ways, has not experienced individualized leadership and varying agendas, but what Burns (2003) has dubbed "collective leadership" (p. 177). This became a central theme through every presidential interview, and was even reinforced in the interviews with the faculty members. Neither the major goals of the university, nor the methods with which the presidents used to achieve them, changed over the nearly three decades encompassed in my study. The outcome may have been a little different, but the reasons behind the effort and the effort itself remained the same.

The best example of this effort was the institution's conversion from a state college into a university. This event was a significant element to my descriptive analysis because it was identified as the most transformational change both from a leadership and an organizational standpoint. However, a broader consideration of the event reveals it was the natural and most logical next step in the institution's development. Dr. Parker alluded to this perspective in his interview; he saw the transition to a university as part of a larger, national trend sweeping the nation. Small colleges across America were becoming universities during 
the 1980s, and Dr. Reitman had once worked at a small institution where he had transitioned it to a university. Not only did Dr. Parker not see the transition to a state university as particularly transformational, he had expected such a shift when Dr. Reitman was brought in as president, knowing his past accomplishment of just that at another institution.

Dr. Reitman led the logical transition to university status, and then Dr. Glansdale followed him with sixteen years of service as president. Dr. Glansdale admitted first and foremost in her interview that her career at the institution was spent getting the infrastructure, programs, and faculty to the level deserving of the university title. She considered this the crowning achievement of her presidency. Her effort was different than Dr. Reitman's work to gain university status, but in many ways Dr. Glansdale was continuing Dr. Reitman's leadership and direction for organizational change on the campus. She brought a different flavor of leadership, but in her own way she transformed the campus just as Dr. Reitman had done. But that transformation continued along the logical path of development for the institution.

Dr. Gail followed behind Dr. Glansdale and immediately made some large personnel changes across the campus. Initially the campus community, along with the surrounding community, expected significant changes in the direction of the institution. Yet, his administration seems to be continuing the advancement of the institution on its predetermined course. For example, Both Dr. Reitman and Dr. Glansdale continued efforts to develop closer ties to the local town situated adjacent to the institution. To combat binge drinking and off-campus student partying, Dr. Glansdale reached out to the town police department in an effort to combine resources and allow campus police the jurisdictional 
authority to enforce local ordinances off campus. She worked diligently for years, but the local town authorities were never receptive to the idea.

Sadly, after a recent student altercation that resulted in a death off-campus, but within a few feet of the campus property, Dr. Gail was able to finally get jurisdictional authority for the campus police within the community. Dr. Glansdale immediately gave praise to Dr. Gail for concluding this effort. Dr. Gail reported in his interview that the impact has been positive and immediate; with more law enforcement resources policing the town, students are less likely to throw binge drinking parties in broad daylight. Although Dr. Gail can claim this achievement personally and for the institution, he was simply finishing a larger effort that was begun primarily by Dr. Glansdale and continued across presidencies.

The green and sustainability efforts recently invoked by Dr. Gail, commonly thought to be his personal initiatives for the institution, also can be viewed from a perspective of collective leadership. He confided in me during the interview that sustainability first became a focus of his right before his inauguration as president, when a group of environmentallyconscious students from the institution approached him and asked if sustainability could be the theme for the event. Dr. Gail was happy to oblige because sustainability and green living aligned with his core values both personally and professionally. In addition, recycling and environmentally-friendly operations can be traced back to Dr. Reitman when he first arrived at the campus in the mid-1980s and implemented the school's first recycling plan. Although Dr. Gail has made sustainability one of his core efforts on campus, its roots can easily be traced to earlier presidencies and to a deeper commitment that was already present on campus before his arrival. 
These differing perspectives quickly show how the theme of collective leadership is more commonplace at the institution than individual efforts. The components of transformational leadership are certainly present as well, but I would argue these three presidencies together showcase effective leadership and significant organizational change more than any one administration considered by itself. The same themes and efforts resonate across administrations, almost as if the institution itself is the driving force and the presidents are simply vehicles and stewards of that effort. Researchers like Bolman and Gallos (2011) and Bess and Dee (2008) have argued that no president has complete control over the direction of a university, but my analysis seems to indicate presidents are simply shepherds of efforts and initiatives that are already in place, maintaining the status quo to the best of their ability as long as the constituency of the institution approves.

True Role of the Presidency within Higher Education. I identified one common, significant theme about the presidency position at the institution that every president acknowledged, told stories about, and frequently lamented over: the presidency as an extension of the state political system. All three presidents mentioned, and in some cases told stories about, their relationships with the state legislature in garnering support for the institution both politically and financially. All three presidents appeared to be very effective with this aspect of the position; however, my study did not consider this aspect of the presidency in detail in my analysis. Nevertheless, I identified the political role of the presidency as a theme and believe it merits discussion and consideration in this analysis, especially in this era of public doomsday budget cuts and weak economic growth.

Dr. Reitman, in many ways, acknowledged and described his presidential role as merely an extension of the state political system. Many of the great accomplishments that 
took place during his presidency, including the conversion to university status, the funding of the Performing Arts Center, and the relocation of the Maryland State Games to the institution, all came to fruition because of Dr. Reitman's strong relationships with politicians in Annapolis. Two of the best stories shared by Dr. Reitman illustrated the conversion to university status and the funding of the Performing Arts Center. Quite simply, Dr. Reitman claimed that he garnered funding for the Performing Arts Center because of a relationship he had with a high school football friend back in Cincinnati who was now in the legislature, while university status was achieved with months of political advocating, networking, and the personal commitment from the Governor of Maryland that he would sign the legislation should it cross his desk.

Dr. Glansdale also spent a good portion of her time working with politicians in Annapolis to garner political and economic support for the institution and surrounding community. Her presidency began with some of the worst state budget cuts in the institution's history, forever stunting its growth in comparison to other small public institutions in the state. She shared several dismal stories concerning the budget shortfalls, but also very positive outcomes from political relationships. One of these accomplishments was attracting the Washington Redskins to the campus for spring training, which would help the area economically. In this particular situation, Dr. Glansdale was working with both state and local politicians as well as high profile business people, including the owner of the Redskins, Jack Kent Cooke. Finally, Dr. Glansdale oversaw potentially the largest capital improvement campaign in the institution's history, with numerous new facilities being constructed under her tenure. Each of those buildings was a result of constant exposure of 
the institution down state by Dr. Glansdale, focusing on the school's financial needs as well as its goals.

Dr. Gail also indicated that an important part of his role as president involved serving the state politically. He commented in his interview about how important it was for the state legislature to know about the institution, even sharing that he planned to individually phone each newly elected state representative this year and have a personal conversation with them and inviting them to visit the institution. Having come from another state institution further north before coming to this institution, Dr. Gail already had a keen understanding of this aspect of the position, but emphasized its importance. In fact, he sees the political role of the presidency as important enough to take students from the institution with him on occasion so they can shadow his testimony and advocacy efforts. He reiterated throughout his interview that the need for advocacy and marketing on behalf of the institution will only grow as the competition for precious state funding grows.

The theme of the small public university presidency as political agent was surprising; I had never expected politicking to be such a huge facet of the job, especially at a small institution. After completing my analysis and considering the accomplishments of each president, I quickly realized how most of the significant changes to the institution, such as the conversion to university status and the new facilities, were a direct result of that particular president's ability to appeal to the political forces in Annapolis. In other words, leadership style may have had very little to do with these significant organizational changes. Dr. Reitman's story about the Performing Arts Center serves as just such an example; he immediately developed a positive connection with a high-ranking state official because they were high school football rivals decades ago in Ohio, but that ultimately lead to funding the 
most expensive building on the state's line-item construction list for that year. As I mentioned in the introduction to this study, the contemporary university president is required to fulfill many diverse roles and responsibilities that go well beyond simple academic leadership (Duderstadt, 2007). However, the political requirements described by these presidents are significant, and if they continue to grow at this institution, call into question the purpose of the presidency and its relationship to the constituency on campus.

\section{Conclusion}

In conducting this study, I was able to identify components of transformational leadership and elements of organizational and institutional change at the institution. In addition, I was able to determine which cultures of the academy were most prolific during each president's administration. Finally, I was able to identify the presence of story with each president. I was able to conclude that transformational leadership and organizational change were present under each president who served at the helm of the institution. I was also able to get a good sense of the culture of the institution during their separate administrations. I was successful in identifying storytelling and narrative among all three presidents as well. I was also able to identify a few significant qualitative themes that shed more light on the presidency, the nature of leadership in the position, and the future role of the presidency in small institutions of higher education in the future.

In the next chapter, I summarize and discuss my dissertation findings, attempting to determine how the presence of transformational leadership affects organizational change. I will also discuss the impact of culture on transformational change, as well as the power of story as a leadership tool in each president's administration. I will also elaborate on the qualitative themes I identified in my analysis. I will conclude the chapter by discussing 
implications for future research opportunities, examine my experience as a researcher tied to the institution, and provide concluding remarks concerning the relationship between transformational leadership and organizational change within the presidency. 


\section{Chapter Five: Summary, Discussion, and Conclusion}

\section{Introduction}

In Transforming Leadership, author James MacGregor Burns (2003) recounts the story of a university president who comes to an institution from the outside. Initially the president did well, showing all the classic characteristics of a successful leader. Eventually, however, Burns (2003) claims the president "talked to the teachers but failed to talk with them, or truly listen to them" (p. 183). The president had mistakenly believed that he was on a course for change at the institution, but underestimated the need to mobilize his followers and involve them in the process. According to Burns (2003), empowerment is one of the most transformational tools a leader has at his/her disposal.

I began my final chapter to this study with this story because it resonates with my research; can a university president alone invoke transformational change on his/her institution? Did the president mentioned by Burns (2003) have the ability to solely lead his followers toward significant, transformational change, or was he/she another victim of the "power of situation" (p. 180)? This dissertation sought to answer that question by examining three sequential presidents at a particular institution during nearly three decades of leadership. In addition, this dissertation sought to evaluate the power of story as both a qualitative research tool and a leadership tool for university presidents. I offered both a descriptive analysis of the phenomenon of transformational leadership and organizational change and an analysis of rich themes that became apparent during the study. To this end, I examined one primary research question using qualitative research methodology:

How do university presidents respond to organizational change? 
In this final chapter, I summarize and discuss my findings, as well as implications for future research and for other institutions. Next, I discuss my role and experiences as a researcher familiar with the institution in this study. I conclude this chapter with my final comments on transformational leadership and organizational change.

\section{Summary of Major Descriptive Analysis Findings}

This study primarily focused on the phenomenon of transformational leadership and organizational change, considered culture, and examined the use of story as both a leadership and qualitative research tool. To remain consistent with the literature, I considered both the formal degree of organizational change and also the four components of institutional transformation developed by Eckel, Hill, and Green (1998). I will first present discussion on my descriptive findings, followed by discussion on the major qualitative themes that came to light during the analysis.

Transformational Leadership and Organizational Change. The goal of my study was not only to identify if transformational leadership existed within the university presidency, but also to determine if transformational leadership led to significant organizational change. My descriptive analysis identified significant levels of transformational leadership components among two of the three presidents. The analysis of Dr. Reitman found the least amount of transformational leadership components, only twenty -seven in all compared to Dr. Glansdale's eighty-eight and Dr. Gail's one-hundred and twenty-six. Dr. Reitman was strongest in the Idealized Influence (II) category, but only nominally in Inspirational Motivation (IM) and Individualized Consideration (IC). Dr. Reitman had no excerpts that aligned with Intellectual Stimulation (IS). 
Like Dr. Reitman, Dr. Glansdale was highest in the Idealized Influence (II) category. In addition, she was also strong in the Inspirational Motivation (IM) and Individualized Consideration (IC) areas, while scoring lowest in the Intellectual Stimulation (IS) component with only fourteen excerpts. Dr. Gail's performance followed the same pattern of behavior; he was highest in the Idealized Influence (II) component with notable scorings in the Inspirational Motivation (IM) and Individualized Consideration (IC) components. Dr. Gail, like his peers, was lowest in the Intellectual Stimulation (IS) component with only thirteen identified excerpts.

My descriptive analysis clearly indicates that components of transformational leadership are present within the university president position at this institution; two of the three participants had at least thirteen excerpts that aligned with every component of transformational leadership. These instances came from the words of the presidents, the words of the three faculty members, or from a document they had written, or a news release in the local newspaper. Dr. Gail and Dr. Glansdale performed the strongest in every category of the three presidents, almost mirror images of each other in fact. This may have been a result of the strong document analysis I was able to perform on them.

I was very surprised, however, by the performance of Dr. Reitman; he arguably oversaw the most transformational change in the institution's history when it became a university, but he had only twenty-seven excerpts that met the transformational leadership criteria, which was much lower than the other two presidents. Figure 6 clearly displays the breakdown in excerpts concerning transformational leadership; with only five excerpts, the entire analysis of Dr. Reitman was at a distinct disadvantage when compared to that of Dr. Glansdale and Dr. Gail because of my inability to find documents pertaining to Dr. 
Reitman's presidency at the institution. However, Dr. Reitman did have the lowest number of excerpts that aligned with components of transformational leadership when compared to his peers, which ultimately impacted the analysis as well.

Figure 6

Components of transformational leadership within interviews and documents

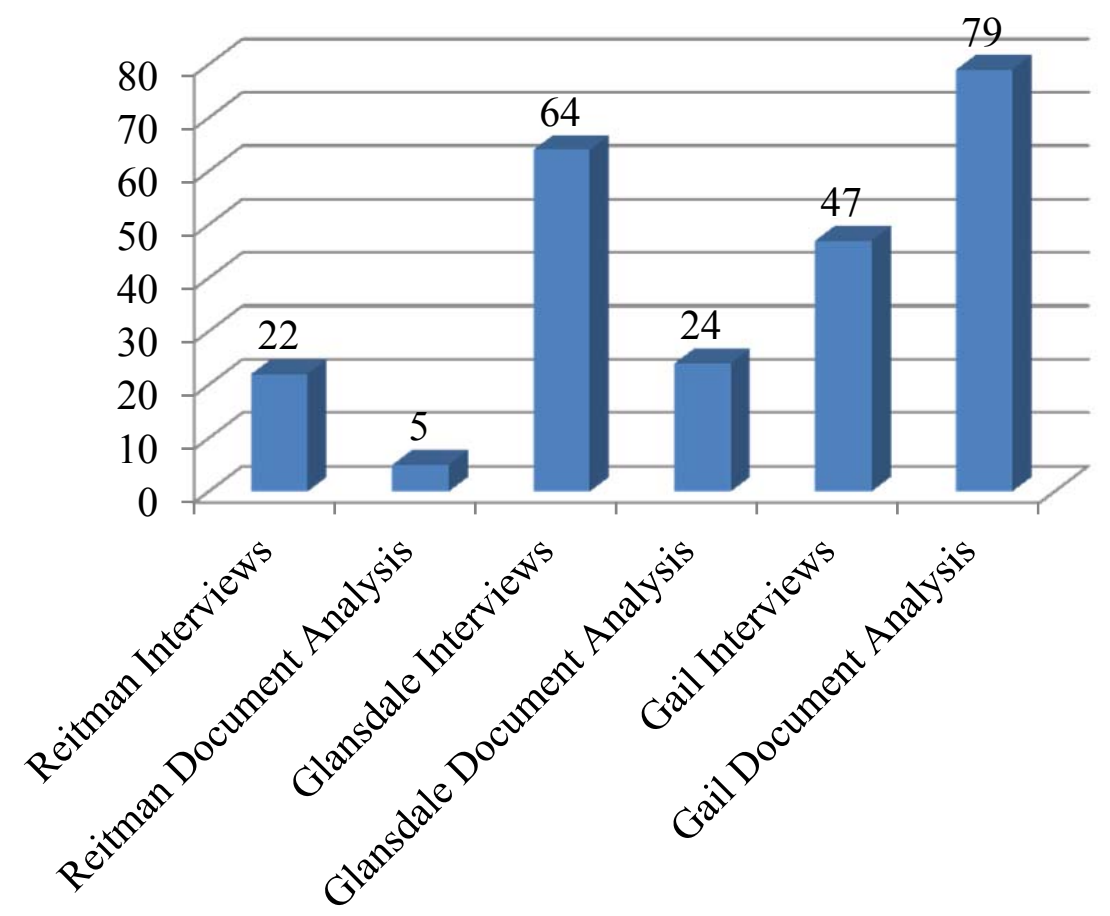

- Components of TL

Although transformational leadership was clearly present in all three presidencies, I had expected to find three clearly different, distinct administrations in these presidents. My prior knowledge and experience with the institution, including attending and working there in student positions for eight years, had prepared me with a baseline assumption that the presidency of these three individuals would be very different. I expected that each would have differing goals and differing methods to reach those goals. What I discovered, however, is that, for the most part, each presidency seemed to build on the previous administration, carrying out unfinished projects or continuing traditions that had been started 
by predecessors. For example, during her interview, Dr. Glansdale admitted that she tried to align the university police with the local town police, garnering concurrent jurisdiction and allowing the two police agencies to combine their resources to combat student binge drinking. She applauded Dr. Gail for making that goal a priority in his administration, and for ultimately achieving it in recent years.

The leadership of these three presidents was undoubtedly transformational in some respects, but was also what Burns (2003) dubbed "a collective leadership over time" (p. 177). Although each president had differing interests and academic backgrounds, they all seemed to indirectly work together while serving at the institution for collective goals merely separated by time, almost as if in a continuum of leadership. For instance, all three presidents stressed that making the institution more well-known outside of the region for its strong academic programs was a priority. Dr. Reitman pursued this goal by making the institution the regional university for the state. Dr. Glansdale increased the institution's awareness by attracting popular majors such as engineering, garnering significant accreditations, and attracting the Washington Redskins Training Camp to the campus. Dr. Gail has increased awareness of the institution by launching the university's first doctoral program and developing the school's niche of sustainability and green practices. Each president went about increasing the institution's awareness in different ways, but all three were committed to advancing the university. According to Burns (2003), using creative innovation to "produce intended change" is one of the best qualities of transformational leadership (p. 231). Each of these three presidents produced tremendous creative innovation during his/her tenure at the helm of the institution, but in very similar directions. 
Another area of my study considered organizational change, and whether or not the presence of transformational leadership contributed to significant organizational change. Figure 7 displays the number of excerpts concerning transformational leadership alongside the instances of organizational change and institutional transformation.

Figure 7

Transformational leadership and organizational change

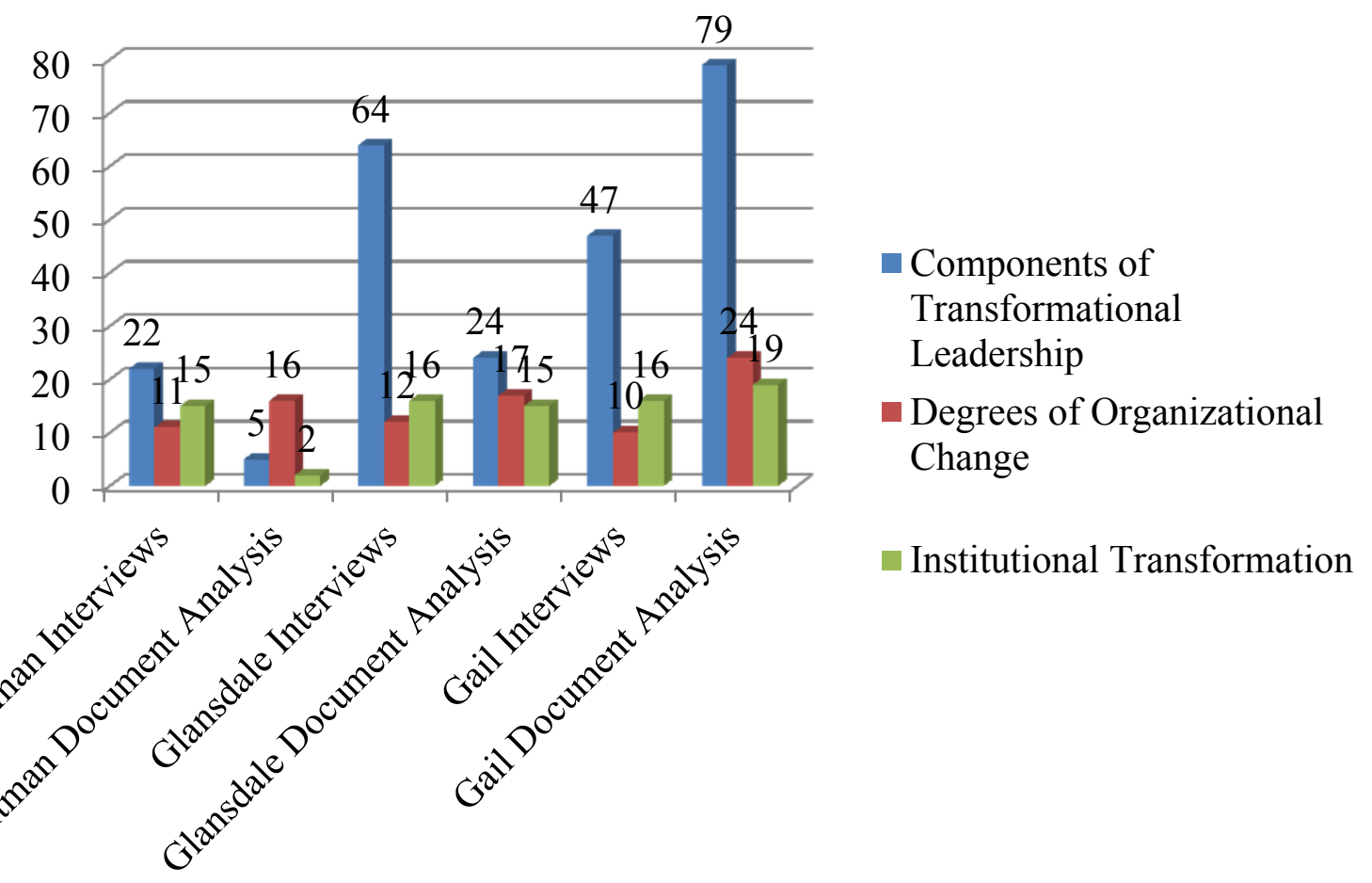

My research reveals that each president experienced organizational change, but it is questionable whether the presence of transformational leadership contributed to that change. Dr. Reitman, for example, oversaw one of the most important transformational changes in the institution's history, yet as can be seen from Figure 7, he exhibited very few transformational leadership qualities during the analysis. Both second-order and third-order change were considered transformational for the purposes of this study when considering each president's tenure at the institution. 
Figure 8 indicates each president's relationship with organizational change; no excerpts constituted third-order change, or the most transformational change possible in this study. Dr. Reitman was the highest in second-order or transformational change with fifteen excerpts dealing with primarily the institution's conversion to a university.

Figure 8

Transformational and institutional change for each president

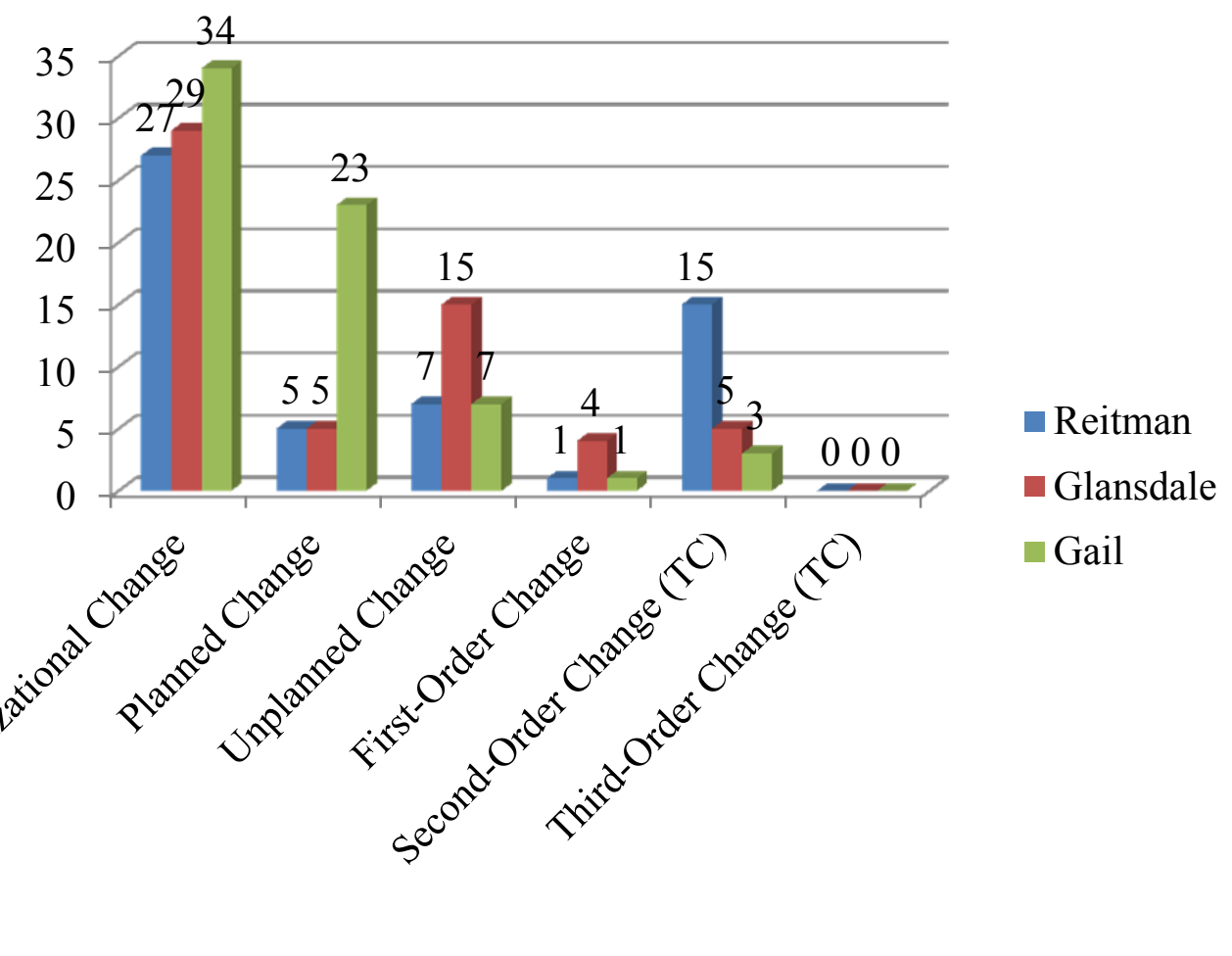

Dr. Glansdale and Dr. Gail were much lower in second-order change, with only five and three excerpts respectively. However, when compared to the presence of transformational leadership, Dr. Glansdale and Dr. Gail were the highest, with Dr. Reitman performing the lowest.

The results from my descriptive analysis indicated there was no relationship between the presence of transformational leadership and significant organizational change. In fact, 
my data analysis indicated, if anything, there was an indirect relationship between the two; when transformational leadership was present, transformational change would not be present and vice versa. However, my analysis was designed as a case study only, so more data would need to be collected to make such a claim. No evidence existed from my study to suggest that transformational leadership, if present within the presidency, would directly lead to significant, transformational change.

The Impact of Culture. The culture of the institution was also considered in my study, mainly because the literature identified culture as a potential deterrent to transformational change. I used Bergquist's (1992) four archetypes for the study, evaluating excerpts from each president and determining with which culture they best aligned. Figure 9 displays each president's descriptive analysis concerning culture.

Figure 9

Analysis of culture for each president

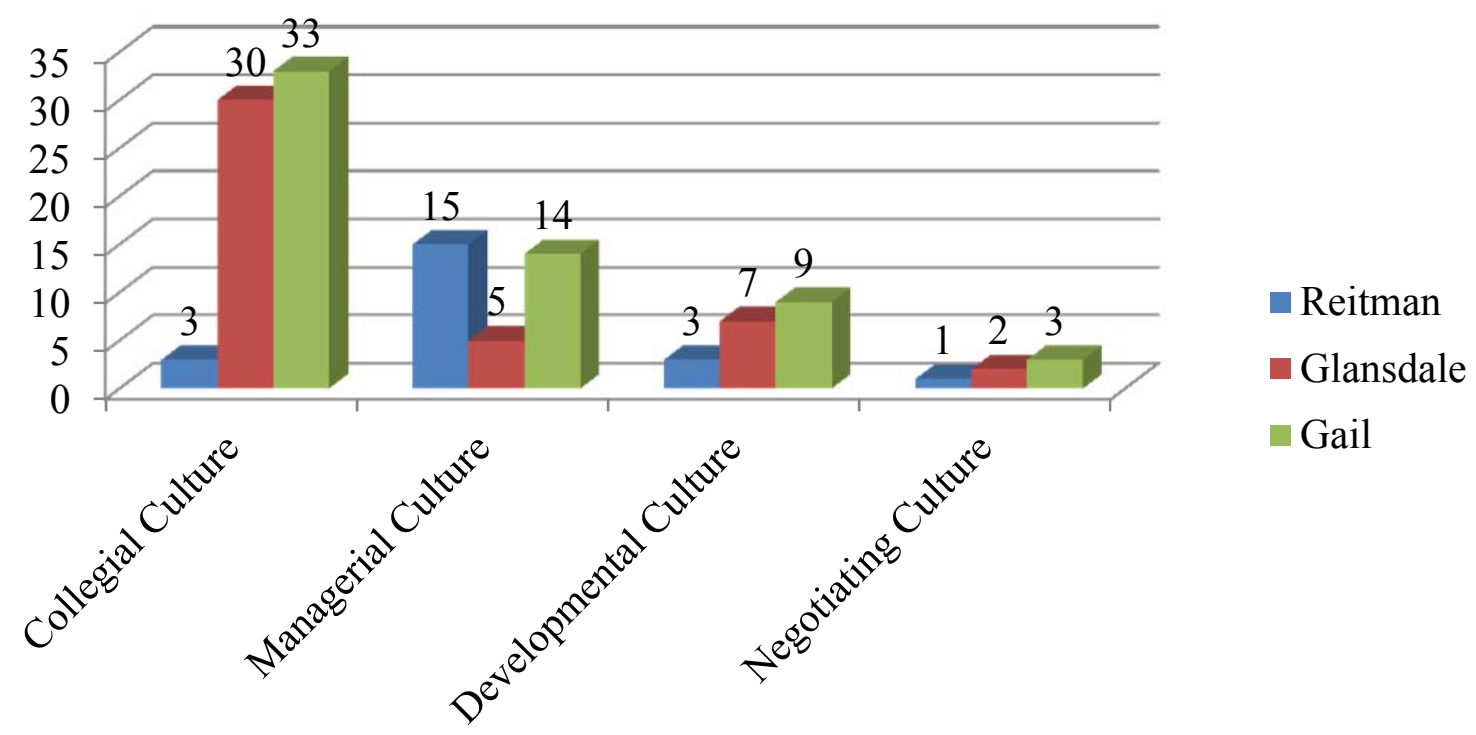

Collegial, developmental, and negotiating culture all lend themselves to qualities of transformational leadership or change. All three are most concerned with involving 
followers in decision-making, empowerment, and developing the skills and abilities of everyone within the organization (Bergquist, 1992). Managerial culture is most concerned with the development and solidification of rules and policies to govern followers and advance the mission of the institution (Bergquist, 1992). Although this type of culture is not negative, it is the most difficult with which to lead transformational change compared to the other three archetypes (Bergquist, 1992).

Dr. Glansdale and Dr. Gail, who were the highest concerning the presence of transformational leadership according to Figure 6, were overwhelmingly high in the collegial culture area, which may be the most favorable culture to enact transformational change because of the shared governance and empowerment of followers that is promoted (Bergquist, 2002). They also had the most excerpts that aligned with developmental and negotiating culture. They both seemed to promote cultures that could lead to transformational change, yet neither experienced significant second-order organizational change according to Figure 8 . The descriptive analysis of Dr. Reitman revealed a primarily managerial culture, which the literature suggests would be the most difficult culture to change during any transformational efforts (Bergquist, 1992). Nevertheless, Figure 8 indicates that Dr. Reitman experienced an overwhelming amount of second-order, or transformational, change during his presidency.

The results of my descriptive analysis indicated that, as far as Bergquist's (1992) four academies are concerned, a certain type of culture within the four culture framework is not conducive to significant organizational change over another. The literature indicated that overcoming cultural change can be the most challenging when instituting transformational change and the results of my case study did not challenge this notion. However, the idea that 
some cultures, such as a collegial culture where the president empowers faculty experts to help lead and make decisions for the betterment of the institution in its entirety, are more conducive to transformational change was dispelled by my results. The overwhelmingly high amount of managerial culture elements for Dr. Reitman could again be a result of the poor document analysis I had to perform on his presidency because of the lack of documents at the institution concerning his presidency.

Storytelling. According to Gardner (2011), stories told by leaders can be one of the most powerful tools for organizational change. My literature review also indicated that stories are excellent leadership tools, but stories are also an excellent method for collecting and analyzing qualitative data. Figure 4 indicates the number of stories shared by each of the presidents. Dr. Glansdale and Dr. Gail shared the most stories and had the most stories shared about them when I interviewed faculty members. Dr. Reitman, on the other hand, had the least amount of involvement with storytelling. Since the majority of the stories from my analysis were told during the interviews, the lack of documents available for the analysis of Dr. Reitman should not have been a factor in these descriptive analysis results.

All three presidents were accomplished storytellers, and listening to them was the most rewarding aspect of my data collection. Each president had his/her own zest for narrative, but each had a wonderful way of drawing me in as a listener, and then relating the story to the topic at hand. The literature suggested that storytelling is a remarkable tool for leaders, especially those who aspire to be transformational, but there is certainly no requirement for leaders to be excellent storytellers (Hackman \& Johnson, 2009). As a result, the number of stories told by each president did not suggest that one president is a better leader than the other. However, I do think the more stories that were shared during the 
interviews, both by the president and those stories shared about the presidents by faculty members, allowed me to better identify elements of transformational leadership, organizational change, or culture during the data analysis. So those presidents who told fewer stories, or had fewer told about them, typically fared worse in the identification of transformational leadership and organizational change excerpts. The descriptive analysis of Dr. Reitman may have fallen victim to this scenario, as he clearly oversaw significant organizational change, yet very few transformational leadership components were identified and he experienced the fewest number of stories during the interviews.

Although I used storytelling and narrative as a method of data collection, my study did little to evaluate the use of story as a leadership tool. All three presidents were very comfortable with the use of story, but my descriptive analysis was unable to discern whether or not story was a commonly used leadership tool by them during their presidencies. Based upon the number of stories told by Dr. Glansdale and Dr. Gail, and their comfort level with telling them, I would argue that storytelling is a natural part of their leadership. Even Dr. Reitman, who told significantly fewer stories than his peers, still had nearly thirty excerpts related to stories he personally told or involved stories told by faculty members. Based upon these results, I argued that story and narrative came naturally to these three presidents, meaning they shared stories in both their personal and professional lives as leaders.

\section{Discussion of Descriptive Findings, Major Themes, and Methodological Issues}

As I reviewed my findings, the phenomenon of transformational leadership and organizational change became more apparent. I chose to focus my discussion specifically on the phenomenon of transformational leadership and organizational change. This discussion will be organized into the three following sections, (1) transformational leadership and 
organizational change, (2) implications for the institution as a result of the study, and (3) suggestions for future research. I will discuss both my findings from the descriptive analysis and further elaborate on the qualitative themes I identified in the previous chapter.

Transformational Leadership and Organizational Change. My case study findings indicated that there is no direct relationship between transformational leadership and organizational change. A significant number of components of transformational leadership were found within all three presidencies that were examined in my descriptive analysis. However, the presence of transformational leadership did not result in organizational change. Dr. Glansdale and Dr. Gail were highest in the presence of transformational leadership, but had minimal elements of second-order change and no indicators of third-order change, both of which were transformational. Dr. Reitman, on the other hand, experienced significant second-order change, but had very few examples of transformational leadership during the rest of the analysis. If anything, my findings suggested there is an inverse relationship between transformational leadership and organizational change, if any direct relationship exists at all.

I was not surprised by the findings of this qualitative case study. I had suspected that determining a relationship between transformational leadership and organizational change would be difficult, if even possible at all. I had expected to find components of transformational leadership present within the presidency, but not to the degree that I discovered in the findings. For example, the number of excerpts which aligned with Idealized Influence (II) component was enlightening, yet this type of behavior, serving as a role model for the institution, should be typical behavior for the president of a higher 
education institution. My case study affirmed much of the information present in the review of literature.

Although the interviews were conducted evenly amongst the presidents, the document analysis, unfortunately, impacted the findings of the analysis. Very few documents were present at the institution concerning Dr. Reitman, and although I was able to find a significant amount for Dr. Glansdale, I was not as successful as I had intended before I began the study. I had an overwhelming number of documents for Dr. Gail, the current president of the institution, and this undoubtedly impacted my analysis. For example, Dr. Reitman may have had more excerpts worthy of transformational leadership criteria if my document analysis on him was more complete. Had this happened, the analysis of Dr. Reitman could have suggested that transformational leadership could indeed lead to organizational change. Instead, the analysis suggested an opposite, inverse relationship. My review of literature includes the value of knowledge management because I recognized before this study began that my analysis would only be as strong as the documents I was able to analyze. I was deeply disappointed with the amount of institutional knowledge that is being preserved, especially within the office of the presidency. Dr. Gail acknowledged this problem and intends, I think, to better preserve the knowledge of the presidency at the institution.

The lack of documents I discovered concerning Dr. Reitman, who served in the presidency over twenty years ago, is probably not a research obstacle exclusive only to the institution in my study. Other studies performed at comparable institutions may experience the same lack of documents, especially with the progression of technology and the rise of digital formats of communication such as email and social media. When examining a presidency that is twenty-five years old, any researcher at any institution would be faced with 
a daunting task to find a few, if any documents exclusive to that particular administration. Although the lack of documentation concerning the administrations of Dr. Reitman and to some degree that of Dr. Glansdale's presidency was disconcerting, this situation is not unique to the institution examined in my study. Researchers should keep this potential challenge in mind when examining presidencies, especially those administrations from twenty or thirty years ago.

The use of video during my analysis was able to help me identify the humanistic side of these leaders. I had hoped that through video and the collection of stories, I would be able to present a more personal and intimate portrayal of the university presidents. I feel that my qualitative analysis achieved this goal; these leaders were cast in a more personal, intimate light, bringing to the forefront their personal interests, their hobbies, and ultimately presenting a humbling portrayal of their dedication to the cause of the institution. The human element, or the element that makes each person characteristically unique, also influences leaders (Gardner, 2011). This element of leadership is often forgotten and has been frequently omitted from the literature (Gardner, 2011). By examining the human element in these presidents, in conjunction with a qualitative descriptive study, I hoped to contribute to the body of leadership knowledge in academia.

In addition to identifying the human element of presidential leadership, the qualitative themes I identified alluded to a culture of "collective leadership" among these three different administrations as opposed to individual agendas and individual goals (Burns, 2003). The collective element to their leadership can speak volumes when trying to understand which types of leadership are most effective in the presidency. As I have already discussed, many of the major events and changes mentioned by the presidents and celebrated in the document 
analysis were efforts that went across presidential administrations, and arguably could not have been accomplished by any one president alone. The overwhelming political element to presidential leadership at the institution, another human element, was identified and discussed, calling into question the true role of the university president. These major analytical themes, which will be discussed in greater detail in the following section, call into question the value of transformational leadership within the presidency and what ultimately contributes to organizational change.

Implications. The findings from both my descriptive and thematic analysis suggest huge implications for the presidency at small public institutions such as the one in my case study. My descriptive analysis suggests that current and future presidents need not adhere or strive to practice the four components of transformational leadership to invoke significant organizational change. My study suggests that presidents within higher education, especially at small, four-year universities, do not have the sole power to invoke change. At best, they need the involvement of others within the institution, and even then they may not have enough influence to change the culture (Bass \& Riggio, 2006). Dr. Reitman undoubtedly engaged in significant organizational change, but practiced very little transformational leadership in doing so. This change may also have been a result of the larger, national trend to make small colleges into universities that Dr. Parker referenced in his interview.

The qualitative themes I identified in my thematic analysis suggest much more revolutionary implications for the presidency of a small public institution. A quick glance at the literature reveals the overwhelming number of books, articles, and training programs that emphasize learning leadership that can be transformational for organizations, including institutions of higher education. Yet, my descriptive analysis findings question the 
effectiveness of transformational leadership. These presidents practiced what Burns (2003) dubbed "collective leadership," and many if not all major initiatives accomplished by these three presidents were already begun by his/her predecessor, so the logical response by the incoming president was to simply continue the effort in most cases. Furthermore, my descriptive analysis identified the conversion of the institution to a university as the most significant organizational change, yet this transition was the logical next step in the evolution of the institution; all three faculty members who participated in this study argued the institution would have become a university over time anyway, even without the efforts of Dr. Reitman in the 1980s.

Regardless of my findings, the reality of presidential leadership is just what Bess and Dee (2008) have already argued: no one single individual within higher education has the ability to control everything. Presidents may not have the ability to solely make change within their position, but they can certainly influence change. Many of the descriptive elements of my findings and the themes I identified clearly portray a presidency position with great abilities to influence. There may not be an absolute and unequivocal relationship between transformational leadership and organizational change within the presidency, or within any leadership position for that matter. With that being said, this realization hints toward a larger, more chaotic world within higher education where multiple forces are at play, both within the confines of academia and outside it, ultimately impacting change and influencing how presidents are leading their institutions. The phenomenon of transformational leadership and organizational change within the presidency is certainly more complicated than I originally suggested at the beginning of this study. 
For example, significant change within higher education, especially by the way of university rankings, is hard for presidents to invoke within the current system. According to Breault and Callejo Perez (2012), those institutions which are already considered prestigious, such as Harvard, have significant financial advantages and large endowments which solidify their prestigious ranking. Presidents of these prestigious institutions are paid handsome bonuses to maintain that prestigious ranking, yet the top spots are all but guaranteed because lower-ranking schools lack the resources to challenge their current spots (Breault \& Callejo Perez, 2012). In this case, these presidents are being compensated not to invoke significant change, but to maintain the status quo and to the keep the university in its current standing. Although many have acknowledged the value of such a climb in rankings, that ascent is not a clear indicator of effective leadership (Breault \& Callejo Perez, 2012).

Is it possible that we are too caught up in the value of effective presidential leadership, especially when that leadership is only centered in one individual at the top of the institution who, as Bess and Dee (2008) have already argued, has very little ability to make sweeping changes? In addition, should we necessarily assume that a lot of change is needed from the presidency in the first place, especially when a system of shared governance is already in place within higher education? We, as a society and as an academic discipline within higher education administration, are the group that needs to change; we need to transform our notion that presidents can be the change agents, and that transformational leadership concentrated within the presidency can be effective. This study revealed that even the presidency of a small public institution is an incredibly complex and difficult job that requires a tremendous amount of work. All three presidents in this study worked very hard 
to be effective leaders for the institution, but the interviews revealed that we are placing unrealistic expectations on these college presidents.

A poll released in April of 2013 found that only 32\% of respondents could name the current president of their alma mater (Kiley, 2013). In addition, the average term of service for university presidents had dropped from eight years in 2006 to roughly six years (Kiley, 2013). We look to the presidency to make these sweeping changes and provide direction for the institution, yet we seem to be more disengaged from the position than ever before, while presidents are staying for shorter terms and being prevented from even having the time to make significant organizational changes. The results of my study indicated, if anything, that change is most effective when started from the bottom and worked up as opposed to coming from one individual at the top and working down. Furthermore, there was very little evidence to suggest that faculty members and staff within higher education have any interest in making changes or having the president make changes for them.

My qualitative analysis revealed that these three presidents engaged in a more collective approach to leadership than executing their own individual agendas. Also, my thematic analysis brought to light the significant political role of the president, especially in affairs conducted down state. Does higher education, especially small public institutions that operate in a larger university system like the school in this study, need to continue having a traditional president as we have always defined it? Or would the position better serve the institution and constituency if it served as the political representation in the larger political framework of the state? Operational leadership of the institution could be delegated to a smaller group of managers, while all political and public responsibilities continued to be concentrated within the presidency position. In this scenario, less emphasis, pressure, and 
responsibility for transformational leadership and organizational change would be placed on the presidency, allowing for more realistic expectations of the position. The majority of presidential efforts are supposedly spent fighting the resistance to organizational change, yet how can these presidents be true leaders of change when many stakeholders in the academy may be afraid of change that can threaten their modus operandi?

Following the same line of thought, I think higher education administration academic programs across the country need to be changed to address this shift. Rather than focusing on theory and conceptualizations in isolation of data, curriculum could focus more on several theories. The theories considered should encompass learning, organizational, curriculum, and leadership theories to name a few, and they should be studied in conjunction with research being conducted on the presidency and administrative levels of higher education. We need to find a more effective way to characterize the relationship between theory, practice, and research when studying presidential leadership within higher education. Doing so could train an entirely new breed of administrators and revitalize the academic rigor of the discipline, preparing students not for the presidency, but with a tool kit that allows them to better understand the presidency and the role of administration within academia. Currently, the majority of programs are focused on training current administrators and practitioners. This behavior, however, is perpetuating the myth that presidents have the ability to invoke significant organizational change and that learning techniques like transformational leadership can actually positively impact presidential effectiveness. Instead the degree could study administration within higher education and focus more on the political landscape and legislative support function for universities, maybe even including a required internship at the institution's respective state legislature. As I alluded to in my review of literature, more 
and more presidencies are coming from outside the traditional paths to the presidency and without a background in higher education administration, so the discipline should focus more on studying the presidency than preparing students for it.

Another implication from this research was the value of video for both my descriptive and qualitative analysis, questioning traditional qualitative research practices. Although not a central tenet to my descriptive analysis, the use of video was very valuable during my research. The ability to constantly review the raw data helped me recognize stories when doing my descriptive analysis, and it was instrumental in helping humanize these presidents and separate them from the position of the presidency, and thus contributing to the knowledge and understanding of the presidency. These individuals offered much by the way of serving as president, but also had accumulated a lifetime of human knowledge and experience in their lives. Video allowed me to see them not just as presidents, but as human beings who have needs and personal convictions just like everyone else. Going into the interview, I was quick to question many decisions that each of them made during his/her tenure at the institution as leader, but I walked away with a new perspective and understanding behind each of those decisions because I was able to understand and sympathize with the human element often cloaked behind leadership jargon or models. This project, if anything, humanized a difficult, complex, and seemingly thankless job. I was able to see aspects of these presidents that the majority of the institution had never seen, or would ever see for that matter. Simple audio recordings could never have captured this enriching, revealing data. Finally, having video-recordings allowed me to discover so much more rich data during my analysis, such as the surroundings of the presidents, which never would have been captured in audio because I was so focused on the presidents during the interviews. 
Video not only allowed me to see the additional themes and trends that were going on with the presidents during the interview, but it also revealed that, during a semi-structured interview, there can be lots of data missed and not captured for the analysis. Video has layers and layers of data embedded, which can be easily missed during the actual interview. As I mentioned several times in my analysis, I initially reviewed each video four times and thought I had discovered every last bit of data relevant to my study. However, when my advisor reviewed the videos, he discovered several relevant themes, such as the value of background props and scenes for revealing more about the president in the interview, which I had missed during my comprehensive analysis. We are convinced that with continued analysis and the involvement of several reviewers, even more data could be extrapolated from these video interviews, which may not be the case with only audio. Video was a tool that both enhanced data capture, but also helped me to realize my inability, as a researcher, to capture everything during the actual interview itself.

Video was not only helpful in humanizing the presidents for my research purposes, but conversely it was also a trigger that allowed me to separate them from the de-humanizing element of transformational leadership. Freire (1970) argues that we tend to oppress students in the discipline of education, making them accept mainstream theories and notions as opposed to more individualized and personal beliefs. Peck (1978) argues that humans, by nature, tend to think of complex issues in a simplistic fashion. I think, in many ways, these two researchers address the conundrum of transformational leadership in the presidency and the value of video: video allowed me to humanize the presidents and separate them from the de-humanizing constructs of transformational leadership. Through video, I saw the presidents as human, fallible people simply trying to live up to unrealistic expectations of the 
position and trying to please every constituency. Video revealed the humanity behind presidential leadership, adding another dimension of knowledge needed to fully understanding transformational leadership and organizational change within the presidency.

Through Peck's (1978) model, which argues that we reject "simplistic" thinking in everything we seek to understand, I was able to separate the presidents from the dehumanizing element, and ultimately embrace the complexity and difficulty of the presidential position and to realize they alone cannot invoke significant change (p. 224). Application of Freire's (1970) thinking helped me realize that presidents alone should not shoulder the complexity and weight of the institution, and that it should be shared amongst the faculty and shared governance models already in place in higher education. "The oppressed," according to Freire (1970), have "internalized the image of oppressor and adopted his guidelines" and are thus "fearful of freedom" (p. 47). When applied to leadership studies, Freire's (1970) and Peck's (1978) models suggested that we should embrace the complexity of the presidential position, seeking to understand that one person at the top of the higher education hierarchy only has the ability to influence change, not invoke it. Again, the mainstream higher education constituency needs to change how we view the presidency while also acknowledging that we all have a responsibility in invoking change. Another implication of my research is to consider the use of video in other qualitative capacities, which will be discussed in the next section.

I also found video appealing because it inherently appeals to multiple human senses. Even though video appeals primarily to the visual sense, it also can help trigger memories of smell or touch sensed during the interview. Audio, on the other hand, only appeals to the sense of hearing with the rest lost for analysis. I would have found it more difficult to 
immerse myself in the data and the experience of the interview with only audio, as the visual triggers that led to many of my recollections would not have been present. Finally, visual manifestations, including video, seemed to be very important to the presidents in the study. Dr. Reitman sat with me after the interview and insisted that we watch two videos featuring him as president, while Dr. Gail encouraged me to view some of his convocation addresses and other videos posted on the internet. If visual representations are important to the presidents, the very individuals that were the focus of my study, I would think that visual representations of their administrations should be important to me as well.

The additional data I was able to extract during my study because of video raises a methodological issue concerning qualitative research: video transcends the personal contribution it gave to me personally during this study and is likely to benefit other researchers and other future studies. My research illuminated how powerful video can be as a qualitative tool. The use of video should be considered as a suitable replacement for strictly audio data collection, as video has the potential to reveal so much more about the interviewee while allowing the researcher to constantly be re-immersed in the experience. With confidentiality measures in place, video can be no less intrusive than audio data collection, yet yield so much more raw data for any study. In addition, newly-developed technologies allow for easy analysis of raw video footage, making ideas and themes more easily identifiable during the data analysis process. I feel confident that other qualitative researchers, no matter the topic of his/her study, would find greater value in the use of video as their primary method of data collection as opposed to strictly audio. As computer and video technology continue to advance, I can foresee a world of qualitative research that may 
someday replace audio-recording with video-recording as the primary method of data collection.

The literature indicated that culture was the most daunting challenge to executing transformational change (Bass \& Riggio, 2006). As a result, I attempted to consider its impact on organizational change at the institution. The descriptive analysis findings of my study suggested that no one of Bergquist's (1992) archetypes is more conducive to transformational change than another. In addition, my descriptive analysis findings affirmed that culture is still a formidable barrier to change, and I argue that current and future presidents should strive to understand their culture as best as possible to lead effectively.

My qualitative analysis, on the other hand, called into question my descriptive findings concerning significant organizational change. Although I was able to identify specific examples of second-order change, which I considered as transformational for the purposes of this study, I question whether these incidents were really examples of change. Have these presidents really changed the culture of the institution, or the surrounding community for that matter? Or has the university been maintaining the status quo, or a reasonably expected rate of slow evolution, for the last three decades, simply responding to external pressures for change when best applicable? When considering organizational change through this lens, the conversion of the institution to a regional university does not look that transformational; the institution was simply responding to a larger, national trend that was sweeping the country in the 1980s. Furthermore, Dr. Reitman may have been selected for the presidency by the political infrastructure of the state because he was already responsible for transitioning another small institution into a university in Pennsylvania earlier in his career. Nevertheless, the qualitative themes I identified in this study called into 
question the presence of significant organizational change at the institution as well as the value of transformational leadership within the presidency.

Knowledge management was another theme that I considered going into the study and, after the analysis, found it valuable to understand within the context of the study. The lack of documents for Dr. Reitman, and to some degree for Dr. Glansdale, really hampered my ability to perform an equitable and conclusive descriptive analysis. Current and future presidents need to strive to preserve their institutional knowledge. Before Peter Drucker (1994) developed the concept of the knowledge society, institutions of higher learning "served as exemplars of organizations for which the primary commodity being exchanged was simply knowledge" (Boston et al., 2013). As information and technology continue to change the national and world economy, universities need to re-position themselves as the leaders of knowledge capital to stay competitive and valuable in producing tomorrow's skilled work force (Stewart, 1999; Drucker, 1993). In addition, preserving and understanding an institution's knowledge base and culture will allow the next leader to better engage in transformational change should it be needed (Bass \& Riggio, 2006).

Although qualitative research depends upon necessary individual deduction on the part of the researcher, more data is never disadvantageous. What qualitative researchers need, especially concerning the phenomenon of educational leadership, is more explicit historical records that can inform the literature. We need to more fully convert tacit knowledge of leadership, especially within the presidency, to explicit knowledge (Nonaka \& Takeuchi, 1995). If we want to continue promoting the value of qualitative research when considering presidential leadership, we need to advocate for sufficient collection of qualitative data. Knowledge management may be more often associated with qualitative 
research in the future and is a mechanism we should study further. Doing theoretical leadership research in the future could be balanced with real-world stories and rich histories within this context.

The possibilities for knowledge management within the realm of leadership are limitless, especially with today's technology and ability to gather and store data. For example, the rise of social media in recent years, as well as email and other forms of online communication presented researchers with data that was inaccessible even a decade ago (S. Diaz, personal communication, April 19, 2013). This new data can reveal social behaviors, patterns, and other elements ripe for social science research. In terms of my study, presidents of the future will stay connected with their constituency through these new mediums; Dr. Gail is extremely proficient in the use of social and new media, conversing regularly with his students and staff in online forums and through email. In order to effectively study the presidential position, these new mediums should be embraced (Diaz, 2013).

From a qualitative perspective, I was able to identify significant themes through story and video that could contribute to the knowledge management of the institution. This knowledge could be better utilized if a knowledge conversion system were developed allowing the tacit, un-codified information, usually consisting of rumors and conjecture that is circulating about presidents and their initiatives for example, to become explicit knowledge that can be utilized by the organization or preserved as institutional knowledge (Nonaka \& Takeuchi, 1995). Video can also serve as a valuable tool for gathering this information. Nevertheless, there is value for institutions to engage in knowledge management and better preserve their institutional knowledge. My study clearly 
demonstrated the incomplete analysis that could result when institutional knowledge is not being preserved.

According to the literature, men and women lead with distinctly different techniques and philosophies (Bass \& Riggio, 2006; Boyce \& Herd, 2003). The findings of my descriptive analysis suggested that Dr. Glansdale led with her own distinct technique of consensus-building and collegial empowerment, but her leadership was not that different from that of Dr. Gail's style. The findings of my study did not support the literature that women tend to lead differently than men, nor did my findings disprove any claims about female leadership in the literature. The small sample size, coupled with only one woman participating in a group of three presidents, meant that nothing conclusive could be deduced from my study concerning gender within the presidency. I make recommendations for future research concerning this arena in the next section.

Storytelling served as an excellent method for collecting both descriptive and qualitative data and assessing a university president's leadership (Gardner, 2011; Webster \& Mertova, 2007; Clandinin \& Connelly, 2000). In addition, presidents who are effective storytellers, and who use storytelling as a leadership tool, may be more influential and able to more easily invoke transformational change (Denning, 2011; Guber, 2011; Hackman \& Johnson, 2009; Armstrong, 1992). Creating a culture that celebrates storytelling is an easier way to preserve institutional knowledge (Stewart, 1999). Both the descriptive and analytical findings of my study indicated that storytelling should continue to be used as a qualitative research measure, while university presidents should also hone their storytelling skills and embrace story within their respective cultures. 
Suggestions for Future Research. This study has provided important insights about the phenomenon of transformational leadership and organizational change, as well as gender within the presidency, the value of knowledge management, and the value of story. After completing this project, many new questions have arisen as others were answered. The following section includes suggestions for several courses of inquiry for future research. These suggestions, if completed, would either improve the information collected in this study or lead to a wholly different case study that would generate new findings on this phenomenon.

This study of the phenomenon of transformational leadership and organizational change could be improved if senior administrators and others who reported directly to the presidents were interviewed either in place of the faculty members or in addition to them. The senior administrators were closer to the operations and daily leadership of the presidents and would have much more to offer and would be better able to verify stories and facts shared by the presidents (R. Riggio, interview, March 8, 2013). Adding senior administrators to the study would result in more accurate and revealing data about presidential leadership and organizational change. Not only would they be better equipped to verify stories told by the presidents, but they too could offer insights about knowledge management and events that lead to organizational change.

In order to better understand the phenomenon in its entirety, a more formal mixed methods approach to understanding transformational leadership and organizational change should be undertaken (Bass \& Riggio, 2006). In addition to the interviews, presidents could be asked to take the MLQ and compare the quantitative scores to the qualitative findings (Bass \& Riggio, 2006). The qualitative analysis could also employ a code weighting system 
that would gauge how significant each qualitative excerpt is to the themes of the study. The analysis of story could go beyond simply identifying and quantifying the narratives. This could be done by examining the types and elements of stories used most frequently by the participants and considering if any trends help explain the phenomenon. Finally, the next study could include one additional level of data-checking: the researcher could train one or two other coders to work with the data, and then compare which excerpts each highlighted before completing the analysis to affirm data relevance to each code (R. Riggio, interview, March 8, 2013). Doing so would strengthen the data and add an extra level of analysis.

My study was significantly hampered by the lack of documents available for certain presidential participants. I completed a wide swath for documents and included anything with which I was able to gain access. As I mention through the previous chapter, this created a significant disadvantage during the analysis for those presidents whom I was unable to generate an equitable and relevant number of documents. Both the descriptive and thematic analysis of Dr. Reitman and Dr. Glansdale was significantly hampered by this challenge. Another study could be more effective if the document analysis only focused on a prescribed number or certain types of documents, leveling the field and making the analysis more equitable.

Looking at this problem broadly, we may be experiencing a change in document analysis as well. Now, emails have replaced the paper-bound memorandum of the Dr. Reitman and beginning of Dr. Glansdale administrations. Without realizing it, we are warehousing an expansive repository of narrative data that can be used to inform current and future qualitative researchers. A study similar to this one conducted ten or even twenty years from now would rely on this digital information, as less and less operational and strategic 
planning materials are housed in printed form. We need to work together to do larger-scale computational analyses, harnessing the richness of this new narrative data format.

The video gathered during this study was very helpful in analyzing and identifying themes, and especially helpful in the identification of stories. The study could be expanded to include video-recording of other participants beyond the presidency. Nevertheless, we, as researchers, need to determine how we find the balance between taking advantage of the rich data video-recording can collect and protecting the privacy of the interviewees. I feel video helped to unlock significant themes in this study which would have gone unnoticed with only audio. Future research needs to be done considering the development of ethical guidelines that allow video data to be captured in an ethical manner, to chronicle stories for example, but still respectful of the participants and traditional qualitative research techniques.

In addition, since completing this study, I have learned of numerous qualitative video researching tools that could have enhanced my analysis. Dedoose, the qualitative web application I used to analyze and code data for this study, began offering qualitative video data analysis capabilities this past spring. A similar case study presented exclusively in video format, or based entirely on elements deduced from the video, could be an incredibly effective study. Other powerful video tools will undoubtedly be developed for research purposes in the future. Since knowledge management has become such a popular topic in the private and public sectors, video can serve as an excellent way to document, preserve, and analyze institutional knowledge or create video biographies.

I initially sought to explore the phenomenon of gender in presidential leadership at the beginning of this study. However, after executing the study and beginning my descriptive analysis, I soon realized that my methodology and research design was not 
conducive to examining the gender phenomenon. As a result, I recommend conducting a similar study focusing exclusively on determining if gender is a factor in leadership. Since my findings have called into question the value of the presidency, this proposed research could focus on other administrative positions within higher education. According to the literature, gender continues to be a topic within the leadership discipline that warrants additional studies, especially as more and more women are entering leadership roles within higher education.

Finally, I mentioned earlier that the basis behind this study of transformational leadership and organizational change is that presidents are expected to invoke change. Additional research in this area should explore if faculty members are actually seeking change in the first place, or if they do seek change, then should it even come from the presidency. This study could also consider the impacts of shared governance structures on presidential leadership, as well as identifying whether faculty members or the president have been behind the most significant events of organizational change in the institution's history. Staff outside of the institutional faculty could also be included, and video-recording the interviews would help the researcher identify major themes which could be relevant to both a descriptive and a thematic analysis.

\section{Postscript}

My attempt to understand the phenomenon of transformational leadership and organizational change within the presidency at an institution with which I have been affiliated for nearly a decade of my professional life was very exciting, yet also caused me great angst. As the researcher, it was difficult for me to ask questions concerning controversial events at the institution while also trying to develop a rapport with each 
president. As I began this study, I felt my strong background and knowledge of the institution would be an advantage to the study. I had developed significant contacts across the campus and was already aware of the resources I could access to get information for the analysis. However, as I interviewed each president and learned everything about his/her administration, I developed a personal relationship with each of them and ultimately respected what he/she had done for the institution. In addition, I aspire to work at the institution sometime in the future, so I had a vested interest in being honest and forthright in my findings, but was cautious of what I wrote in the study findings.

Regardless of my personal experience with the institution beforehand, I believe my background and understanding of the institution enhanced my role as researcher in this study. I believe the presidents automatically connected with me because I was a student from the institution and a resident of the immediate area. Had I been an outsider, someone who had not attended the institution or still lived in the immediate area, connecting with the presidents may have been more difficult, and some presidents may not have agreed to participate at all. My connection with the institution was ambiguous; it garnered me access to the presidents, but it also influenced my research and ultimately the findings of my study. Any additional case studies or research following the format of my study should consider this challenge.

Reflecting back, I also believe my role as researcher and instrument in this project affected me personally. I became much closer to the participants in this study than I had expected. I ended up spending time with them, particularly the presidents, outside of the formal interview time. We shared stories about the institution, went through their personal collections of photos and memories while they were president, and I even shared meals with some of them. I had never expected to become so connected with these individuals when I 
proposed this study. However, the relationships I developed with these individuals were critical in identifying the human element behind leadership, while also allowing me to separate the de-humanizing element of leadership from each of them. Although I initially viewed these relationships as a challenge to objective and accurate reporting of my findings in this study, I ultimately believe it only enhanced my research in the end.

The video-recordings of the presidents allowed me, throughout the investigative process, to stay mindful of the mannerisms, behaviors, and small nuances of each president. The first interview was with Dr. Reitman, and I overcame much of my anxiety and awkwardness toward the interview process as we chatted in his home. As I listened to his stories about the institution, I began to reflect on the place it had become and how much it had grown since he took the helm in the 1980s. Over the next month, the interviews became more comfortable as I realized that my role as researcher, former student, and native of the community, contributed positively to the data collection process. In addition, I had primarily completed the document analysis as I was finishing up the last of the presidential interviews, so by that time had begun to realize the gross inadequacies in the institution's history being housed at the library. I felt, in some ways, my study had become a crusade to preserve the valuable institutional knowledge that would continue to make this institution the learning center of the region (Stewart, 1999). As Constantine Cavafy noted in his celebrated twentieth-century poem Ithaca, sometimes the journey is just as important, if not more so, than the outcome. In reflecting upon my research and analysis, I feel the journey was just as important as the outcome of this study.

In addition to serving as an institutional leadership guide for the school I studied, this study was very revealing about leadership and organizational change from a descriptive 
perspective, but even more perplexing from an analytical perspective. I purposely focused exclusively on descriptive and analytical data for this study; I wanted to see leadership from the human perspective without the quantitative jargon that can become cumbersome and impersonal. In doing so, I hope the findings from this study will be an easier read for some and serve as an attractive model for understanding leadership at small public, four-year institutions. Nevertheless, like any research study, more questions have been raised from my findings. Completing a similar study on another small institution and adding a mixed method approach could be even more revealing about presidential leadership and organizational change within this context. The findings from my study represent a somewhat clearer picture of leadership and change at the institution, but can easily serve as the launching pad for additional studies that hope to learn more on this subject.

The study of leadership has grown into a discipline in and of itself over the past few decades, but "the increase in knowledge - and in wisdom - about leadership is not nearly so striking" (Gardener, 2011, p. xvi). My study was an effort to increase that knowledge base by providing a descriptive, analytical, and humanistic angle to presidential leadership and its relationship to organizational change. In addition, I used story and narrative inquiry as one of my central tenets of data collection. Story, in my opinion, best represented and portrayed the human experience these leaders endured while serving at the helm of the institution. In addition to the information conveyed in these narratives, the stories told by these presidents revealed their characters, personal beliefs, values, and ability to connect with their followers. Furthermore, the stories offered a chance to capture valuable institutional knowledge that may not be recorded anywhere else in the institution. 
The study of leadership will continue to dominate political science, business, and psychology classes alike for decades to come. The world is so hungry for strong effective leadership coinciding with fluid organizational change that the discipline will continue to become big business in higher education institutions around the world (Gardner, 2011). As this desire grows, new and unique ways to measure transformational leadership and its effectiveness beyond assessments like the MLQ and other quantitative measures will continue to be developed. I feel confident some of these measures will consider a qualitative approach, focusing on the stories and narratives being told not just by the presidents of institutions, but also by what stories are being shared among followers and their constituents. I look forward to what the future brings concerning the understanding of presidential leadership and organizational change, and more importantly how both elements operate within the confines of higher education, and the use of story in that understanding. 


\section{References}

Altbach, P. G., Gumport, P. J., \& Berdahl, R. O. (Eds.). (2011). American higher education in the $21^{\text {st }}$ Century: Social, political, and economic challenges. Baltimore, MD: Johns Hopkins University Press.

Armstrong, D. (1992). Managing by storying around: A new method of leadership. New York: Doubleday Currency.

Avolio, B. J., Bass, B., M., \& Jung, D. I. (1997). Replicated confirmatory factor analyses of the Multifactor Leadership Questionnaire. Binghamton, NY: Center for Leadership Studies, Binghamton University.

Ayman, R., Adams, S., Fisher, B., \& Hartman, E. (2003). Leadership development in higher educationa insitutions: A present and future perspective. In S. E. Murphy \& R. E. Riggio (Eds.), The future of leadership development (pp. 201-222). Mahweh, NJ: Lawrence Erlbaum Associates.

Bartunek, J. M., \& Moch, M. K. (1994). Third-order Organizational Change and the Western Mystical Tradition. Journal of Organizational Change Management, 7(1), 24.

Bass, B. M. (1985). Leadership and performance beyond expectations. New York, NY: The Free Press.

Bass, B. M. (1990). Bass \& Stogdill's handbook of leadership: Theory, research, and managerial applications ( $3^{\text {rd }}$ ed.). New York, NY: The Free Press.

Bass, B. M. (1992). VMI's high contrast culture: A setting for the development of civilian and military leaders (Tech. Rep. No. 1). Binghamton, NY: Center for Leadership Studies, Binghamton University. 
Bass, B. M. (1997). Does the transactional/transformational leadership paradigm transcend organizational and national boundaries? American Psycholgist, 52(130-139).

Bass, B. M. (1998). Transformational leadership: Industrial, military, and educational impact. Mahwah, NJ: Lawrence Erlbaum Associates, Publishers.

Bass, B. M. (1999). Two decades of research and development in transformational leadership. European Journal of Work and Organizational Psychology, 8(9-32).

Bass, B. M. \& Riggio, R. E. (2006). Transformational leadership ( $2^{\text {nd }}$ Ed.). New York, NY: Psychology Press, Taylor \& Francis Group.

Bass, B. M. \& Bass, R. (2008). The Bass handbook of leadership: Theory, research, and managerial applications ( $4^{\text {th }}$ ed.). New York, NY: The Free Press.

Bergquist, W. H. (1992). The four cultures of the academy: Insights and strategies for improving leadership in collegiate organizations. San Francisco, CA: Jossey-Bass.

Bess, J. L., \& Dee, J. R. (2008). Understanding college and university organization: Theories for effective policy and practice. Sterling: Stylus Publishing, LLC.

Bettelheim, B. (1989). The uses of enchantment: The meaning and importance of fairy tales. New York: Random House, Inc.

Birnbaum, R. (1992). How academic leadership works: Understanding success and failure in the college presidency. San Francisco: Jossey-Bass Publishers.

Bogdan, R., \& Biklen, S. (2007). Qualitative research for education: An introduction to theories and methods ( $5^{\text {th }}$ Ed.). Boston, MA: Pearson.

Bolman, L. G., \& Gallos, J. V. (2011). Reframing academic leadership. San Francisco: Jossey-Bass. 
Bolman, L. G., \& Deal, T. E. (2008). Reframing organizations: Artistry, choice, and leadership ( $4^{\text {th }}$ ed.). San Francisco, CA: Jossey-Bass.

Boston, W., Ice, P., Díaz, S. R., \& Layne, M. (In Press). The use of knowledge management for quality assurance in education. In Shattuck, K. (Ed.), Quality Assurance in Online Distance Education: Improving Practice at the Program, Teaching and Resource Levels. Stylus Publishing.

Boubsil, O., Carabajal, K., \& Vidal, M. (2011). Implications of Globalization for Distance Education in the United States. American Journal Of Distance Education, 25(1), 520. doi:10.1080/08923647.2011.544604

Boyce, L. A., \& Herd, A. M. (2003). The relationship between gender role stereotypes and requisite military leadership characteristics. Sex Roles, 29, 365-378.

Breault, D. A., \& Callejo Perez, D. M. (2012). The red light in the ivory tower: Contexts and implications of entrepreneurial education. New York, NY: Peter Lang Publishing, Inc.

Bruininks, R. H., Keeney, B., \& Thorp, J. (2010). Transforming America's Universities to Compete in the "New Normal". Innovative Higher Education, 35(2), 113-125. doi:10.1007/s10755-009-9135-y

Burke, W. W. (2002). Organization change: Theory and practice. Thousand Oaks, CA: Sage Publications, Inc.

Burns, J. M. (1978). Leadership. New York, NY: Harper Perennial.

Burns, J. M. (2003). Transforming leadership: A new pursuit of happiness. New York. NY: Grove Press. 
Bycio, P., Hackett, R. D., \& Allen, J. S. (1995). Further assessment of Bass's (1985) conceptualization of transactional and transformational leadership. Journal of Applied Psychology, 80(468-478).

Cameron, K. S., \& Ulrich, D. O. (1986). Transformational leadership in colleges and universities. In J. C. Smart (Ed.), Higher education: Handbook of theory and research, Vol. 2 (pp. 1-42). New York, NY: Agathon Press.

Cohen, W. A. (2010). Drucker on leadership: New lessons from the father of modern management. San Francisco, CA: Jossey-Bass.

Cohen, M. D., \& March, J. G. (1974). Leadership and ambiguity: The American college president. New York, NY: McGraw-Hill.

Collins, J. (2001). Good to great: Why some companies make the leap...and others don't. New York, NY: HarperCollins Publishers.

Collins, R., \& Cooper, P. J. (1997). The power of story: Teaching through storytelling (2 ${ }^{\text {nd }}$ ed.). Boston: Allyn \& Bacon.

Connelly, F. M., \& Clandinin, D. J. (1990). Stories of experience and narrative inquiry. Educational Researcher, 19(5), 2-14.

Cook, S. G. (2012, May). Women presidents: Now 26.4\% but still underrepresented. Women in Higher Education, 21(5), 1-3.

Covey, S. (2004). The 7 habits of highly effective people: Powerful lessons in personal change. New York, NY: The Free Press.

Clandinin, D. J. (2007). Handbook of narrative inquiry: Mapping a methodolgy. Thousand Oaks: Sage Publications, Inc. 
Clandinin, D. J., \& Connelly, E. M., (2000). Narrative inquiry: Experience and story in qualitative research. San Francisco: Jossey-Bass Publishers.

Creswell, J. W. (2013). Qualitative inquiry and research design: Choosing among five approaches ( $3^{\text {rd }}$ ed.). Thousand Oaks, CA: Sage Publications, Inc.

Crotty, M. (1998). The foundations of social research: Meaning and perspective in the research process. Thousand Oaks, CA: Sage Publications, Inc.

Czarnecki, K. (2009). Storytelling in Context. Library Technology Reports , 45 (7), 5-8.

Deal, T, E., \& Kennedy, A. A. (1982). Corporate cultures: The rites and rituals of corporate life. Reading, MA: Addison-Wesley.

Delbanco, A. (2012). College at Risk. Chronicle Of Higher Education, 58(26), B6-B9.

Denning, S. (2001). The springboard: How storytelling ignites action in knowledge-era organizations. Boston: Butterworth Heinemann.

Denning, S. (2011). The leader's guide to storytelling. San Francisco: Jossey-Bass.

Díaz, S. R. (2013). The Data that Bind Us: Finding Our Hidden Wholeness in Education. In Callejo-Pérez, D. \& Ode, J. The Stewardship of Higher Education. Sense Publishers.

Dodds, H. W. (1962). The academic president-educator or caretaker?. New York, NY: McGraw-Hill Book Company.

Drucker, P. F. (1993). Post-capitalist society. New York, NY: HarperCollins Publishers, Inc.

Drucker, P. F. (1994). The Age of Social Transformation. The Atlantic Monthly, 274(5), 53-80.

Duderstadt, J. J. (2007) The view from the helm: Leading the American university during an era of change. Ann Arbor, MI: The University of Michigan Press. 
Eckard, S. (2009). The ties that bind: Storytelling as a teaching technique in composition classrooms and writing centers. Saarbrucken: VDM Verlag Dr. Muller.

Eckel, P. D., Hill, B., \& Green, M. (1998). En route to transformation (On Change Occasional Paper No. 1). Washington, DC: American Council on Education.

Eckel, P. D, \& Kezar, A. (2003). Taking the reins: Insitutional transformation in higher education. Westport, CT: Praeger.

Fischer, K. (2011). Crisis of confidence threatens colleges. Chronicle Of Higher Education, 57(37), A1-A4.

Foster, R. N., \& Kaplan, S. (2001). Creative destruction: Why companies that are built to last underperforma the market - and how to successfully transform them. New York, NY: Currency Press.

Friere, P. (1970). Pedagogy of the oppressed. New York, New York: Continuum International Publishing Group Ltd.

Gardner, H. (2011). Leading minds: An anatomy of leadership. New York, NY: Basic Books.

Gee, E. (2011). Colleges must find innovative ways to finance their missions. Chronicle Of Higher Education, 58(11), A37-A38.

Goodchild, L. F., \& Wechsler, H. S. (Eds.). (1997). The History of Higher Education (2 ${ }^{\text {nd }}$ ed.). Boston, MA: Pearson Custom Publishing.

Goodstein, L. D., \& Lanyon, R. I. (1999). Applications of personalty assessment to the workplace: A review. Journal of Business \& Psychology, 13(291-322).

Groves, K. S. (2005). Linking leader skills, follower attitudes, and contextual variable via an integrated model of charismatic leadership. Journal of Management, 31(255-277). 
Guber, P. (2011). Tell to win: Connect, persuade, and triumph with the hidden power of story. New York: Crown Business.

Hackman, M. Z., \& Johnson, C. E. (2009). Leadership: A communication perspective (5 ed.). Long Grove: Waveland Press, Inc.

Hardesty, D. C. (2007). Leading the public university. Morgantown, WV: West Virginia University Press.

Howell, J. M., \& Avolio, B. J. (1993). Transformational leadership, transactional leadership, locus of control, and support for innovation: Key predictors of consolidated business-unit performance. Journal of Applied Psychology, 78(891902).

Jalongo, M. R., Isenberg, J. P., \& Gerbracht, G. (1995). Teachers’stories: From personal narrative to professional insight. San Francisco: Jossey-Bass.

Kamler, H. (1983). Communication: Sharing our stories of experience. Seattle: Psychological Press.

Kezar, A. J., Carducci R., \& Contreras-McGavin, M. (2006). Rethinking the “ $L$ ” word in higher education: The revolution of research on leadership. San Francisco: Wiley Periodicals, Inc.

Kiley, K. (2013, April 12). Who’s in charge? Inside Higher Ed. Retrieved from http://www.insidehighered.com/news/2013/04/12/university-presidents-workincrease-recognizability-alumni

Kouzes, J. M., \& Posner, B. Z. (2007). The leadership challenge $\left(4^{\text {th }}\right.$ ed.). San Francisco, CA: John Wiley \& Sons, Inc. 
Lauritzen, C., \& Jaeger, M. (1997). Integrating learning through story: The narrative curriculum. Albany: Delmar Publishers.

Lawrence, F. L. (2006). Views from the presidency: Leadership in higher education. New Brunswick: Transaction Publishers.

Lieblich, A., Tuval-Mashiach, R., \& Zilber, T. (1998). Narrative research: Reading, analysis, and interpretation. Thousand Oaks: SAGE Publications, Inc.

Lyons, N., \& LaBoskey, V. K. (Eds.). (2002). Narrative inquiry in practice: Advancing the knowledge of teaching. New York: Teachers College Press.

McDrury, J., \& Alterio, M. (2002). Learning through storytelling in higher education: Using reflection \& experience to improve learning. London: Kogan Page.

McEwan, H., Egan, K. (Eds.). (1995). Narrative in teaching, learning, and research. New York, NY: Teachers College Press.

Maguire, J. (1998). The power of personal storytelling: Spinning tales to connect with others. New York, NY: Penguin Putnam, Inc.

Miller, P. J. (2009). Stories have histories: Reflections on the personal in personal storytelling. Taiwan Journal of Anthropology , 7(1), 67-84.

Myers, I. B., McCauley, M. H. (1985). Manual: A guide to the development and use of the Myers-Briggs type indicator. Palo-Alto, CA: Consulting Psychologists Press.

Neumann, A. (1991). Defining “good faculty leadership.” Thought and Action, 7(1), 45-60.

Neumann, A. (1992). Colleges under pressure: Budgeting, presidential competence, and faculty uncertainty. The Leadership Quarterly, 3(191-215).

Nohria, N., \& Khurana, R. (Eds.). (2010). Handbook of leadership theory and practice. Boston, MA: Harvard Business Press. 
Nonaka, I., \& Takeuchi, H. (1995). The knowledge-creating company: How Japanese companies create the dynamics of innovation. New York, NY: Oxford University Press.

Patton, M. Q. (2002). Qualitative Research \& Evaluation Methods (3 ${ }^{\text {rd }}$ ed.). Thousand Oaks, CA: Sage Publications.

Peck, M. S. (1978). The road less-traveled: A new psychology of love, traditional values and spiritual growth. New York, New York: Simon \& Schuster.

Perez-Pena, R. (2012, June 27). Ousted head of university is reinstated in Virginia. New York Times. p. 13.

Pierce, S. R. (2012). On being presidential: A guide for college and university leaders. San Francisco, CA: Jossey-Bass.

Pink, S. (2007). Doing visual ethnography ( $2^{\text {nd }}$ ed.). Thousand Oaks, CA: Sage Publications, Inc.

Porras, J. I., \& Silvers, R. C. (1991). Organization development and transformation. Annual Review of Psychology, 42, 51-78.

Porras, J. I., \& Robertson, P. J. (1992). Organizational development: Theory, practice and reasearch. In M. D. Dunnette \& L. M. Hough (Eds.), Handbook of industrial and organizational psychology (Vol. 3, $2^{\text {nd }}$ ed., pp. 719-822). Palo Alto, CA: Consulting Psychologists Press.

Readings, B. (1996). The university in ruins. Cambridge, MA: Harvard University Press. Roemer, M. (1995). Telling stories: Postmodernism and the invalidation of the traditional narrative. London, England: Rowman \& Littlefield Publishers, Inc. 
Rubin, H. J., \& Rubin, K. S. (2012). Qualitative interviewing ( $3^{\text {rd }}$ ed.). Los Angeles, CA: Sage Publications, Inc.

Sandelowski, M. (2000). Focus on research methods: Whatever happened to qualitative description? The Journal of Nursing Scholarship, 23(1), 334-340.

Schank, R. C. (1990). Tell me a story: Narrative and intelligence. Evanston: Northwestern University Press.

Schram, T. H. (2006). Conceptualizing and proposing qualitative research $\left(2^{\text {nd }}\right.$ ed.). Upper Saddler River River, NJ: Pearson Education, Inc.

Schwandt, T. A. (2007). The SAGE dictionary of qualitative inquiry. Thousand Oaks, CA: Sage Publications, Inc.

Simons, H. (1996). The paradox of case study. Cambridge Journal of Education, 26(2), $225-240$.

Stake, R. (1995). The art of case study research. Thousand Oaks, CA: Sage Publications, Inc.

Stewart, Thomas A. (1999). Intellectual capital: The new wealth of organizations. New York, NY: Bantam Doubleday Dell Publishing Group, Inc.

Stripling, J., \& Medina, B. (2011). The graying presidency. Chronicle Of Higher Education, 58(6), A1-A10.

Tierney, W. G. (1991). Advancing democracy: A critical interpretation of leadership. Peabody Journal of Education, 66(3), 157-175.

Tierney, W. G. (1991). Academic work and institutional culture: Constructing knowledge. Review of Higher Education, 14(2), 199-216. 
Tierney, W. G. (2010). For-profit colleges and universities: Their markets, regulation, performance, and place in higher education. G. C. Hentschke, V. M. Lechuga, \& W. G. Tierney, (Ed.). Sterling, VA: Stylus Publishing, LLC.

Vaira, M. (2004). Globalization and higher education organizational change: A framework for analysis. Higher Education, 48(4), 483-510.

Webster, L., \& Mertova, P. (2007). Using narrative inquiry as a research method: An introduction to using critical event narrative analysis in research on learning and teaching. New York: Routledge.

Wilson, R. (2010). For-profit colleges change higher education's landscape. Chronicle Of Higher Education, 56(22), A1-A19.

Witherell, C. \& Noddings, N. (Eds.). (1991). Stories lives tell: Narrative and dialogue in education. New York: Teachers College Press.

Yin, R. K. (2009). Case study research: Design and method $\left(4^{\text {th }}\right.$ ed.). Thousand Oaks, CA: Sage Publications, Inc. 


\section{WWestVirginiaUniversity.}

Office of Research Compliance

\section{Expedited-IRB Protocol-Approval}

To: Diaz, Sebastian

From: $\quad$ WVU Office of Research Compliance

Date: $\quad$ Monday, November 19, 2012

Subject: Approval Letter

Tracking \#: $\mathrm{H}-24372$

Title: $\quad$ An Exploratory Case Study Examining Transformational Leadership and Organizational Change Within the Presidency of a Small, FourYear University

The research study referenced above was reviewed by the West Virginia University Instituional Review Board (IRB) via expedited review procedures and was approved in accordance with 46 CFR 46.101(b).

This protocol was reviewed using the following:

This protocol was reviewed using the following:Initial Protocol Review Checklist Subcommittee/Contingent Approval Checklist (210d)

Category 6 and 7

The following documents have been approved and validated for use in this study and are available in the BRAAN system:

Surveys, Questionnaires, Interviews

Attachments

Filer - Protocol of Questions REVISED PDF.pdf This PDF defines the interview protocol for the study.

Consent Form(s)

Forms

OMR ICF

Miscellaneous Attachments

Attachments 
Filer - Study Cover Letter FINAL PDF.pdf This document will serve as cover letter.

Thank you.

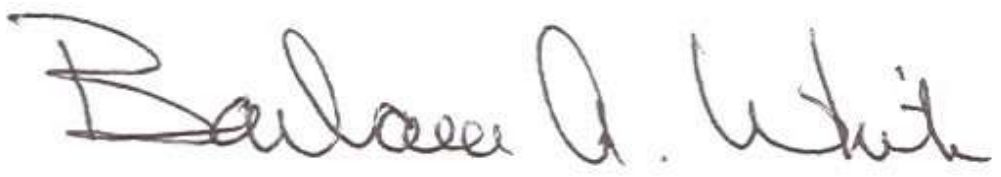

Board Designee: White, Barbara

Letter Sent By: White, Barbara, 11/19/2012 9:38 AM

Once you begin your human subject research, the following regulations apply:

1. Unanticipated or serious adverse events/side effects encountered in this research study must be reported to the IRB within five (5) days.

2. Any modifications to the study protocol or informed consent form must be reviewed and approved by the IRB prior to implementation.

3. You may not use a modified informed consent form until it has been approved and validated by the IRB. 


\section{WestVrrginiaUniversity。}

College of Human

Resources \&Education

Dear Participant,

This letter is a request for you to take part in a research project to examine the relationship between leadership and change. This project is being conducted by Daniel M. Filer, M.Ed. and MBA, at Frostburg State University with the supervision of Sebastián R. Díaz, an Associate Professor in the College of Human Resources \& Education at West Virginia University, for a Doctoral Degree in Educational Leadership Studies. Your participation in this project is greatly appreciated. It will take approximately 60-90 minutes to participate in an initial videotaped (for the presidents) and audiotaped (for the faculty members) interview, and may also include several informal, follow-up interviews.

Your involvement in this project will be kept as confidential as legally possible. However, presidents participating in the study must understand it is impossible to keep their identities completely anonymous. Given the geographic location of the institution being examined, as well as the clearly stated timeline my study will examine, someone could potentially discover the true identities of the presidents.

Your participation is completely voluntary. You may skip any question that you do not wish to answer during the interview and you may discontinue at any time. After completing the interview, I will give you the opportunity to review the transcript and strike anything you do not wish to be a part of the study. All video and audio recordings of the interview, as well as the transcript, will be destroyed immediately at the conclusion of the study. West Virginia University's Institutional Review Board acknowledgement of this project is on file.

I hope that you will participate in this research project, as it could be beneficial in better understanding the relationship between higher education leadership and organizational change within a college or university campus. Thank you very much for your time. Should you have any questions about this letter or the research project, please feel free to contact Daniel M. Filer at (301) 268-6897 or by e-mail at dfiler@mix.wvu.edu.

Thank you for your time and help with this project.

Sincerely,

Daniel M. Filer

Phone: 304-293-3707

Fax: 304-293-2279
Educational Leadership Studies

608 Allen Hall

PO BX 6122

Morgantown, WV 26506 


\section{West WirginiaUniversity.}

Office of Research Compliance

CONSENT AND INFORMATION FORM

OMR ICF

Principal Investigator: Diaz, Sebastian

Department: HUMAN RESOURCES \& EDUCATION - Technology, Tracking Number: Learning, and Culture (TLC) $\mathrm{H}-24372$

Study Title:

An Exploratory Case Study Examining Transformational Leadership and Organizational Change Within the Presidency of a Small, Four-Year University

Co-Investigator(s):

Daniel M. Filer

Sponsor

No sponsor exists for the study.

Contact Persons

In the event you experience any side effects or injury related to this research, you should contact Dr. Sebastian R. Diaz at 304/293-2075. If you have any questions, concerns, or complaints about this research, you can contact Dr. Sebastian R. Diaz at 304/293-2075

For information regarding your rights as a research subject, you may contact the Office of Research Compliance at 304/293-7073.

Introduction

In addition if you would like to discuss problems, concerns, have suggestions related to research, or would like to offer input about the research, contact the Office of Research Integrity and Compliance at 304-

\begin{tabular}{lllll}
\hline Tracking \#: & $\mathrm{H}-24372$ & Page 1 of 5 & \\
Approved On: & $11 / 19 / 2012$ & & & Initials \\
Valid Through: & $11 / 18 / 2013$ & & & \\
Last Amended: & N/A & & &
\end{tabular}


293-7073.

You, (as a university president or faculty member), have been asked to participate in this research study, which has been explained to you by Daniel M. Filer. This study is being conducted by Dr. Sebastian R. Diaz, Ph.D, J.D., and Daniel M. Filer, M.Ed., M.B.A., in the Department of Curriculum \& Instruction/Literacy Studies at West Virginia University. This research is being conducted to fulfill the requirements for a doctoral dissertation in Educational Leadership Studies in the Department of Curriculum \& Instruction/Literacy Studies at West Virginia University, under the supervision of Dr. Sebastian R. Diaz, Ph.D., J.D.

\section{Purposes of the Study}

The purpose of this study is to learn more about the relationship between leadership and change within higher education. WVU expects to enroll approximately six subjects in this study.

\section{Description of Procedures}

This study involves one (1), audiotaped (for faculty members) or videotaped (for presidents), 90 minute interview with the Student Principal Investigator. All interviews will take place in either your office or home to ensure confidentiality and privacy. The interviews will be conducted during a time that works for you. The Presidents will be questioned about different strategies they use or have used during their leadership at the institution, as well as significant events or changes that took place at the institution during their tenure. The faculty members will be questioned about those strategies and events identified by the presidents, to collect their perceptions as followers of the leader as well as their individual reflections. The interview script for the presidents and faculty members are available for review by each respective party prior to signing this document.After completing the interview, I will give you the opportunity to review the transcript and strike anything you do not wish to be a part of the study. I may also contact you for several brief, informal follow-up interviews that will be videotaped (for the presidents) or audiotaped (for the faculty) as I conduct the document analysis portion of my study. You do not have to answer all the questions in the interviews.

\begin{tabular}{lllll}
\hline Tracking \#: & $\mathrm{H}-24372$ & Page 2 of 5 & & \\
Approved On: & $11 / 19 / 2012$ & & Initials & Date \\
Valid Through: & $11 / 18 / 2013$ & & & \\
Last Amended: & $\mathrm{N} / \mathrm{A}$ & & &
\end{tabular}


Tracking \#: $\mathrm{H}-24372$

Risks and Discomforts

There are no known or expected risks from participating in this study, except for the mild frustration associated with answering the questions.

\section{Alternatives}

You do not have to participate in this study.

\section{Benefits}

You may not receive any direct benefit from this study. The knowledge gained from this study may eventually benefit others, as hope to gain information about the relationship between transformational leadership and organizational change.

Financial Considerations

There are no costs associated with your participation in this study, nor will you be paid for your time.

Confidentiality

Any information about you that is obtained as a result of your participation in this research will be kept as confidential as legally possible. Your research records and test results, just like hospital records, may be subpoenaed by court order or may be inspected by federal regulatory authorities without your additional consent. Presidents participating in the study must understand it is impossible to keep their identities completely anonymous. Given the geographic location of the institution being examined, as well as the clearly stated timeline my study will examine, someone could potentially discover the true identities of the presidents.Audiotapes or videotapes will be kept locked up and will be destroyed as soon as possible after the research is finished.

\section{Voluntary Participation}

Participation in this study is voluntary. You are free to withdraw your consent to participate in this study at any time. You may skip questions or stop at any time during the interview as well. In the event new information

\begin{tabular}{lllll}
\hline Tracking \#: & $\mathrm{H}-24372$ & Page 3 of 5 & & \\
Approved On: & $11 / 19 / 2012$ & & & Date \\
Valid Through: & $11 / 18 / 2013$ & & & \\
Last Amended: & $\mathrm{N} / \mathrm{A}$ & & &
\end{tabular}


Tracking \#:

becomes available that may affect your willingness to participate in this study, this information will be given to you so that you can make an informed decision about whether or not to continue your participation. You have been given the opportunity to ask questions about the research, and you have received answers concerning areas you did not understand.

$\begin{array}{lll}\text { Tracking \#: } & \mathrm{H}-24372 & \text { Page } 4 \text { of } 5 \\ \text { Approved On: } & 11 / 19 / 2012 & \\ \text { Valid Through: } & 11 / 18 / 2013 & \\ \text { Last Amended: } & \text { N/A } & \end{array}$


Upon signing this form, you will receive a copy.

I willingly consent to participate in this research.

\begin{tabular}{llll}
\hline $\begin{array}{l}\text { Signature of Subject or } \\
\text { Subjects Legal Representative }\end{array}$ & Date & & Timed Name
\end{tabular}

The participant has had the opportunity to have questions addressed. The participant willingly agrees to be in the study.

$\begin{array}{lll}\text { Tracking \#: } & \mathrm{H}-24372 & \text { Page } 5 \text { of } 5 \\ \text { Approved On: } & 11 / 19 / 2012 & \\ \text { Valid Through: } & 11 / 18 / 2013 & \\ \text { Last Amended: } & \text { N/A } & \end{array}$

$\overline{\text { Initials }} \overline{\text { Date }}$


Appendix D: President Reitman Interview Protocol

"Innovative and Enthusiastic"

Each prompt will be used to start a discussion during the 60-90 minute interview. The participants will be encouraged to share examples through stories. The goal is to draw out at least 2-3 stories from each president. These stories will be discussed and reaffirmed with the faculty members during their interviews.

\section{Presidential Interviews (Videotaped): Guiding Questions/Prompts}

*The presidents will be interviewed first and follow-up questions will depend upon what the researcher discovers during the study.

1. Wasn't it during your presidency that occurred? Can you tell me a story concerning how this event took place?

a. I have identified the following significant events that took place during Dr. Reitman's tenure at the institution - I hope to discuss each event and record any stories concerning leadership and change regarding the event.

b. Please share any reflections concerning the different events.

i. Organizational Change

1. College becomes university (1987)

2. Physical changes

a. Expansion -Hagerstown (1988) and Frederick (1989)

b. Secured funding for Performing Arts Center

c. Input for creation of University System of MD

3. Re-organization of departments on campus

a. i.e. Student and Educational Services

4. MBA program created (1989)

5. Extensive campus growth

a. Surpassed 5,000 students for the first time

b. 68 new faculty added

c. First capital campaign - $\$ 1$ million for equipment

6. Funding for Performing Arts Center

7. Recycling Pilot Program

ii. Town and Gown Relations

1. Cumberland Summer Theatre

2. International White Water Racing

3. Dedications

a. Library (1989)

b. Leake Room (1988)

4. University Medallions - started the program

a. Ort (1989)

b. Schaefer (1990)

5. MD State games through 1995 (1990)

6. Promote use of facilities by local community (1987)

iii. Challenges

1. Dwindling budget near end of presidency (1990)

2. Diversity controversy with NAACP

2. What is a change at the institution that you are most proud of?

3. Was there ever a time that you wanted to bring about change and it didn't happen? Please explain and reflect.

4. Can you tell me about your most challenging experience as president?

5. Please tell me about the instances where you felt most successful during your tenure as president.

6. Please reflect - much of the university, as it is today, was formed during your presidency (the foundations were laid concerning structure, town and gown, programs, fundraising, etc.) 
7. Please reflect on how your past experiences in leadership (other presidencies, etc.) impacted your leadership here at the institution.

8. Please reflect on the culture at the institution - at the beginning of your tenure vs. after 3-4 years of your leadership. 
Appendix E: President Glansdale Interview Protocol

"Consensus Builder...Skilled Negotiator...Making Connections"

Each prompt will be used to start a discussion during the 60-90 minute interview. The participants will be encouraged to share examples through stories. The goal is to draw out at least 2-3 stories from each president. These stories will be discussed and reaffirmed with the faculty members during their interviews.

\section{Presidential Interviews (Videotaped): Guiding Questions/Prompts}

*The presidents will be interviewed first and follow-up questions will depend upon what the researcher discovers during the study.

1. Wasn't it during your presidency that occurred? Can you tell me a story concerning how this event took place?

a. I have identified the following significant events that took place during Dr. Glansdale's tenure at the institution - I hope to discuss each event and record any stories concerning leadership and change regarding the event.

b. Please share any reflections concerning the different events.

i. Organizational Change

1. New facilities (built or planned; garnered funding):

a. Performing Arts Center (1991-1994)

b. Compton Science Center

c. Center for Communications and Information Technology (CCIT) - funding

d. Lane Center re-habilitation - funding

e. UMD Appalachian Laboratory

f. Allegany Business Center - 2007 funding

2. Redskins (1995-1997): \$2-4 million in revenue to the area

3. Growth and expansion of the Hagerstown Center

4. Increased minority enrollment - 1991: 6-7\%; 2006: 15\%

5. AIDS Awareness programs

6. Grants: First 6 years of presidency they went up from $\$ 300,000$ to over $\$ 1$ million ii. Town and Gown Relations

1. Arts Alive Consortium - 1993

2. Block Party - 1993

3. "Big Event" - Fall 1993

4. Volunteerism and Public Service - AmeriCorps Program - 1994

5. Laid groundwork for Appalachian Festival - 2006

6. Pealer Recital Hall dedicated - 1995

7. $\$ 10$ million Capital Campaign

iii. Challenges

1. Dwindling budget from the very beginning - State Appropriations cut from $50 \%$ to just over $30 \%$ in the first two years of your presidency

a. Furloughs, layoffs, academic programs in jeopardy (i.e. chemistry)

2. Alcohol - "the party school" image

3. Strained town and gown relationship - 1993: "No student can use city public facilities" - (Leads to "Big Event")

4. 1992 Winter Graduation cancelled

2. What is a change at the institution that you are most proud of?

3. Was there ever a time that you wanted to bring about change and it didn't happen? Please explain and reflect.

4. Can you tell me about your most challenging experience as president?

5. Please tell me about the instances where you felt most successful during your tenure as president.

6. Please reflect - much of the university, as it is today, was formed during your presidency (the foundations were laid concerning structure, town and gown, programs, fundraising, etc.) 
7. Please reflect: Extensive research exists arguing that women bring a different flavor and style to leadership (you're the only woman participating in this study; $2^{\text {nd }}$ female president of the institution; 1997 - inducted into MD Women's Fall of Fame). Over the years you have defined your leadership as:

a. "Consensus Builder"

b. Inclusivity in government

c. Open system - knowledge is power for faculty

d. Different than top-down traditional administration

e. "Involve campus colleagues and the broader community"

f. "Respectful of tradition, cognizant for need to change"

8. You often quoted literature in your speeches - what role did this have in your style of leadership?

9. Early on you referred to yourself as a "good fit to the campus" and claimed that gender was not a variable in leadership. Can you please elaborate on this?

10.Your presidency can easily be seen as one of partnerships, promoting economic development in the area, community service, and networking with other institutions (engineering, health sciences, sister school abroad). Please reflect on this.

11.Please reflect on how your past experiences in leadership (Provost, teaching, etc.) impacted your leadership here at the institution.

12.Please reflect on the culture at the institution - at the beginning of your tenure vs. when you left the institution.

13.Please reflect: Even after leaving the institution, you have showed continued commitment to the organization (Campus to Community Fund, continued to meet with student leaders, etc.) - how is that part of your leadership?

14.Please reflect on the fund that carries your name at the institution, which focuses on leadership, alumni connections, and community service - what skills and values are you trying to instill and why? 
Appendix F: President Gail Interview Protocol

"Change...Leadership Focused...Transparency"

Each prompt will be used to start a discussion during the 60-90 minute interview. The participants will be encouraged to share examples through stories. The goal is to draw out at least 2-3 stories from each president. These stories will be discussed and reaffirmed with the faculty members during their interviews.

\section{Presidential Interviews (Videotaped): Guiding Questions/Prompts}

*The presidents will be interviewed first and follow-up questions will depend upon what the researcher discovers during the study.

1. Wasn't it during your presidency that occurred? Can you tell me a story concerning how this event took place?

a. I have identified the following significant events that took place during Dr. Gail's tenure at the institution - I hope to discuss each event and record any stories concerning leadership and change regarding the event.

b. Please share any reflections concerning the different events.

i. Organizational Change

1. Administrative Re-structuring when you first arrived

2. 2011 - Strategic Plan

3. New Facilities

a. Allegany Business Center

b. Center for Communications and Information Technology (CCIT)

c. Lane Center re-habilitation

d. Sustainable Energy Research Facility

4. New programs

a. "Course Re-Design" and transition to blended/online - student-centered

b. Minor in Sustainability Studies

c. Doctorate in Educational Leadership

d. Entirely online MBA program

e. Bachelor's Degree in Nursing

f. Bachelor's Degree in Information Technology

5. Sustainability Efforts

a. Numerous awards and designations for the campus

b. Drives the institution operationally and academically

c. Learning Green, Living Green Program

6. Commitment to cultural diversity on campus

7. Gender-based violence initiatives

ii. Town and Gown Relations

1. Innovative Alcohol Prevention Strategy

a. Creation of Campus-Wide Alcohol Task Force

b. Unprecedented community outreach with local businesses

c. Combining law enforcement efforts with the town

d. Received numerous awards and appointed to numerous national committees

2. CHILL

a. Over $\$ 225,000$ from AstraZeneca

b. Healthy lifestyles - students and community residents

iii. Leadership Initiatives (identified in Strategic Plan)

1. Graduate of Leadership Maryland Class of 2008

2. Creation of the President's Leadership Circle

3. Presidential Merit Scholarship Program

4. President's Distinguished Faculty Award 
iv. Transparency

1. Commencement and convocation speeches are readily accessible via the institution's website, YouTube, and the WFWM's website.

2. Hosting online Q\&A sessions with students on the institution's Blog site.

3. Presence on social media - Twitter, etc.

4. "Dispatches," "Dialogues," television and radio appearances, posting of legislative testimonies and reports on the institution's website.

\section{v. Challenges}

1. Alcohol - "the party school" image

2. What is a change at the institution that you are most proud of?

3. Was there ever a time that you wanted to bring about change and it didn't happen? Please explain and reflect.

4. Can you tell me about your most challenging experience as president?

5. Please tell me about the instances where you felt most successful during your tenure as president.

6. Please reflect - the institution today seems to be more in line with national trends in higher education. You, in many ways, have become a voice for the institution in the national conversation.

7. Please reflect - In many ways, information about the institution is more readily accessible under your leadership than it ever has before. Do you feel transparency and fueling a larger conversation is integral to effective leadership? Please explain if you agree or disagree and why?

8. You have written a number of pieces in nationally-viewed forums concerning systemic challenges in higher education today, always being sure to tie this institution's relevancy to the conversation. What value does this play in your leadership efforts?

9. Please reflect - Many have argued that you immediately began "change" at this institution when you arrived (specifically "Dialogues"). Do you agree or disagree and why?

10.Your presidency can easily be seen as one of partnerships, promoting economic development in the area, community service, and networking with other institutions and the community. Please reflect on this.

11.Please reflect on how your past experiences/background in leadership (other presidencies, etc.) has impacted your leadership here at this institution.

12.Please reflect on the culture at the institution - when you arrived vs. the culture at present. 
Faculty Member Interviews (Audiotaped): Guiding Questions/Prompts for 60-90 Minute Interview

*These questions/prompts were revised after the presidential interviews had been conducted to ensure that any themes that were identified by the presidents were also discussed with the faculty members. Any Follow-up questions are also subject to discovery in the study and will include more exact prompts concerning specific events, etc. Please share examples through stories.

1. During the interviews with FSU Presidents, the following events were discussed and deemed the most significant of each respective president's administration. What do you recall of these events? Please share your perspective.

a. Dr. Reitman (1986-1991)

i. College becoming university

ii. Extensive campus growth (68 new faculty added; surpassed 5,000 students for the first time; $1^{\text {st }}$ capital campaign for $\$ 1$ million; MD State Games; White Water)

iii. MBA Program created

iv. Expansion - Hagerstown (1988) and Frederick (1989)

b. Dr. Glansdale (1991-2006)

i. Expansion of institution "on many fronts" to make the institution "deserving of the title of university" (construction of numerous new facilities; addition of engineering and other academic programs; \$10 million capital campaign completed; Redskins; collaborative efforts; increased minority enrollment; addition of ethno botany; research work - writing and River Otters)

ii. Bringing the Redskins to the campus (1995-1997): \$2-4 million in revenue to the area

iii. Dwindling budget from the very beginning - State Appropriations cut from $50 \%$ to just over 30\% in the first two years of her presidency (Furloughs, layoffs, academic programs in jeopardy such as chemistry)

iv. Impressive number of physical additions to the campus (Performing Arts Center completed; Compton Science Center, Center for Communications and Information Technology (CCIT) funding attained; Lane Center re-habilitation funding secured; UMD Appalachian

Laboratory; Allegany Business Center funding attained; Edgewood Commons

c. Dr. Gail (2006-Present)

i. Exceeding campaign goal of $\$ 15$ million (raised over $\$ 16$ million - scholarships; pure cash to build endowment)

ii. Efforts made in binge drinking reduction (named on National Institute of Alcoholism and Alcohol Abuse Task Force - recognized nationally)

iii. Increasing university's diversity (now better represents the nation and Maryland; Recruiter and admissions materials in Spanish)

iv. Efforts at transparency and widespread communication (Commencement and convocation speeches are readily accessible via the institution's website, YouTube, and the WFWM's website; Hosting online Q\&A sessions with students on the institution's Blog site and "Down to Earth with Dr. G"; Presence on social media - Twitter, etc.; "Dispatches," "Dialogues," television and radio appearances, posting of legislative testimonies and reports on the institution's website.

2. Are there other significant events or changes the presidents omitted in their interviews that you felt were important during their tenure? Please share through story.

3. How did you perceive each president during their tenure at the institution?

4. Which president oversaw the most amount of change at this institution?

a. Please share specific examples of that change and why you feel this change is more significant than other events.

5. Did you have a personal relationship with any of the presidents in this study and/or serve on any direct committees or boards with them? If so, please describe your impression of them and this experience.

6. Please reflect on the culture at the institution - when you arrived vs. the culture at present. 
Appendix H: Study Codes and Sub-Codes

\begin{tabular}{|cc|}
\hline Codes & Sub-Codes \\
\hline Components of Transformational Leadership & Idealized Influence (II) \\
& Inspirational Motivation (IM) \\
Intellectual Stimulation (IS) \\
Individualized Consideration (IC)
\end{tabular}




\section{Is it a Great Quote?}

\section{Appendix I: Code Sheet}

\section{Is it a Story?}

\section{Components of Transformational Leadership (4)}

- Idealized Influence (II): transformational leaders "behave in ways that allow them to serve as role models" to others in the organization.

- Inspirational Motivation (IM): excel at mobilizing "team spirit" and can easily display "enthusiasm and optimism." Transformational leaders are effective at convincing followers to share in their overall vision for the organization.

- Intellectual Stimulation (IS): encourage followers to identify organizational problems and their solutions, then they work together to address these problems, implement solutions, and make lasting changes to the organization.

- Individualized Consideration (IC): the leaders' ability to "pay special attention to each individual follower's needs" for professional development; able to serve as a "coach or mentor" to followers on an individual basis; two-way communication is encouraged.

\section{Degrees of Organizational Change (5)}

- Planned Change: intentional efforts to improve the organization and its operation in some capacity.

- Unplanned Change: refers to situations where an organization is reacting to change as a result of external forces.

- First-Order Change: involves efforts to continually change and improve over time, making subtle changes incrementally rather than deep, sweeping changes all at once; evolutionary.

- Second-Order Change (Transformational): as the most powerful type of change, with lasting, deep impacts that significantly transform the organization; revolutionary.

- Third-Order Change (Transformational): allows organizational members to "transcend" the organizational framework; members to become more self-aware of their role within the organization; more aware of their own limitations, begin to develop their own understanding of their role, and to ultimately become more effective at self-evaluation and change without prodding from the leader or supervisor.

\section{Institutional Transformation (4)}

- Intentionally Executed: A transformation that alters the culture of the institution by changing the underlying assumptions and institutional behaviors.

- Deep and Pervasive: A transformation that is deep, pervasive, and permeates throughout the entire institution.

- Alters Culture: A transformation that is intentionally executed through clearly identified and communicated goals;

- Occurs over Time: A transformation that occurs over time.

\section{Type of Culture (4)}

- Collegial: values the interests of the faculty, which in most cases involves interests such as shared governance and "scholarly engagement"

- Managerial: represents the interests of the institution as an organization, focusing on values such as supervisory skills and mission.

- Developmental: is most concerned with the growth of members within the organization.

- Negotiating: involves the understanding of organizational policies and rules as well as distribution of power among the various groups 